Yoshida M (see Sakiyama et al). 2003;126:1207-9 (Brief comm.)

Yoshida M (see Yoshimura et al). 2003;126:1417-26

Yoshida S (see Chiyo et al). 2003;126:1141-6

Yoshida S (see Sakiyama et al). 2003;126:1207-9 (Brief comm.)

Yoshii S (see Osawa et al). 2003;126:604-5 (Brief comm.)

Yoshikawa M (see Yoshitatsu et al). 2003;126:1531-6

Yoshimura N,Yamaguchi M, Ohashi H, Oshima Y, Oka S, Yoshida M, Murakami H, Tei T. Pulmonary atresia with intact ventricular septum: strategy based on right ventricular morphology. 2003;126:1417-26

Yoshimura N (see Ootaki et al). 2003;126:1411-6

Yoshimura N (see Ootaki et al). 2003;126:1655-6 (Brief comm.)

Yoshino I (see Yamaguchi et al). 2003;126:870-2 (Brief comm.)

Yoshitatsu M, Miyamoto Y, Mitsuno M, Toda K, Yoshikawa M, Fukui S, Nomura F, Hirata N, Onishi K. Changes in left anterior descending coronary artery flow profiles after coronary artery bypass grafting examined by means of transthoracic Doppler echocardiography. 2003;126:1531-6

Yu H-Y, Ho Y-L, Chu S-H, Chen Y-S, Wang S-S, Lin F-Y. Long-term evaluation of Carpentier-Edwards porcine bioprosthesis for rheumatic heart disease. 2003;126:80-9

Yu J (see Xia et al). 2003;126:1404-10

Yun J (see Fischbein et al). 2003;126:216-23

\section{Z}

Zacharias J, Clark SC, Hamilton JRL, Dark JH, Hasan A. Unilateral pulmonary thromboendarterectomy for iatrogenic pulmo- nary hypertension in a ten-year-old child. 2003;126:1210-1 (Brief comm.)

Zackai EH (see Gaynor et al). 2003;126:1736-45

Zamparelli R (see Gaudino et al). 2003;126:1107-12

Zamvar V, Sivaprakasam R. The left anterior descending coronary artery is the best recipient. 2003;126:923 (Letter)

Zegdi R, Fabre O, Lila N, Fornès P, Cambillau M, Shen M, Hervé P, Carpentier A, Fabiani J-N. Exhaled carbon monoxide and inducible heme oxygenase expression in a rat model of postperfusion acute lung injury. 2003;126:1867-74

Zenati MA (see Bonanomi et al). 2003;126:851-2 (Evolving tech.)

Zenati MA (see Bonanomi et al). 2003;126:1859-66

Zerkowski H-R (see Georgiadis et al). 2003;126:1638-9 (Brief comm.)

Zhang S (see Wu et al). 2003;126:1477-82

Zielinsky P (see Assad et al). 2003;126:300-2 (Brief comm.)

Ziemer S (see von Heymann et al). 2003;126:1667-8 (Letter)

Zimmerman MA (see Selzman et al). 2003;126:688-93

Zimpfer D (see Czerny et al). 2003;126:916-8 (Brief comm.)

Zimpfer D (see Czerny et al). 2003;126:1296-301

Zitser-Gurevich Y (see Galai et al). 2003;126:1018-25

Zoffoli G (see Colli et al). 2003;126:881-3 (Brief comm.)

Zou W, Yang Q, Yim APC, He G-W. Impaired endotheliumderived hyperpolarizing factor-mediated relaxation in porcine pulmonary microarteries after cold storage with Euro-Collins and University of Wisconsin solutions. 2003;126:208-15

Zrenner B (see Kaemmerer et al). 2003;126:1048-52

\title{
Subject Index*
}

A

Abnormalities; see also specific abnormality

Anomalous origin of the left coronary artery from the main pulmonary artery associated with Berry syndrome (Senzaki et al). 2003;126:1645-7 (Brief comm.)

Benign intrapulmonary teratoma: report of a case (Eren et al). 2003;126:855-7 (Brief comm.)

Bilateral lung transplantation for pulmonary hypoplasia caused by congenital diaphragmatic hernia (Lee et al). 2003;126:295-7 (Brief comm.)

Congenital thoracoabdominal aortic aneurysm (Ko et al). 2003;126:897-9 (Brief comm.)

Emergency hospital admissions and three-year survival of adults with and without cardiovascular surgery for con-

*July, 1-310; August 311-616; September, 617-928; October, 929-1234; November, 1235-1680; December, 1681-2202. genital cardiac disease (Kaemmerer et al). 2003;126:1048-52

New lead for in utero pacing for fetal congenital heart block (Assad et al). 2003;126:300-2 (Brief comm.)

Pulmonary blood pressure, not flow, is associated with net endothelin-1 production in the lungs of patients with congenital heart disease and normal pulmonary vascular resistance (Fratz et al). 2003;126:1724-9

Rapid progression of midventricular obstruction in adults with double-chambered right ventricle (Oliver et al). 2003; 126:711-7

Relationship of aortic cross-sectional area to height ratio and the risk of aortic dissection in patients with bicuspid aortic valves (Svensson et al). 2003;126:892-3 (Brief comm.)

Successful Fontan procedure for asplenia with pulmonary atresia and major aortopulmonary collateral arteries (Miyaji et al). 2003;126:1648-50 (Brief comm.) 
Tricuspidization of incompetent bicuspid aortic valve (Kawazoe et al). 2003;126:908-10 (Brief comm.)

Unroofed coronary sinus syndrome: Diagnosis, classification, and surgical treatment (Ootaki et al). 2003;126:1655-6 (Brief comm.)

Vascular matrix remodeling in patients with bicuspid aortic valve malformations: implications for aortic dilatation (Fedak et al). 2003;126:797-806

\section{Acetylcysteine}

$\mathrm{N}$-acetylcysteine prevents reactive oxygen species-mediated myocardial stress in patients, undergoing cardiac surgery: results of a randomized, double-blind, placebo-controlled clinical trial (Tossios et al). 2003;126:1513-20

\section{Adenocarcinoma}

Cyclooxygenase- 2 inhibition decreases primary and metastatic tumor burden in a murine model of orthotopic lung adenocarcinoma (DiPerna et al). 2003;126:1129-33

Extracapsular lymph node involvement is a negative prognostic factor in T3 adenocarcinoma of the distal esophagus and gastroesophageal junction (Lerut et al). 2003;126: 1121-8

Histogram analysis of computed tomography numbers of clinical T1 N0 M0 lung adenocarcinoma, with special reference to lymph node metastasis and tumor invasiveness (Nomori et al). 2003;126:1584-9

Lymph node involvement in esophageal adenocarcinoma: if you see one, have you seen them all? (DeMeester). 2003; 126:947-9 (Editorial)

Resection of multifocal non-small cell lung cancer when the bronchioloalveolar subtype is involved (Roberts et al). 2003;126:1597-602

\section{Adenosine}

Integrated pharmacological preconditioning in combination with adenosine, a mitochondrial $\mathrm{K}_{\mathrm{ATP}}$ channel opener and

\section{Adenoviridae} a nitric oxide donor (Uchiyama et al). 2003;126:148-59

Adenovirus encoding soluble tumor necrosis factor $\alpha$ receptor immunoglobulin prolongs gene expression of a cotransfected reporter gene in rat lung (Suda et al). 2003;126: 1155-61

Direct comparison of efficiency and stability of gene transfer into the mammalian heart using adeno-associated virus versus adenovirus vectors (Chu et al). 2003;126:671-9

\section{Adolescent}

Bronchioloalveolar carcinoma arising from a congenital cystic adenomatoid malformation in an adolescent: the first case report from the Orient (Sudou et al). 2003;126:902-3 (Brief comm.)

Age factors; see also Child; Infant

The aging human myocardium: tolerance to ischemia and responsiveness to ischemic preconditioning (Loubani et al). 2003;126:143-7

The influence of perioperative factors on outcomes in children aged less than 18 months after repair of tetralogy of Fallot (van Dongen et al). 2003;126:703-10

Intralobar sequestration in the middle-aged and elderly adult: recognition and radiographic evaluation (Petersen et al). 2003;126:2086-9 (Brief comm.)
Long-term results of heart transplantation in patients older than 60 years (Demers et al). 2003;126:224-31

Minimally invasive mitral valve repair suggests earlier operations for mitral valve disease (Greelish et al). 2003;126: 365-73

Aldosterone

The effect of the maze procedure on the secretion of argininevasopressin and aldosterone (Ad et al). 2003;126:1095100

American Association for Thoracic Surgery

Annual meeting announcements. 2003;126:308; 614; 926; $1232 ; 1678 ; 2126$

American Board of Thoracic Surgery

Notices of examination and recertification process. 2003;126: $309-10$; 615-6; 927-8; 1233-4; 1679-80; 2127-8

American College of Surgeons Oncology Group Z0050 Trial

Results of the American College of Surgeons Oncology Group Z0050 Trial: the utility of positron emission tomography in staging potentially operable non-small cell lung cancer (Reed et al). 2003;126:1943-51

Analgesia; see also Anesthesia and analgesia

Extrapleural regional versus systemic analgesia for relieving postthoracotomy pain: a clinical study of bupivacaine compared with metamizol (Bilgin et al). 2003;126:1580-3

\section{Anaphylaxis}

Life-threatening anaphylactic shock caused by porcine heparin intravenous infusion during mitral valve repair (Bottio et al). 2003;126:1194-5 (Brief comm.)

Anastomosis, surgical; see also Coronary artery bypass

Aortic arch repair for Stanford type A aortic dissection with distal anastomosis to the proximal level of the distal aortic arch (Mori et al). 2003;126:415-9

Aortic arch repair with a working beating heart in premature infants (Ishino and Sano). 2003;126:1653-4 (Brief comm.)

Automated proximal anastomosis for redo coronary artery bypass grafting through a lateral thoracotomy (Perreas et al). 2003;126:606-7 (Brief comm.)

Clinical outcomes and utility of cardiac catheterization prior to superior cavopulmonary anastomosis (Brown et al). 2003;126:272-81

Comparison of polytetrafluoroethylene patch aortoplasty and end-to-end anastomosis for coarctation of the aorta (Walhout et al). 2003;126:521-8

Coronary anastomotic devices: blood-exposed non-intimal surface and coronary wall stress (Scheltes et al). 2003; 126:191-9 (Evolving tech.)

Evaluation of a novel sutureless anastomotic connector: from endothelial function to mid-term clinical and angiographic follow-up (Verma et al). 2003;126:1555-60 (Evolving tech.)

In situ retrocaval skeletonized right internal thoracic artery anastomosed to the circumflex system via transverse sinus: technical aspects and postoperative outcome (Bonacchi et al). 2003;126:1302-13

Sodium nitroprusside infusion after bidirectional superior cavopulmonary connection: preserved cerebral blood flow velocity and systemic oxygenation (Simsic et al). 2003; 126:186-90 


\section{Anesthesia and analgesia}

Improved pain control after cardiac surgery: results of a randomized, double-blind, clinical trial (Dowling et al). 2003;126:1271-8

No pain, much gain? (Schwann and Chaney). 2003;126: 1261-4 (Editorial)

Aneurysm; see also Aortic aneurysm; Heart aneurysm

Bilateral lung transplantation and pulmonary artery reconstruction in a patient with chronic obstructive pulmonary disease, and a giant pulmonary artery aneurysm (Force et al). 2003;126:864-6 (Brief comm.)

Giant atherosclerotic aneurysm of the left anterior descending artery (Attar et al). 2003;126:888-90 (Brief comm.)

\section{Aneurysm, dissecting}

Acute type A aortic dissection complicated by aortic regurgitation: composite valve graft versus separate valve graft versus conservative valve repair (Lai et al). 2003;126: 1978-86

Aortic arch repair for Stanford type A aortic dissection with distal anastomosis to the proximal level of the distal aortic arch (Mori et al). 2003;126:415-9

Candidate locus analysis of familial ascending aortic aneurysms and dissections confirms the linkage to the chromosome 5q13-14 in Finnish families (Kakko et al). 2003;126: 106-13

Intentional delay of surgery for acute type A dissection with stroke (Fukuda and Imazuru). 2003;126:290-1 (Brief comm.)

Platelet dysfunction in acute type A aortic dissection evaluated by the laser light-scattering method (Tanaka et al). 2003;126:837-41

Relationship of aortic cross-sectional area to height ratio and the risk of aortic dissection in patients with bicuspid aortic valves (Svensson et al). 2003;126:892-3 (Brief comm.)

Severe pulmonary stenosis and aortopulmonary fistula caused by a dissecting aneurysm in the ascending aorta (Imanaka et al). 2003;126:598-600 (Brief comm.)

Surgical repair of acute type A aortic dissection: continuous pulmonary perfusion during retrograde cerebral perfusion prevents lung injury in a pilot study (De Santo et al). 2003;126:826-31

\section{Aneurysm, false}

Aortopulmonary fistula in pseudoaneurysm after ascending aortic surgery (Kitamura et al). 2003;126:904-5 (Brief comm.)

Stent graft treatment for abdominal pseudoaneurysm near the celiac artery (Takahashi et al). 2003;126:600-2 (Brief comm.)

\section{Aneurysm, infected}

Successful treatment of a mycotic aortic arch aneurysm associated with an isolated left vertebral artery (Naito et al). 2003;126:883-5 (Brief comm.)

\section{Announcements}

2003;126:308-10; 614-6; 926-8; 1232-4; 1678-80; 2126-8

\section{Anoxemia}

Hypoventilation improves oxygenation after bidirectional superior cavopulmonary connection (Bradley et al). 2003; 126:1033-9

\section{Anticoagulants}

Resistance to aspirin after external ventricular assist device implantation (Houël). 2003;126:1636-7 (Brief comm.)

\section{Antifibrinolytic agents}

Antifibrinolytic therapy during cardiopulmonary bypass reduces proinflammatory cytokine levels: a randomized, double-blind, placebo-controlled study of $\epsilon$-aminocaproic acid and aprotinin (Greilich et al). 2003;126:1498-503

Pharmacologic platelet anesthesia by glycoprotein IIb/IIIa complex antagonist and argatroban during in vitro extraAntigens corporeal circulation (Kanemitsu et al). 2003;126:428-35

Prolonged survival of fully allogeneic cardiac grafts in naive mice and those with sensitization induced by antigen delivery through the respiratory tract (Aramaki et al). 2003;126:853-4 (Brief comm.)

\section{Antioxidants}

The antioxidant $\mathrm{N}$-acetylcysteine preserves myocardial function and diminishes oxidative stress after cardioplegic arrest (Fischer et al). 2003;126:1483-8

Antioxidant therapy with Salvia miltiorrhiza decreases plasma endothelin-1 and thromboxane B2 after cardiopulmonary bypass in patients with congenital heart disease (Xia et al). 2003;126:1404-10

\section{Antithrombins}

Canine endothelial progenitor cell-lined hybrid vascular graft with nonthrombogenic potential ( $\mathrm{He}$ et al). 2003;126:455-64

High antithrombin III levels attenuate hemostatic activation and leukocyte activation during cardiopulmonary bypass (Koster et al). 2003;126:906-7 (Brief comm.)

\section{Aorta, thoracic}

Aortic arch repair for Stanford type A aortic dissection with distal anastomosis to the proximal level of the distal aortic arch (Mori et al). 2003;126:415-9

Aortic arch repair with a working beating heart in premature infants (Ishino and Sano). 2003;126:1653-4 (Brief comm.)

Aortopulmonary fistula in pseudoaneurysm after ascending aortic surgery (Kitamura et al). 2003;126:904-5 (Brief comm.)

Can particulate extraction from the ascending aorta reduce neurologic injury in cardiac surgery? (Schmitz et al). 2003;126:1829-38

Cannulation of the left common carotid artery for proximal aortic repair (Urbanski). 2003;126:887-8 (Brief comm.)

Diabetes and evidence of atherosclerosis are major risk factors for adverse outcome after elective thoracic aortic surgery (Hagl et al). 2003;126:1005-12

Isolated persistent fifth aortic arch with systemic-to-pulmonary arterial connection (Hwang et al). 2003;126:1643-4 (Brief comm.)

Neuropsychometric outcome following aortic arch surgery: a prospective randomized trial of retrograde cerebral perfusion (Harrington et al). 2003;126:638-44

Pulmonary artery remodeling in transposition of the great arteries: relevance for neoaortic root dilatation (Lalezari et al). 2003;126:1053-60 
Regional low-flow perfusion provides comparable blood flow and oxygenation to both cerebral hemispheres during neonatal aortic arch reconstruction (Andropoulos et al). 2003; 126:1712-7

Risk factors of mortality and permanent neurologic injury in patients undergoing ascending aortic and arch repair $(\mathrm{Cz}-$ erny et al). 2003;126:1296-301

Aortic aneurysm; see also Aneurysm, dissecting

Altered patterns of gene expression distinguishing ascending aortic aneurysms from abdominal aortic aneurysms: complementary DNA expression profiling in the molecular characterization of aortic disease (Absi et al). 2003;126: 344-57

Candidate locus analysis of familial ascending aortic aneurysms and dissections confirms the linkage to the chromosome 5q13-14 in Finnish families (Kakko et al). 2003;126: 106-13

Combined repair of an aortic arch aneurysm by sequential transposition of the supra-aortic branches and endovascular stent-graft placement (Czerny et al). 2003;126:916-8 (Brief comm.)

Congenital thoracoabdominal aortic aneurysm (Ko et al). 2003;126:897-9 (Brief comm.)

Endovascular flexible stent grafting with arch vessel bypass for a case of aortic arch aneurysm (Nitta et al). 2003;126: 1186-8 (Brief comm.)

Express yourself-but consider the consequences (Pyeritz). 2003;126:334-6 (Editorial)

The gut-first approach for repair of Crawford extent III thoracoabdominal aortic aneurysms (Karck et al). 2003;126: 602-4 (Brief comm.)

Left-sided cervical aortic arch aneurysm: case report (Higuchi et al). 2003;126:2098-100 (Brief comm.)

Off-pump management of aortic arch aneurysm by using an endovascular thoracic stent graft (Dietl et al). 2003;126: 1181-3 (Brief comm.)

Preoperative and operative predictors of delayed neurologic deficit following repair of thoracoabdominal aortic aneurysm (Estrera et al). 2003;126:1288-95

Relocation of supra-aortic vessels to facilitate endovascular treatment of a ruptured aortic arch aneurysm (Drenth et al). 2003;126:1184-5 (Brief comm.)

Successful treatment of a mycotic aortic arch aneurysm associated with an isolated left vertebral artery (Naito et al). 2003;126:883-5 (Brief comm.)

Syphilitic aortic aneurysm: a rare case of tracheomalacia (Pacini et al). 2003;126:900-2 (Brief comm.)

Tuberculosis aneurysm of the aortic arch (Abad and Santamaria). 2003;126:1229 (Letter)

\section{Aortic aneurysm, abdominal}

Altered patterns of gene expression distinguishing ascending aortic aneurysms from abdominal aortic aneurysms: complementary DNA expression profiling in the molecular characterization of aortic disease (Absi et al). 2003;126: 344-57

Congenital thoracoabdominal aortic aneurysm (Ko et al). 2003;126:897-9 (Brief comm.)
Express yourself-but consider the consequences (Pyeritz). 2003;126:334-6 (Editorial)

The gut-first approach for repair of Crawford extent III thoracoabdominal aortic aneurysms (Karck et al). 2003;126: 602-4 (Brief comm.)

\section{Aortic coarctation}

Coarctation: the search for the Holy Grail (Backer). 2003; 126:329-31 (Editorial)

Comparison of polytetrafluoroethylene patch aortoplasty and end-to-end anastomosis for coarctation of the aorta (Walhout et al). 2003;126:521-8

A safe strategy for surgical repair of coarctation of the aorta in an adult (Yamada et al). 2003;126:597-8 (Brief comm.)

Aortic diseases

The clamshell approach for the treatment of extensive thoracic aortic disease (Doss et al). 2003;126:814-7

The influence of mechanical properties on wall stress and distensibility of the dilated ascending aorta (Okamoto et al). 2003;126:842-50

Modification of surgical technique for ascending aortic atherosclerosis: impact on stroke reduction in coronary artery bypass grafting (Hangler et al). 2003;126:391-400

Vascular matrix remodeling in patients with bicuspid aortic valve malformations: implications for aortic dilatation (Fedak et al). 2003;126:797-806

\section{Aortic valve}

Assessment of mechanical aortic valve prosthesis by means of Doppler echocardiography: what to measure and why? (Vannan and Sarkar). 2003;126:317-20 (Editorial)

Comparison of autograft and allograft aortic valve replacement in children (Lupinetti et al). 2003;126:240-6

Is degenerative calcification of the native aortic valve similar to calcification of bioprosthetic heart valves? (David and Ivanov). 2003;126:939-41 (Editorial)

Left atrial dissection after aortic valve replacement (Osawa et al). 2003;126:604-5 (Brief comm.)

A new aortoventriculoplasty for prosthetic aortic valve replacement (Hvass et al). 2003;126:818-20

Obstruction of St Jude Medical valves in the aortic position: histology and immunohistochemistry of pannus (Teshima et al). 2003;126:401-7

Prosthesis size and long-term survival after aortic valve replacement (Blackstone et al). 2003;126:783-96

Relationship of aortic cross-sectional area to height ratio and the risk of aortic dissection in patients with bicuspid aortic valves (Svensson et al). 2003;126:892-3 (Brief comm.)

Serial Doppler echocardiographic evaluation of small-sized Sorin Bicarbon prostheses (De Carlo et al). 2003;126: 337-43

Tricuspidization of incompetent bicuspid aortic valve (Kawazoe et al). 2003;126:908-10 (Brief comm.)

Valve-sparing aortic root reconstruction with a valveless aortic allograft (Schoof et al). 2003;126:282-3 (Brief comm.)

Vascular matrix remodeling in patients with bicuspid aortic valve malformations: implications for aortic dilatation (Fedak et al). 2003;126:797-806 


\section{Aortic valve insufficiency}

Acute type A aortic dissection complicated by aortic regurgitation: composite valve graft versus separate valve graft versus conservative valve repair (Lai et al). 2003;126: 1978-86

Closed correction of systemic semilunar valve insufficiency in the neonate (Pigula et al). 2003;126:1650-2 (Brief comm.)

Prevalence and predictors of neoaortic regurgitation after arterial switch operation for transposition of the great arteries (Formigari et al). 2003;126:1753-9

\section{Aortic valve stenosis}

Severe quadricuspid aortic valve stenosis after mediastinal irradiation (Mecozzi et al). 2003;126:1198-9 (Brief comm.)

\section{Apolipoproteins E}

Apolipoprotein E genotype and neurodevelopmental sequelae of infant cardiac surgery (Gaynor et al). 2003;126:1736-45

\section{Apoptosis}

Interleukin-10 gene transfection of donor lungs ameliorates posttransplant cell death by a switch from cellular necrosis

\section{Aprotinin} to apoptosis (Fischer et al). 2003;126:1174-80

A randomized trial of aprotinin (Trasylol) on blood loss, blood product requirement, and myocardial injury in total arterial grafting (Taggart et al). 2003;126:1087-94

\section{Argatroban}

Pharmacologic platelet anesthesia by glycoprotein IIb/IIIa complex antagonist and argatroban during in vitro extra-

\section{Argipressin} corporeal circulation (Kanemitsu et al). 2003;126:428-35

The effect of the maze procedure on the secretion of argininevasopressin and aldosterone (Ad et al). 2003;126:1095100

\section{Arteriosclerosis}

Atherogenic effects of Chlamydia pneumoniae: refuting the innocent bystander hypothesis (Selzman et al). 2003;126: 688-93

Atherosclerotic involvement of the radial artery in patients with coronary artery disease and its relation with midterm radial artery graft patency and endothelial function (Gaudino et al). 2003;126:1968-71

C-reactive protein activates the nuclear factor- $\kappa \mathrm{B}$ signal transduction pathway in saphenous vein endothelial cells: implications for atherosclerosis and restenosis (Verma et al). 2003;126:1886-91

Diabetes and evidence of atherosclerosis are major risk factors for adverse outcome after elective thoracic aortic surgery (Hagl et al). 2003;126:1005-12

Does antegrade blood cardioplegia alone provide adequate myocardial protection in patients with left main stem disease? (Onorati et al). 2003;126:1345-52

Giant atherosclerotic aneurysm of the left anterior descending artery (Attar et al). 2003;126:888-90 (Brief comm.)

Modification of surgical technique for ascending aortic atherosclerosis: impact on stroke reduction in coronary artery bypass grafting (Hangler et al). 2003;126:391-400
Results after transplantation using donor hearts with preexisting coronary artery disease (Marelli et al). 2003;126: $821-5$

Risk factors for atherosclerosis and the degeneration of pericardial valves after aortic valve replacement (Nollert et al). 2003;126:965-8

\section{Arteriovenous fistula}

Combined endovascular and video-assisted thoracoscopic procedure for treatment of a ruptured pulmonary arteriovenous fistula: case report and review of the literature (Litzler et al). 2003;126:1204-7 (Brief comm.)

\section{Ascorbic acid}

Lack of evidence for vitamin $\mathrm{C}$ as acute vasodilator (Madhavan and Goodfellow) (Letter); (Toumpoulis et al) (Reply). 2003;126:1671-2

\section{Aspirin}

Resistance to aspirin after external ventricular assist device implantation (Houël). 2003;126:1636-7 (Brief comm.)

\section{Atrial fibrillation}

Atrial fibrillation after esophagectomy is a marker for postoperative morbidity and mortality (Murthy et al). 2003; 126:1162-7

Atrial fibrillation I: a new classification system (Cox). 2003; 126:1686-92 (Editorial)

Atrial fibrillation II: rationale for surgical treatment (Cox). 2003;126:1693-9 (Editorial)

The Cox maze III procedure for atrial fibrillation: long-term efficacy in patients undergoing lone versus concomitant procedures (Prasad et al). 2003;126:1822-8

Fibrillation in patients subjected to coronary artery bypass grafting (Wu et al). 2003;126:1477-82

The long-term outcome of patients with coronary disease and atrial fibrillation undergoing the Cox maze procedure (Damiano et al). 2003;126:2016-21

A new device for beating heart bipolar radiofrequency atrial ablation (Bonanomi et al). 2003;126:1859-66

Origin of atrial fibrillation from the pulmonary veins in a mitral patient (Melo et al). 2003;126:914-6 (Brief comm.)

Surgery for atrial fibrillation using radiofrequency catheter ablation (Chiappini et al). 2003;126:1788-91

Surgical radiofrequency ablation of both atria for atrial fibrillation: results of a multicenter trial (Raman et al). 2003; 126:1357-66

\section{Atrial natriuretic factor}

Secretion of A-type and B-type natriuretic peptides into the bloodstream and pericardial space in children with congenital heart disease (Ootaki et al). 2003;126: 1411-6

\section{B}

\section{Barrett esophagus}

Simultaneous progression of oxidative stress and angiogenesis in malignant transformation of Barrett esophagus ( $\mathrm{Si}-$ hvo et al). 2003;126:1951-7 
Bechterew disease; see Spondylitis, ankylosing

\section{Berry syndrome}

Anomalous origin of the left coronary artery from the main pulmonary artery associated with Berry syndrome (Senzaki et al). 2003;126:1645-7 (Brief comm.)

\section{Bioprosthesis}

Acellularized porcine heart valve scaffolds for heart valve tissue engineering and the risk of cross-species transmission of porcine endogenous retrovirus (Leyh et al). 2003; 126:1000-4

Hancock II bioprosthesis: a glance at the microscope in mid-long-term explants (Bottio et al). 2003;126:99-105

Hypercholesterolemia is a risk factor for bioprosthetic valve calcification and explanation (Farivar and Cohn). 2003; 126:969-76

Is degenerative calcification of the native aortic valve similar to calcification of bioprosthetic heart valves? (David and Ivanov). 2003;126:939-41 (Editorial)

Long-term durability of the Hancock II porcine bioprosthesis (Rizzoli et al). 2003;126:66-74

Long-term evaluation of Carpentier-Edwards porcine bioprosthesis for rheumatic heart disease (Yu et al). 2003; 126:80-9

Risk factors for atherosclerosis and the degeneration of pericardial valves after aortic valve replacement (Nollert et al). 2003;126:965-8

\section{Biopsy, needle}

Transthoracic needle biopsy in the diagnosis of solitary pulmonary nodules: a survey of Canadian physicians (Lacasse et al). 2003;126:761-8

\section{Bivalirudin}

Bivalirudin as alternative to both danaparoid and heparin in off-pump coronary artery bypass grafting (Baciewicz) (Letter); (Carrier) (Reply). 2003;126:2108-9

\section{Blood coagulation}

Coagulation, fibrinolysis, and cell activation in patients and in shed mediastinal blood during coronary artery bypass grafting with a new heparin-coated surface (Baufreton and de Brux). 2003;126:2116 (Letter)

Physiological coagulation can be maintained in extracorporeal circulation by means of shed blood separation and coating (Albes et al). 2003;126:1504-12

\section{Blood coagulation factors}

Activated prothrombin complex concentrates and recombinant factor VIIa in the bleeding patient: are they appropriate and safe? (Aledort). 2003;126:2112-3 (Letter)

Caveat against the use of FEIBA in combination with recombinant factor VIIa (von Heymann et al). 2003;126:1667-8 (Letter)

Blood loss, surgical; see also Postoperative hemorrhage

Comparative study of microfibrillar collagen hemostat (Colgel) and oxidized cellulose (Surgicel) in high transfusionrisk cardiac surgery (Sirlak et al). 2003;126:666-70

Management of major hemorrhage during mediastinoscopy (Park et al). 2003;126:726-31

A randomized trial of aprotinin (Trasylol) on blood loss, blood product requirement, and myocardial injury in total arterial grafting (Taggart et al). 2003;126:1087-94

\section{Blood removal}

Controlled exsanguination during sternal reentry (Aris). 2003;126:918-9 (Brief comm.)

\section{Blood transfusion}

The influence of blood transfusion on survival in operated non-small cell lung cancer patients (Rzyman et al). 2003; 126:755-60

Blood transfusion, autologous

Controlled exsanguination during sternal reentry (Aris). 2003;126:918-9 (Brief comm.)

\section{Body weights and measures}

Relationship of aortic cross-sectional area to height ratio and the risk of aortic dissection in patients with bicuspid aortic valves (Svensson et al). 2003;126:892-3 (Brief comm.)

\section{Bone marrow cells}

Transcoronary implantation of bone marrow stromal cells ameliorates cardiac function after myocardial infarction (Saito et al). 2003;126:114-23

\section{Brachial artery}

Brachial artery cannulation (Kucuker and Tasdemir) (Letter); (Galajda et al) (Reply). 2003;126:2106-7

Brain ischemia; see also Neurologic manifestations

Can particulate extraction from the ascending aorta reduce neurologic injury in cardiac surgery? (Schmitz et al). 2003; $126: 1829-38$

Combined use of off-pump techniques and a sutureless proximal aortic anastomotic device reduces cerebral microemboli generation during coronary artery bypass grafting (Scarborough et al). 2003;126:1561-7 (Evolving tech.)

Conditioned blood reperfusion markedly enhances neurologic recovery after prolonged cerebral ischemia (Allen et al). 2003;126:1851-8

The dynamic air bubble trap reduces cerebral microembolism during cardiopulmonary bypass (Schoenburg et al). 2003; 126:1455-60

Retrograde cerebral perfusion: more risk than benefit? (Murkin). 2003;126:631-3 (Editorial)

Sodium nitroprusside infusion after bidirectional superior cavopulmonary connection: preserved cerebral blood flow velocity and systemic oxygenation (Simsic et al). 2003; 126:186-90

Surgical repair of acute type A aortic dissection: continuous pulmonary perfusion during retrograde cerebral perfusion prevents lung injury in a pilot study (De Santo et al). 2003;126:826-31

\section{Brief Communications}

2003;126:282-302; 582-607; 853-919; 1181-223; 1634-59; 2072-103

\section{Bronchial neoplasms}

Bronchioloalveolar carcinoma arising from a congenital cystic adenomatoid malformation in an adolescent: the first case report from the Orient (Sudou et al). 2003;126:902-3 (Brief comm.)

Granular cell tumors of the tracheobronchial tree (van der Maten et al). 2003;126:740-3

Management of complicated pneumatocele (DiBardino et al). 2003;126:859-61 (Brief comm.) 
Primary malignant melanoma of the bronchus intermedius (Filosso et al). 2003;126:1215-7 (Brief comm.)

Solitary squamous papillomas of the bronchus: a rare case report and literature review (McNamee et al). 2003;126: 861-3 (Brief comm.)

\section{Bronchoalveolar lavage fluid}

Pleural lavage cytology in non-small cell lung cancer: lessons from 1000 consecutive resections (Okada et al). 2003;126: 1911-5

\section{Bronchogenic cyst}

Giant parenchymal bronchogenic cyst mimicking hydropneumothorax (Basoglu et al). 2003;126:1201-2 (Brief comm.)

\section{Bronchopulmonary sequestration}

Intralobar sequestration: a rare cause of severe hemothorax (Wandschneider and Illiasch). 2003;126:872-3 (Brief comm.)

Intralobar sequestration in the middle-aged and elderly adult: recognition and radiographic evaluation (Petersen et al). 2003;126:2086-9 (Brief comm.)

Video-assisted thoracoscopic resection for intralobar pulmonary sequestration: single modality treatment with videoassisted thoracic surgery (Klena et al). 2003;126:857-9 (Brief comm.)

\section{Buffers}

A new role for cardioplegic buffering: should acidosis or calcium accumulation be counteracted to salvage jeopardized hearts? (Castellá et al). 2003;126:1442-8

\section{C}

\section{C-reactive protein}

$\mathrm{C}$-reactive protein activates the nuclear factor $-\kappa \mathrm{B}$ signal transduction pathway in saphenous vein endothelial cells: implications for atherosclerosis and restenosis (Verma et al). 2003;126:1886-91

\section{Calcification, physiologic}

Hypercholesterolemia is a risk factor for bioprosthetic valve calcification and explanation (Farivar and Cohn). 2003; 126:969-76

Is degenerative calcification of the native aortic valve similar to calcification of bioprosthetic heart valves? (David and Ivanov). 2003;126:939-41 (Editorial)

Mitral valve surgery in patients with extensive calcification of

\section{Canada} the mitral annulus (Feindel et al). 2003;126:777-82

Transthoracic needle biopsy in the diagnosis of solitary pulmonary nodules: a survey of Canadian physicians (Lacasse et al). 2003;126:761-8

\section{Capital punishment}

Medical resources and capital punishment (Kumar) (Letter); (McKneally) (Reply). 2003;126:2107-8

\section{Carcinoid tumor}

Possible Tx N2 M0 atypical bronchial carcinoid associated with Cushing syndrome (Filosso) (Letter); (Sugawara et al) (Reply). 2003;126:1224-5

\section{Carcinoma, non-small-cell lung}

A comparative analysis of positron emission tomography and mediastinoscopy in staging non-small cell lung cancer (Gonzalez-Stawinski et al). 2003;126:1900-5

The influence of blood transfusion on survival in operated non-small cell lung cancer patients (Rzyman et al). 2003; 126:755-60

Long-term survival and prognostic factors of five-year survivors with complete resection of non-small cell carcinoma (Okada et al). 2003;126:558-62

Malignant status at surgical margin of limited-resected nonsmall cell lung cancer: a crucial finding for predicting local relapse (Sawabata) (Letter); (Higashiyama et al) (Reply). 2003;126:610-1

Negative aspects of preoperative delay in early stage nonsmall cell lung cancer (Sortini et al) (Letter); (Block) (Reply). 2003;126:609-10

A novel method for sentinel lymph node mapping using magnetite in patients with non-small cell lung cancer (Nakagawa et al). 2003;126:563-7

Pattern of lymphatic spread and prognosis of pN1 non-small cell lung cancer: what does it stand for? (Margaritora et al) (Letter); (Marra and Stamatis) (Reply). 2003;126:1664-5

Pleural lavage cytology in non-small cell lung cancer: lessons from 1000 consecutive resections (Okada et al). 2003;126: 1911-5

Positron emission tomography with $2-\left[{ }^{18} \mathrm{~F}\right]$ fluoro-2-deoxy-Dglucose: can it be used to accurately stage the mediastinum in non-small cell lung cancer as an alternative to mediastinoscopy? (Kernstine). 2003;126:1700-3 (Editorial)

The prognostic significance of intranodal isolated tumor cells and micrometastases in patients with non-small cell carcinoma of the lung (Marchevsky et al). 2003;126:551-7

Resection of multifocal non-small cell lung cancer when the bronchioloalveolar subtype is involved (Roberts et al). 2003; 126:1597-602

Results of the American College of Surgeons Oncology Group Z0050 Trial: the utility of positron emission tomography in staging potentially operable non-small cell lung cancer (Reed et al). 2003;126:1943-51

Value of accelerated multimodality therapy in stage IIIA and IIIB non-small cell lung cancer (DeCamp et al). 2003; 126:17-27

\section{Cardiac output, low}

The relationship between plasma free $15-\mathrm{F}_{2 \mathrm{t}}$-isoprostane concentration and early postoperative cardiac depression following warm heart surgery (Ansley et al). 2003;126:1222-3 (Brief comm.)

Cardiac surgery; see Thoracic surgery

Cardiac surgical procedures; see also specific procedure

Acute type A aortic dissection complicated by aortic regurgitation: composite valve graft versus separate valve graft versus conservative valve repair (Lai et al). 2003;126: 1978-86

Atrial fibrillation II: rationale for surgical treatment (Cox). 2003;126:1693-9 (Editorial) 
"Cinching" the mitral valve (Robicsek). 2003;126:942-3 (Editorial)

Closed correction of systemic semilunar valve insufficiency in the neonate (Pigula et al). 2003;126:1650-2 (Brief comm.)

The "clover technique" as a novel approach for correction of post-traumatic tricuspid regurgitation (Alfieri et al). 2003; 126:75-9

Coarctation: the search for the Holy Grail (Backer). 2003; 126:329-31 (Editorial)

Free right atrial patches for septal defect closure (Kumar). 2003;126:303-4 (Letter)

Incisional atrial reentrant tachycardia: experimental study on the conduction property through the isthmus (Ishii et al). 2003; 126:254-62

Left ventricular external subannular plication: an indirect off-pump mitral annuloplasty method in a canine model (Kollár et al). 2003;126:977-82

Midterm results of edge-to-edge mitral valve repair without annuloplasty (Maisano et al). 2003;126:1987-97

Mitral valve surgery in patients with extensive calcification of the mitral annulus (Feindel et al). 2003;126:777-82

A new aortoventriculoplasty for prosthetic aortic valve replacement (Hvass et al). 2003;126:818-20

Perventricular device closure of muscular ventricular septal defects on the beating heart: technique and results (Bacha et al). 2003;126:1718-23

Restrictive mitral annuloplasty in refractory cardiogenic shock with acute postinfarction mitral insufficiency and intact papillary muscle (Braun et al). 2003;126:284-6 (Brief comm.)

Staged repair of tetralogy of Fallot with pulmonary atresia and major aortopulmonary collateral arteries (Duncan et al). 2003;126:694-702

Surgically created double orifice repair of tricuspid regurgitation in infants with congenital heart disease (Fukuda et al). 2003;126:1220-1 (Brief comm.)

Systolic anterior motion after mitral valve repair: myectomy as an alternative solution (Rescigno et al). 2003;126:1196-7 (Brief comm.)

Tricuspidization of incompetent bicuspid aortic valve (Kawazoe et al). 2003;126:908-10 (Brief comm.)

Unroofed coronary sinus syndrome: Diagnosis, classification, and surgical treatment (Ootaki et al). 2003;126:1655-6 (Brief comm.)

\section{Cardiomyopathy, congestive}

Improved early outcome for end-stage dilated cardiomyopathy in children (McMahon et al). 2003;126:1781-7

Mitral valve in ischemic versus idiopathic dilated cardiomyopathy (Grossi et al). 2003;126:922 (Letter)

Persistent abnormal left ventricular systolic torsion in dilated cardiomyopathy after partial left ventriculectomy (Setser et al). 2003;126:48-55

Transplantation of cryopreserved muscle cells in dilated cardiomyopathy: effects on left ventricular geometry and function (Ohno et al). 2003;126:1537-48
Cardioplegia; see Heart arrest, induced

Cardioplegic solutions

A new role for cardioplegic buffering: should acidosis or calcium accumulation be counteracted to salvage jeopardized hearts? (Castellá et al). 2003;126:1442-8

\section{Cardiopulmonary bypass}

Antifibrinolytic therapy during cardiopulmonary bypass reduces proinflammatory cytokine levels: a randomized, double-blind, placebo-controlled study of $\epsilon$-aminocaproic acid and aprotinin (Greilich et al). 2003;126:1498-503

Antioxidant therapy with Salvia miltiorrhiza decreases plasma endothelin-1 and thromboxane B2 after cardiopulmonary bypass in patients with congenital heart disease (Xia et al). 2003;126:1404-10

Cardiac surgery during pregnancy: pulsatile or nonpulsatile perfusion? (Jahangiri et al) 2003;126:894-895 (Brief comm.) Correction 2003;126:1680

Doppler microembolic signals during cardiac surgery: comparison between arterial line and middle cerebral artery (Georgiadis et al). 2003;126:1638-9 (Brief comm.)

The dynamic air bubble trap reduces cerebral microembolism during cardiopulmonary bypass (Schoenburg et al). 2003; 126:1455-60

Gene expression profile after cardiopulmonary bypass and cardioplegic arrest (Ruel et al). 2003;126:1521-30

High antithrombin III levels attenuate hemostatic activation and leukocyte activation during cardiopulmonary bypass (Koster et al). 2003;126:906-7 (Brief comm.)

The influence of hemodilution on outcome after hypothermic cardiopulmonary bypass: results of a randomized trial in infants (Jonas et al). 2003;126:1765-74

Plasma levels of interleukin-8 and expression of interleukin- 8 receptors on circulating neutrophils and monocytes after cardiopulmonary bypass in children (Gessler et al). 2003; 126:718-25

Protection of the human heart with ischemic preconditioning during cardiac surgery: role of cardiopulmonary bypass (Ghosh and Galiñanes). 2003;126:133-42

Transit time flow measurement in on-pump and off-pump coronary artery surgery (Schmitz et al). 2003;126:645-50

Vacuum-assisted venous return reduces blood usage (Banbury et al). 2003;126:680-7

Cardiopulmonary resuscitation

Long-term outcome after coronary artery bypass grafting in cardiogenic shock or cardiopulmonary resuscitation (Sergeant et al). 2003;126:1279-87

Cardiopulmonary Support and Physiology

2003;126:114-90; 420-64; 638-93; 1061-120; 1442-554; 1788-899

Cardiothoracic Transplantation

2003;126:200-31; 469-89; 1174-80; 1624-33; 2052-71

Carotid artery, common

Cannulation of the left common carotid artery for proximal aortic repair (Urbanski). 2003;126:887-8 (Brief comm.)

Case report

Benign intrapulmonary teratoma: report of a case (Eren et al). 2003;126:855-7 (Brief comm.) 
Bronchioloalveolar carcinoma arising from a congenital cystic adenomatoid malformation in an adolescent: the first case report from the Orient (Sudou et al). 2003;126:902-3 (Brief comm.)

Chondrosarcoma arising in the trachea: a case report and review of the literature (Maish and Vaporciyan). 2003; 126:2077-80 (Brief comm.)

Combined endovascular and video-assisted thoracoscopic procedure for treatment of a ruptured pulmonary arteriovenous fistula: case report and review of the literature (Litzler et al). 2003;126:1204-7 (Brief comm.)

A giant gastroenteric cyst associated with pectus excavatum and compression of the thoracic duct: a case report (Reisli et al). 2003;126:584-5 (Brief comm.)

Left-sided cervical aortic arch aneurysm: case report (Higuchi et al). 2003;126:2098-100 (Brief comm.)

Solitary squamous papillomas of the bronchus: a rare case report and literature review (McNamee et al). 2003;126: 861-3 (Brief comm.)

\section{Caspases}

Pharmacologic inhibition of intracellular caspases after myocardial infarction attenuates left ventricular remodeling: a potentially novel pathway (Yarbrough et al). 2003;126: 1892-9

\section{Catheter ablation}

Atrial fibrillation II: rationale for surgical treatment (Cox). 2003;126:1693-9 (Editorial)

Atrioesophageal fistula: Is it an unavoidable complication of radiofrequency ablation? (Sonmez et al) (Letter); (Doll et al) (Reply). 2003;126:1662-3

Esophageal perforation during left atrial radiofrequency ablation: is the risk too high? (Gillinov et al) (Letter); (Doll et al) (Reply). 2003;126:1661-2

Esophageal perforation during left atrial radiofrequency ablation (Laczkovics et al) (Letter); (Doll et al) (Reply). 2003;126:2119-20

A new device for beating heart bipolar radiofrequency atrial ablation (Bonanomi et al). 2003;126:1859-66

Surgery for atrial fibrillation using radiofrequency catheter ablation (Chiappini et al). 2003;126:1788-91

Surgical radiofrequency ablation of both atria for atrial fibrillation: results of a multicenter trial (Raman et al). 2003; 126:1357-66

\section{Catheterization}

Axillary artery cannulation for extracorporeal membrane oxygenator support in adults: an approach to minimize complications (Moazami et al). 2003;126:2097-8 (Brief comm.)

Brachial artery cannulation (Kucuker and Tasdemir) (Letter); (Galajda et al) (Reply). 2003;126:2106-7

Cannulation of the left common carotid artery for proximal aortic repair (Urbanski). 2003;126:887-8 (Brief comm.)

Cervical cannulation for resternotomy in pediatric patients (Delius et al). 2003;126:2095-6 (Brief comm.)

Clinical outcomes and utility of cardiac catheterization prior to superior cavopulmonary anastomosis (Brown et al). 2003;126:272-81

\section{Celiac artery}

Stent graft treatment for abdominal pseudoaneurysm near the celiac artery (Takahashi et al). 2003;126:600-2 (Brief comm.)

\section{Cell death}

Cell death induced by down-regulation of heat shock protein 70 in lung cancer cell lines is p53-independent and does not require DNA cleavage (Frese et al). 2003;126:748-54

\section{Cell extraction}

Decellularization of rat aortic valve allografts reduces leaflet destruction and extracellular matrix remodeling (Grauss et al). 2003;126:2003-10

Cell therapy; see Tissue therapy

\section{Cell transplantation}

Myogenesis after myocardial stem cell transplantation (Taheri) (Letter); (Chiu) (Reply). 2003;126:2116-7

Transplantation of cryopreserved muscle cells in dilated cardiomyopathy: effects on left ventricular geometry and function (Ohno et al). 2003;126:1537-48

\section{Cellulose, oxidized}

Comparative study of microfibrillar collagen hemostat (Colgel) and oxidized cellulose (Surgicel) in high transfusionrisk cardiac surgery (Sirlak et al). 2003;126:666-70

Cerebral ischemia; see Brain ischemia

Cerebrovascular accident

Early and late stroke after mitral valve replacement with a mechanical prosthesis: risk factor analysis of a 24-year experience (Bando et al). 2003;126:358-64

Intentional delay of surgery for acute type A dissection with stroke (Fukuda and Imazuru). 2003;126:290-1 (Brief comm.)

Modification of surgical technique for ascending aortic atherosclerosis: impact on stroke reduction in coronary artery bypass grafting (Hangler et al). 2003;126:391-400

Chemotherapy, adjuvant

Benefit of postoperative adjuvant chemoradiotherapy in locoregionally advanced esophageal carcinoma (Rice et al). 2003;126:1590-6

Preoperative chemotherapy for esophageal cancer with paclitaxel and carboplatin: results of a phase II trial (Keresztes et al). 2003;126:1603-8

Chest wall; see Thoracic wall

Child

Cervical cannulation for resternotomy in pediatric patients (Delius et al). 2003;126:2095-6 (Brief comm.)

Comparison of autograft and allograft aortic valve replacement in children (Lupinetti et al). 2003;126:240-6

Human leukocyte antigen-DR and ABO mismatch are associated with accelerated homograft valve failure in children: implications for therapeutic interventions (Baskett et al). 2003;126:232-9

Immunogenicity of decellularized cryopreserved allografts in pediatric cardiac surgery: comparison with standard cryopreserved allografts (Hawkins et al). 2003;126:247-53

Improved early outcome for end-stage dilated cardiomyopathy in children (McMahon et al). 2003;126:1781-7 
The influence of perioperative factors on outcomes in children aged less than 18 months after repair of tetralogy of Fallot (van Dongen et al). 2003;126:703-10

Mitral valve replacement by a Gore-Tex reinforced pulmonary autograft in a child (Yamagishi et al). 2003;126: 1218-9 (Brief comm.)

Neurodevelopmental status of eight years in children with dextro-transposition of the great arteries: the Boston Circulatory Arrest Trial (Bellinger et al). 2003;126:1385-96

Plasma levels of interleukin- 8 and expression of interleukin-8 receptors on circulating neutrophils and monocytes after cardiopulmonary bypass in children (Gessler et al). 2003; 126:718-25

Pneumonectomy in children for destroyed lung and the longterm consequences (Eren et al). 2003;126:574-81

Reoperations and survival after primary repair of congenital heart defects in children (Monro et al). 2003;126:511-20

Secretion of A-type and B-type natriuretic peptides into the bloodstream and pericardial space in children with congenital heart disease (Ootaki et al). 2003;126:1411-6

Single-finger subcutaneous defibrillation lead and "active can": a novel minimally invasive defibrillation configuration for implantable cardioverter-defibrillator implantation in a young child (Madan et al). 2003;126:1657-9 (Brief comm.)

Unilateral pulmonary thromboendarterectomy for iatrogenic pulmonary hypertension in a ten-year-old child (Zacharias et al). 2003;126:1210-1 (Brief comm.)

\section{Chlamydophila pneumoniae}

Atherogenic effects of Chlamydia pneumoniae: refuting the innocent bystander hypothesis (Selzman et al). 2003;126: 688-93

\section{Chondrosarcoma}

Chondrosarcoma arising in the trachea: a case report and review of the literature (Maish and Vaporciyan). 2003; 126:2077-80 (Brief comm.)

\section{Chromosome deletion}

Influence of chromosome 22q11.2 microdeletion on surgical outcome after treatment of tetralogy of Fallot with pulmonary atresia (Carotti et al). 2003;126:1666-7 (Letter)

\section{Chyloperitoneum}

Chylous leak after cervical mediastinoscopy (Barthes et al).

\section{Chylothorax} 2003;126:1199-200 (Brief comm.)

Refractory chylothorax after lung transplantation for lymphangioleiomyomatosis successfully cured with instillation of povidone (Duariat et al). 2003;126:875-7 (Brief comm.)

\section{Cisplatin}

Cisplatin augments cytotoxic T-lymphocyte-mediated antitumor immunity in poorly immunogenic murine lung cancer (Merritt et al). 2003;126:1609-17

\section{Clinical-Pathologic Conference}

Clinical-pathologic conference in general thoracic surgery: pulmonary blastoma (Force and Patterson). 2003;126:1247-50

\section{Clinical trials}

Clinical and six-month angiographic evaluation of coronary arterial graft interrupted anastomoses by use of a selfclosing clip device: a multicenter prospective clinical trial (Wolf et al). 2003;126:168-78

Extrapleural regional versus systemic analgesia for relieving postthoracotomy pain: a clinical study of bupivacaine compared with metamizol (Bilgin et al). 2003; 126:1580-3

Factors affecting saphenous vein graft patency: clinical and angiographic study in 1402 symptomatic patients operated on between 1977 and 1999 (Shah et al). 2003;126: 1972-7

Improved pain control after cardiac surgery: results of a randomized, double-blind, clinical trial (Dowling et al). 2003;126:1271-8

$\mathrm{N}$-acetylcysteine prevents reactive oxygen species-mediated myocardial stress in patients, undergoing cardiac surgery: results of a randomized, double-blind, placebo-controlled clinical trial (Tossios et al). 2003;126:1513-20

Preoperative chemotherapy for esophageal cancer with paclitaxel and carboplatin: results of a phase II trial (Keresztes et al). 2003;126:1603-8

Remote control of pulmonary blood flow: initial clinical experience (Corno et al). 2003;126:1775-80

Clopidogrel

Clopidogrel before urgent coronary artery bypass graft (Genoni et al). 2003;126:288-9 (Brief comm.)

Coin lesion, pulmonary

Transthoracic needle biopsy in the diagnosis of solitary pulmonary nodules: a survey of Canadian physicians (Lacasse et al). 2003;126:761-8

\section{Collagen}

Comparative study of microfibrillar collagen hemostat (Colgel) and oxidized cellulose (Surgicel) in high transfusionrisk cardiac surgery (Sirlak et al). 2003;126:666-70

\section{Collis, J. Leigh}

Short esophagi and long career (Herbella). 2003;126:1668 (Letter)

\section{Combined modality therapy}

Safety of bronchoplastic resection after induction therapy for lung cancer (Veronesi et al) (Letter); (Ohta et al) (Reply). 2003;126:1670-1

Survival following intensive preoperative combined modality therapy with paclitaxel, cisplatin, 5-fluorouracil, and radiation in resectable esophageal carcinomas: a phase I report (Goldberg et al). 2003;126:1168-73

Value of accelerated multimodality therapy in stage IIIA and IIIB non-small cell lung cancer (DeCamp et al). 2003; 126:17-27

\section{Comparative study}

Comparative study of microfibrillar collagen hemostat (Colgel) and oxidized cellulose (Surgicel) in high transfusionrisk cardiac surgery (Sirlak et al). 2003;126:666-70

Doppler microembolic signals during cardiac surgery: comparison between arterial line and middle cerebral artery (Georgiadis et al). 2003;126:1638-9 (Brief comm.) 


\section{Complement activation}

Generation of platelet-derived microparticles in patients undergoing cardiac surgery is not affected by complement activation (van den Goor et al). 2003;126:1101-6

Confounding factors (epidemiology)

Authors should list confounding factors and alternative explanations for adverse events seen with new technologies (Anyanwu) (Letter); (Hornik) (Reply). 2003;126:1663-4

\section{Coronary angiography}

Noninvasive evaluation of internal thoracic artery and left anterior descending coronary artery anastomotic sites using transthoracic Doppler echocardiography: comparison with coronary arteriography (Hirata et al). 2003;126:1080-6

\section{Coronary artery bypass}

Activation of mitogen-activated protein kinases during preparation of vein grafts and modulation by a synthetic inhibitor (Bizekis et al). 2003;126:659-665. Correction 2003; $126: 1680$

Association of lipoprotein(a) excess with early vein graft occlusions in middle-aged men undergoing coronary artery bypass surgery (Pokrovsky et al). 2003;126:1071-5

Automated proximal anastomosis for redo coronary artery bypass grafting through a lateral thoracotomy (Perreas et al). 2003;126:606-7 (Brief comm.)

Bivalirudin as alternative to both danaparoid and heparin in off-pump coronary artery bypass grafting (Baciewicz) (Letter); (Carrier) (Reply). 2003;126:2108-9

Carbon dioxide embolism during endoscopic saphenous vein harvesting in coronary artery bypass surgery (Lin et al). 2003; 126:2011-5

Changes in left anterior descending coronary artery flow profiles after coronary artery bypass grafting examined by means of transthoracic Doppler echocardiography (Yoshitatsu et al). 2003;126:1531-6

Clinical and six-month angiographic evaluation of coronary arterial graft interrupted anastomoses by use of a selfclosing clip device: a multicenter prospective clinical trial (Wolf et al). 2003;126:168-78

Clopidogrel before urgent coronary artery bypass graft (Genoni et al). 2003;126:288-9 (Brief comm.)

Coagulation, fibrinolysis, and cell activation in patients and in shed mediastinal blood during coronary artery bypass grafting with a new heparin-coated surface (Baufreton and de Brux). 2003;126:2116 (Letter)

Combination of the HEARTSTRING proximal seal system with a blower mister: a possible source of gas emboli (Nollert et al). 2003;126:1192-4 (Brief comm.)

Combined use of off-pump techniques and a sutureless proximal aortic anastomotic device reduces cerebral microemboli generation during coronary artery bypass grafting (Scarborough et al). 2003;126:1561-7 (Evolving tech.)

Comparative efficacies and durations of action of phenoxybenzamine, verapamil/nitroglycerin solution, and papaverine as topical antispasmodics for radial artery coronary bypass grafting (Mussa et al). 2003;126:1798-805

Decreasing significance of left ventricular dysfunction and reoperative surgery in predicting coronary artery bypass grafting-associated mortality: a twelve-year study (Davierwala et al). 2003;126:1335-44

Detrimental effects of papaverine on the human internal thoracic artery (Gao et al). 2003;126:179-85

Does size matter? What is your infarct rate after coronary artery bypass grafting? (Mentzer). 2003;126:326-8 (Editorial)

Facilitated endoscopic beating heart coronary artery bypass grafting using a magnetic coupling device (Falk et al). 2003;126:1575-9 (Evolving tech.)

Fibrillation in patients subjected to coronary artery bypass grafting (Wu et al). 2003;126:1477-82

Future technologic innovations for intraoperative visualization of native coronary artery and graft anastomoses (Suematsu and Takamoto) (Letter); (Borst et al) (Reply). 2003; 126:304-5

Gender and outcomes after coronary artery bypass grafting: a propensity-matched comparison (Koch et al). 2003;126: 2032-43

Gender differences in quality of distal vessels: effect on results of coronary artery bypass grafting (Mickleborough et al). 2003;126:950-8

Gender profiling in coronary artery bypass grafting (Koch et al). 2003;126:2044-51

Gender-related differences in morbidity and mortality during combined valve and coronary surgery (Ibrahim et al). 2003;126:959-64

Impact of sodium-hydrogen exchange inhibition by cariporide on death or myocardial infarction in high-risk CABG surgery patients: results of the CABG surgery cohort of the GUARDIAN study (Boyce et al). 2003;126:420-7

Improving outcomes for women after coronary artery bypass grafting: a case for prevention (Oparil). 2003;126:1704-6 (Editorial)

Intraoperative assessment of coronary artery bypass grafts (Wolf and Falk). 2003;126:634-7 (Editorial)

Is it gender, methodology, or something else? (Koch et al). 2003;126:932-5 (Editorial)

Is there a hypercoagulable state after off-pump coronary artery bypass surgery? What do we know and what can we do? (Kurlansky). 2003;126:7-10 (Editorial)

Is there an evidence in favor of off-pump coronary artery bypass? (El Oakley et al). 2003;126:1668 (Letter)

Is what's good for the gander good for the goose? (Wenger). 2003;126:929-31 (Editorial)

Long-term benefits of coronary bypass surgery: are the gains for women less than for men? (Vaccarino and Koch). 2003;126:1707-11 (Editorial)

Long-term outcome after coronary artery bypass grafting in cardiogenic shock or cardiopulmonary resuscitation (Sergeant et al). 2003;126:1279-87

Magnetic vascular coupling for distal anastomosis in coronary artery bypass grafting: a multicenter trial (Klima et al). 2003;126:1568-74 (Evolving tech.)

Modification of surgical technique for ascending aortic atherosclerosis: impact on stroke reduction in coronary artery bypass grafting (Hangler et al). 2003;126:391-400 
Preoperative use of enoxaparin is not a risk factor for postoperative bleeding after coronary artery bypass surgery (Medalion et al). 2003;126:1875-9

Prognostic significance of elevated creatine kinase MB after coronary bypass surgery and after an acute coronary syndrome: results from the GUARDIAN trial (Gavard et al). 2003;126:807-13

Quantitative gated myocardial perfusion single photon emission computed tomography improves the prediction of regional functional recovery in akinetic areas after coronary bypass surgery: useful tool for evaluation of myocardial viability (Murashita et al). 2003;126:1328-34

A randomized trial of aprotinin (Trasylol) on blood loss, blood product requirement, and myocardial injury in total arterial grafting (Taggart et al). 2003;126:1087-94

Risk factors for leg harvest surgical site infections after coronary artery bypass graft surgery (Olsen et al). 2003; 126:992-9

Sixty-year perspective on coronary artery bypass grafting in women (Hartz et al). 2003;126:620-2 (Editorial)

Surgical revascularization in women: unique intraoperative factors and considerations (Lawton et al). 2003;126:936-8 (Editorial)

Transit time flow measurement in on-pump and off-pump coronary artery surgery (Schmitz et al). 2003;126:645-50

\section{Coronary disease}

The long-term outcome of patients with coronary disease and atrial fibrillation undergoing the Cox maze procedure (Damiano et al). 2003;126:2016-21

\section{Coronary vessels}

Giant atherosclerotic aneurysm of the left anterior descending artery (Attar et al). 2003;126:888-90 (Brief comm.)

The left anterior descending coronary artery is the best recip-

\section{Corrections} ient (Zamvar and Sivaprakasam). 2003;126:923 (Letter)

Activation of mitogen-activated protein kinases during preparation of vein grafts and modulation by a synthetic inhibitor (Bizekis et al). 2003;126:659-665. Correction 2003; $126: 1680$

Cardiac surgery during pregnancy: pulsatile or nonpulsatile perfusion? (Jahangiri et al) 2003;126:894-895 (Brief comm.) Correction 2003;126:1680

Correspondence; see Letters to the Editor

Costs and cost analysis

Is discharge policy a balanced decision between clinical considerations and hospital ownership policy? The CABG example (Galai et al). 2003;126:1018-25

Optimal management when unsuspected N2 nodal disease is identified during thoracotomy for lung cancer: cost-effectiveness analysis (Ferguson). 2003;126:1935-42

\section{Cox maze procedure}

The Cox maze III procedure for atrial fibrillation: long-term efficacy in patients undergoing lone versus concomitant procedures (Prasad et al). 2003;126:1822-8

The long-term outcome of patients with coronary disease and atrial fibrillation undergoing the Cox maze procedure (Damiano et al). 2003;126:2016-21

\section{Creatine kinase}

Prognostic significance of elevated creatine kinase MB after coronary bypass surgery and after an acute coronary syndrome: results from the GUARDIAN trial (Gavard et al). 2003; 126:807-13

\section{Cryopreservation}

Immunogenicity of decellularized cryopreserved allografts in pediatric cardiac surgery: comparison with standard cryopreserved allografts (Hawkins et al). 2003;126:247-53

\section{Cryosurgery}

Outcome of symptomatic patients undergoing extracardiac Fontan conversion and cryoablation (Weinstein et al). 2003;126:529-36

Culture (organizational)

Our surgical culture of blame: a time for change (Dickey et al). 2003;126:1259-60 (Editorial)

\section{Cushing syndrome}

Possible Tx N2 M0 atypical bronchial carcinoid associated with Cushing syndrome (Filosso) (Letter); (Sugawara et al) (Reply). 2003;126:1224-5

\section{Cyclooxygenase inhibitor}

Cyclooxygenase- 2 inhibition decreases primary and metastatic tumor burden in a murine model of orthotopic lung adenocarcinoma (DiPerna et al). 2003;126:1129-33

Cystic adenomatoid malformation of lung, congenital

Bronchioloalveolar carcinoma arising from a congenital cystic adenomatoid malformation in an adolescent: the first case report from the Orient (Sudou et al). 2003;126:902-3 (Brief comm.)

\section{Cytokines}

Antifibrinolytic therapy during cardiopulmonary bypass reduces proinflammatory cytokine levels: a randomized, double-blind, placebo-controlled study of $\epsilon$-aminocaproic acid and aprotinin (Greilich et al). 2003;126:1498-503

\section{D}

\section{Defibrillators, implantable}

Single-finger subcutaneous defibrillation lead and "active can": a novel minimally invasive defibrillation configuration for implantable cardioverter-defibrillator implantation in a young child (Madan et al). 2003;126:1657-9 (Brief comm.)

\section{Dependovirus}

Direct comparison of efficiency and stability of gene transfer into the mammalian heart using adeno-associated virus versus adenovirus vectors (Chu et al). 2003;126:671-9

\section{Diabetes mellitus}

Diabetes and evidence of atherosclerosis are major risk factors for adverse outcome after elective thoracic aortic surgery (Hagl et al). 2003;126:1005-12

Skeletonization of bilateral internal thoracic artery grafts lowers the risk of sternal infection in patients with diabetes (Peterson et al). 2003;126:1314-9

\section{Disease progression}

Rapid progression of midventricular obstruction in adults with double-chambered right ventricle (Oliver et al). 2003; 126:711-7 
Simultaneous progression of oxidative stress and angiogenesis in malignant transformation of Barrett esophagus ( $\mathrm{Si}$ hvo et al). 2003;126:1951-7

Donors; see Tissue donors

Drainage, vacuum-assisted

Evaluation of vacuum-assisted closure in the treatment of poststernotomy mediastinitis (Domkowski et al). 2003; 126:386-90

\section{Drowning}

Drowned donor lung for bilateral lung transplantation (McNamee et al). 2003;126:910-2 (Brief comm.)

\section{Drug administration routes}

Intraoperative inhalation of the long-acting prostacyclin analog iloprost for pulmonary hypertension (Langer et al). 2003;126:874-5 (Brief comm.)

\section{Ductus arteriosus, patent}

Isolated persistent fifth aortic arch with systemic-to-pulmonary arterial connection (Hwang et al). 2003;126:1643-4 (Brief comm.)

\section{E}

\section{Echinococcosis}

Single-stage transthoracic approach for right lung and liver hydatid disease (Şahin et al). 2003;126:769-73

\section{Echocardiography}

Future technologic innovations for intraoperative visualization of native coronary artery and graft anastomoses (Suematsu and Takamoto) (Letter); (Borst et al) (Reply). 2003; 126:304-5

\section{Echocardiography, Doppler}

Assessment of mechanical aortic valve prosthesis by means of Doppler echocardiography: what to measure and why? (Vannan and Sarkar). 2003;126:317-20 (Editorial)

Changes in left anterior descending coronary artery flow profiles after coronary artery bypass grafting examined by means of transthoracic Doppler echocardiography (Yoshitatsu et al). 2003;126:1531-6

Noninvasive evaluation of internal thoracic artery and left anterior descending coronary artery anastomotic sites using transthoracic Doppler echocardiography: comparison with coronary arteriography (Hirata et al). 2003;126:1080-6

Serial Doppler echocardiographic evaluation of small-sized Sorin Bicarbon prostheses (De Carlo et al). 2003;126: $337-43$

\section{Editorials}

2003;126:1-10; 313-36; 617-37; 929-49; 1251-70; 1681-711

\section{Education, medical}

Thoracic surgery education: responding to a changing environment (Crawford). 2003;126:1235-42 (Pres. address)

Embolism; see also Pulmonary embolism; Thromboembolism

Can particulate extraction from the ascending aorta reduce neurologic injury in cardiac surgery? (Schmitz et al). 2003;126:1829-38

\section{Embolism, air}

Carbon dioxide embolism during endoscopic saphenous vein harvesting in coronary artery bypass surgery (Lin et al). 2003;126:2011-5
Combination of the HEARTSTRING proximal seal system with a blower mister: a possible source of gas emboli (Nollert et al). 2003;126:1192-4 (Brief comm.)

Doppler microembolic signals during cardiac surgery: comparison between arterial line and middle cerebral artery (Georgiadis et al). 2003;126:1638-9 (Brief comm.)

The dynamic air bubble trap reduces cerebral microembolism during cardiopulmonary bypass (Schoenburg et al). 2003; 126:1455-60

Fatal air embolism during computed tomography-guided pulmonary marking with a hook-type marker (Sakiyama et al). 2003;126:1207-9 (Brief comm.)

Rapid recognition and treatment of cerebral air embolism: the role of neuromonitoring (Yeh et al). 2003;126:589-91 (Brief comm.)

Emergency service, hospital

Emergency hospital admissions and three-year survival of adults with and without cardiovascular surgery for congenital cardiac disease (Kaemmerer et al). 2003;126:1048-52

\section{Emphysema}

Development of a canine model of pulmonary emphysema and imaging of the emphysematous lung with infrared thoracoscopy (Gotoh et al). 2003;126:1916-21

Spontaneous pneumomediastinum: a rare benign entity (Gerazounis et al). 2003;126:774-6

\section{Endarterectomy}

Indications for pulmonary endarterectomy (Riedel) (Letter); (Thistlethwaite and Jamieson) (Reply). 2003;126:1227-9

Unilateral pulmonary thromboendarterectomy for iatrogenic pulmonary hypertension in a ten-year-old child (Zacharias et al). 2003;126:1210-1 (Brief comm.)

Endogenous retroviruses

Acellularized porcine heart valve scaffolds for heart valve tissue engineering and the risk of cross-species transmission of porcine endogenous retrovirus (Leyh et al). 2003; 126:1000-4

\section{Endoscopy}

Endoscopic, robotically assisted implantation of phrenic pacemakers (Morgan et al). 2003;126:582-3 (Brief comm.)

Facilitated endoscopic beating heart coronary artery bypass grafting using a magnetic coupling device (Falk et al). 2003;126:1575-9 (Evolving tech.)

Microelectromechanical systems for endoscopic cardiac surgery (Bonanomi et al). 2003;126:851-2 (Evolving tech.)

Totally endoscopic atrial septal repair in adults with computer-enhanced telemanipulation (Wimmer-Greinecker et al). 2003;126:465-8 (Evolving tech.)

\section{Endothelin-1}

Antioxidant therapy with Salvia miltiorrhiza decreases plasma endothelin-1 and thromboxane B2 after cardiopulmonary bypass in patients with congenital heart disease (Xia et al). 2003;126:1404-10

Pulmonary blood pressure, not flow, is associated with net endothelin-1 production in the lungs of patients with congenital heart disease and normal pulmonary vascular resistance (Fratz et al). 2003;126:1724-9 


\section{Endothelium}

Impaired endothelium-derived hyperpolarizing factor-mediated relaxation in porcine pulmonary microarteries after cold storage with Euro-Collins and University of Wisconsin solutions (Zou et al). 2003;126:208-15

Implantation of an autologously endothelialized homograft (Gulbins et al). 2003;126:890-1 (Brief comm.)

Epstein-Barr virus; see Herpesvirus 4, human

\section{Esophageal neoplasms}

Benefit of postoperative adjuvant chemoradiotherapy in locoregionally advanced esophageal carcinoma (Rice et al). 2003;126:1590-6

Extracapsular lymph node involvement is a negative prognostic factor in T3 adenocarcinoma of the distal esophagus and gastroesophageal junction (Lerut et al). 2003;126: 1121-8

Lymph node involvement in esophageal adenocarcinoma: if you see one, have you seen them all? (DeMeester). 2003; 126:947-9 (Editorial)

Preoperative chemotherapy for esophageal cancer with paclitaxel and carboplatin: results of a phase II trial (Keresztes et al). 2003;126:1603-8

Simultaneous progression of oxidative stress and angiogenesis in malignant transformation of Barrett esophagus ( $\mathrm{Si}$ hvo et al). 2003;126:1951-7

Survival following intensive preoperative combined modality therapy with paclitaxel, cisplatin, 5-fluorouracil, and radiation in resectable esophageal carcinomas: a phase I report (Goldberg et al). 2003;126:1168-73

\section{Esophageal perforation}

Esophageal perforation during left atrial radiofrequency ablation: is the risk too high? (Gillinov et al) (Letter); (Doll et al) (Reply). 2003;126:1661-2

Esophageal perforation during left atrial radiofrequency ablation (Laczkovics et al) (Letter); (Doll et al) (Reply). 2003;126:2119-20

\section{Esophagectomy}

Atrial fibrillation after esophagectomy is a marker for postoperative morbidity and mortality (Murthy et al). 2003; 126:1162-7

Benefit of postoperative adjuvant chemoradiotherapy in locoregionally advanced esophageal carcinoma (Rice et al). 2003;126:1590-6

\section{Esophagus}

Short esophagi and long career (Herbella). 2003;126:1668 (Letter)

Tissue-engineered esophagus: experimental substitution by onlay patch or interposition (Grikscheit et al). 2003;126: 537-44

Ethics; see also Prisoners

The peer-review process in medical publishing: a reviewer's perspective (Sellke). 2003;126:1683-5 (Editorial)

\section{Evaluation studies}

Hancock II bioprosthesis: a glance at the microscope in mid-long-term explants (Bottio et al). 2003;126:99-105

Long-term durability of the Hancock II porcine bioprosthesis (Rizzoli et al). 2003;126:66-74
Long-term evaluation of Carpentier-Edwards porcine bioprosthesis for rheumatic heart disease (Yu et al). 2003; 126:80-9

\section{Events of Interest}

2003;126:306-7; 612-3; 924-5; 1230-1; 1676-7; 2124-5

\section{Evolving Technology}

2003;126:191-9; 465-8; 851-2; 1555-79; 1958-67

Experimental studies; see Therapies, investigational

Exsanguination; see Blood removal

\section{Extracellular matrix}

Decellularization of rat aortic valve allografts reduces leaflet destruction and extracellular matrix remodeling (Grauss et al). 2003;126:2003-10

Rapamycin has no effect on fibrosis-associated gene expression or extracellular matrix accumulation when administered to animals with established or early allograft vasculopathy (Murphy and Nicholson). 2003;126:2058-64

Vascular matrix remodeling in patients with bicuspid aortic valve malformations: implications for aortic dilatation (Fedak et al). 2003;126:797-806

\section{Extracorporeal circulation}

Activated prothrombin complex concentrates and recombinant factor VIIa in the bleeding patient: are they appropriate and safe? (Aledort). 2003;126:2112-3 (Letter)

Caveat against the use of FEIBA in combination with recombinant factor VIIa (von Heymann et al). 2003;126:1667-8 (Letter)

Exhaled carbon monoxide and inducible heme oxygenase expression in a rat model of postperfusion acute lung injury (Zegdi et al). 2003;126:1867-74

Exhaled nitric oxide and cardiac surgery with extracorporeal circulation (Marczin) (Letter); (Adatia et al) (Reply). 2003;126:1673-5

A milestone in cardiovascular surgery (Cooley). 2003;126: 1243-4 (Hon. guest's address)

Pharmacologic platelet anesthesia by glycoprotein IIb/IIIa complex antagonist and argatroban during in vitro extracorporeal circulation (Kanemitsu et al). 2003;126:428-35

Physiological coagulation can be maintained in extracorporeal circulation by means of shed blood separation and coating (Albes et al). 2003;126:1504-12

Vacuum-assisted venous return reduces blood usage (Banbury et al). 2003;126:680-7

\section{Extracorporeal membrane oxygenation}

Successful LVAS and RVAS-ECMO support in a patient with fulminant myocarditis who failed to recover from ventricular fibrillation with PCPS and IABP (Gojo et al). 2003;126:885-6 (Brief comm.)

\section{$\mathrm{F}$}

\section{Far East}

Bronchioloalveolar carcinoma arising from a congenital cystic adenomatoid malformation in an adolescent: the first case report from the Orient (Sudou et al). 2003;126:902-3 (Brief comm.) 


\section{Fetoscopy}

Fetal cardiac surgery: simplicity versus success in a new frontier (Allen). 2003;126:1254-6 (Editorial)

New lead for in utero pacing for fetal congenital heart block (Assad et al). 2003;126:300-2 (Brief comm.)

Fever

Pyrexia after cardiac surgery: natural history and association with infection (Lim et al). 2003;126:1013-7

\section{Fibroblast growth factor}

Gelatin sheet incorporating basic fibroblast growth factor enhances sternal healing after harvesting bilateral internal Finland thoracic arteries (Iwakura et al). 2003;126:1113-20

Candidate locus analysis of familial ascending aortic aneurysms and dissections confirms the linkage to the chromosome 5q13-14 in Finnish families (Kakko et al). 2003;126: 106-13

\section{Fistula}

Aortopulmonary fistula in pseudoaneurysm after ascending aortic surgery (Kitamura et al). 2003;126:904-5 (Brief comm.)

Atrioesophageal fistula: Is it an unavoidable complication of radiofrequency ablation? (Sonmez et al) (Letter); (Doll et al) (Reply). 2003;126:1662-3

Severe pulmonary stenosis and aortopulmonary fistula caused by a dissecting aneurysm in the ascending aorta (Imanaka et al). 2003;126:598-600 (Brief comm.)

Flowmetry; see Rheology

Follow-up studies; see also Survival rate

Evaluation of a novel sutureless anastomotic connector: from endothelial function to mid-term clinical and angiographic follow-up (Verma et al). 2003;126:1555-60 (Evolving tech.)

Problems with complication rate analysis (Horstkotte) (Letter); (Wu and Grunkemeier) (Reply). 2003;126:1668-70

Survival after myocardial revascularization for ischemic cardiomyopathy: a prospective ten-year follow-up study (Shah et al). 2003;126:1320-7

Ten-year follow-up in patients with combined heart and kidney transplantation (Trachiotis et al). 2003;126:2065-71

Ventricular aneurysms, shock, and late follow-up in patients with heart failure (McCarthy). 2003;126:323-5 (Editorial)

\section{Fontan procedure}

Bovine valved xenograft conduits in the extracardiac Fontan procedure (Baslaim et al). 2003;126:586-8 (Brief comm.)

Computational fluid dynamics in the evaluation of hemodynamic performance of cavopulmonary connections after the Norwood procedure for hypoplastic left heart syndrome (Bove et al). 2003;126:1040-7

Extracardiac total cavopulmonary connection using a tissueengineered graft (Isomatsu et al). 2003;126:1958-62 (Evolving tech.)

Hypoventilation improves oxygenation after bidirectional superior cavopulmonary connection (Bradley et al). 2003; 126:1033-9

Impaired systemic ventricular relaxation affects postoperative short-term outcome in Fontan patients (Border et al). 2003;126:1760-4
Left ventricular remodeling in hearts with tricuspid atresia: morphologic observations and possible basis for ventricular dysfunction after surgery (Binotto et al). 2003;126: 1026-32

Outcome of symptomatic patients undergoing extracardiac Fontan conversion and cryoablation (Weinstein et al). 2003;126:529-36

Successful Fontan procedure for asplenia with pulmonary atresia and major aortopulmonary collateral arteries (Miyaji et al). 2003;126:1648-50 (Brief comm.)

\section{Foreign bodies}

Foreign bodies expectorated through the pneumonectomy stump (Dieter). 2003;126:2104 (Letter)

Posttraumatic and iatrogenic foreign bodies in the heart: report of fourteen cases and review of the literature (Dato et al). 2003;126:408-14

\section{Funnel chest}

A giant gastroenteric cyst associated with pectus excavatum and compression of the thoracic duct: a case report (Reisli et al). 2003;126:584-5 (Brief comm.)

Videothoracoscopic extrapleural insertion of Walter Lorenz Surgical bar for pectus excavatum (Hernández et al). 2003;126:2081-2 (Brief comm.)

\section{G}

\section{Gastroplasty}

Short esophagi and long career (Herbella). 2003;126:1668 (Letter)

Gender differences; see Women's health

Gene expression

Adenovirus encoding soluble tumor necrosis factor $\alpha$ receptor immunoglobulin prolongs gene expression of a cotransfected reporter gene in rat lung (Suda et al). 2003;126: 1155-61

Altered patterns of gene expression distinguishing ascending aortic aneurysms from abdominal aortic aneurysms: complementary DNA expression profiling in the molecular characterization of aortic disease (Absi et al). 2003;126: 344-57

Express yourself-but consider the consequences (Pyeritz). 2003;126:334-6 (Editorial)

Gene expression profile after cardiopulmonary bypass and cardioplegic arrest (Ruel et al). 2003;126:1521-30

Rapamycin has no effect on fibrosis-associated gene expression or extracellular matrix accumulation when administered to animals with established or early allograft vasculopathy (Murphy and Nicholson). 2003;126:2058-64

\section{Gene transfer techniques}

Cell death induced by down-regulation of heat shock protein 70 in lung cancer cell lines is p53-independent and does not require DNA cleavage (Frese et al). 2003;126:748-54

Direct comparison of efficiency and stability of gene transfer into the mammalian heart using adeno-associated virus versus adenovirus vectors (Chu et al). 2003;126:671-9

Tumor necrosis factor inhibitor gene transfer ameliorates lung graft ischemia-reperfusion injury (Tagawa et al). 2003; 126:1147-54 
In vivo gene transfer of pigment epithelium-derived factor inhibits tumor growth in syngeneic murine models of thoracic malignancies (Mahtabifard et al). 2003;126:28-38

\section{General Thoracic Surgery}

2003;126:11-38; 537-81; 726-76; 1121-73; 1580-623; 1900-57

Genetic predisposition to disease

Genetic control of postoperative systemic inflammatory reaction and pulmonary and renal complications after coronary artery surgery (Gaudino et al). 2003;126:1107-12

\section{Genetic techniques}

Candidate locus analysis of familial ascending aortic aneurysms and dissections confirms the linkage to the chromosome 5q13-14 in Finnish families (Kakko et al). 2003;126: 106-13

Gibbon, John H Jr

A milestone in cardiovascular surgery (Cooley). 2003;126: 1243-4 (Hon. guest's address)

\section{Glucocorticoids}

Inflammatory response to cardiac bypass in ewe fetuses: effects of steroid administration or continuous hemodiafiltration (Carotti et al). 2003;126:1839-50

Glucose transporters; see Monosaccharide transport proteins

Graft; see Transplants

Graft patency, vascular; see also specific vessel

Association of lipoprotein(a) excess with early vein graft occlusions in middle-aged men undergoing coronary artery bypass surgery (Pokrovsky et al). 2003;126:1071-5

Atherosclerotic involvement of the radial artery in patients with coronary artery disease and its relation with midterm radial artery graft patency and endothelial function (Gaudino et al). 2003;126:1968-71

Canine endothelial progenitor cell-lined hybrid vascular graft with nonthrombogenic potential ( $\mathrm{He}$ et al). 2003;126:455-64

Cartilaginous metaplasia and calcification in aortic allograft is associated with transforming growth factor $\beta 1$ expression (Mathieu et al). 2003;126:1449-54

Clinical and six-month angiographic evaluation of coronary arterial graft interrupted anastomoses by use of a selfclosing clip device: a multicenter prospective clinical trial (Wolf et al). 2003;126:168-78

Evaluation of a novel sutureless anastomotic connector: from endothelial function to mid-term clinical and angiographic follow-up (Verma et al). 2003;126:1555-60 (Evolving tech.)

Factors affecting saphenous vein graft patency: clinical and angiographic study in 1402 symptomatic patients operated on between 1977 and 1999 (Shah et al). 2003; 126:1972-7

Intraoperative assessment of coronary artery bypass grafts (Wolf and Falk). 2003;126:634-7 (Editorial)

Pretreatment with phenoxybenzamine attenuates the radial artery's vasoconstrictor response to $\alpha$-adrenergic stimuli (Corvera et al). 2003;126:1549-54

Transit time flow measurement in on-pump and off-pump coronary artery surgery (Schmitz et al). 2003;126:645-50

\section{Graft rejection}

Human leukocyte antigen-DR and ABO mismatch are associated with accelerated homograft valve failure in children: implications for therapeutic interventions (Baskett et al). 2003;126:232-9

Regulated interleukin-10 expression prevents chronic rejection of transplanted hearts (Fischbein et al). 2003;126: 216-23

\section{Graft survival}

Does bridging to transplantation with a left ventricular assist device adversely affect posttransplantation survival? A comparative analysis of mechanical versus inotropic support (Morgan et al). 2003;126:1188-90 (Brief comm.)

Implantation of an autologously endothelialized homograft (Gulbins et al). 2003;126:890-1 (Brief comm.)

Prolonged donor ischemic time does not adversely affect long-term survival in adult patients undergoing cardiac transplantation (Morgan et al). 2003;126:1624-33

Prolonged survival of fully allogeneic cardiac grafts in naive mice and those with sensitization induced by antigen delivery through the respiratory tract (Aramaki et al). 2003;126:853-4 (Brief comm.)

Ten-year follow-up in patients with combined heart and kidney transplantation (Trachiotis et al). 2003;126:2065-71

\section{Granular cell tumor}

Granular cell tumors of the tracheobronchial tree (van der Maten et al). 2003;126:740-3

\section{GUARDIAN trial}

Impact of sodium-hydrogen exchange inhibition by cariporide on death or myocardial infarction in high-risk CABG surgery patients: results of the CABG surgery cohort of the GUARDIAN study (Boyce et al). 2003;126:420-7

Prognostic significance of elevated creatine kinase MB after coronary bypass surgery and after an acute coronary syndrome: results from the GUARDIAN trial (Gavard et al). 2003; 126:807-13

\section{Guest reviewers}

Guest reviewers for The Journal of Thoracic and Cardiovascular Surgery. 2003;126:2121-3

\section{$\mathrm{H}$}

\section{Heart}

The helix and the heart (Lunkenheimer) (Letter); (Buckberg) (Reply). 2003;126:920-2

\section{Heart aneurysm}

Factors affecting late survival rate after surgical remodeling of left ventricular aneurysms (Bolooki et al). 2003;126: 374-85

Ventricular aneurysms, shock, and late follow-up in patients with heart failure (McCarthy). 2003;126:323-5 (Editorial)

Heart arrest, induced; see also Hypothermia, induced

The antioxidant $N$-acetylcysteine preserves myocardial function and diminishes oxidative stress after cardioplegic arrest (Fischer et al). 2003;126:1483-8

Attenuation of postcardioplegia injury with inhibitors of the sodium-hydrogen exchanger (Vinten-Johansen and Mentzer). 2003;126:1265-7 (Editorial) 
Does antegrade blood cardioplegia alone provide adequate myocardial protection in patients with left main stem disease? (Onorati et al). 2003;126:1345-52

Gene expression profile after cardiopulmonary bypass and cardioplegic arrest (Ruel et al). 2003;126:1521-30

Leukocyte-depleted terminal blood cardioplegia provides superior myocardial protective effects in association with myocardium-derived nitric oxide and peroxynitrite production for patients undergoing prolonged aortic crossclamping for more than 120 minutes (Hayashi et al). 2003;126:1813-21

$\mathrm{N}$-acetylcysteine prevents reactive oxygen species-mediated myocardial stress in patients, undergoing cardiac surgery: results of a randomized, double-blind, placebo-controlled clinical trial (Tossios et al). 2003;126:1513-20

Study of warm perfusion rather than cardioplegia (Savage) (Letter); (Mallidi and Fremes) (Reply). 2003;126:2111-2

Subcellular distribution of protein kinase $\mathrm{C}$ isozymes during cardioplegic arrest (Jonjev et al). 2003;126:1880-5

\section{Heart-assist devices}

BVS 5000 support after cardiac transplantation (Petrofski et al). 2003;126:442-7

Does bridging to transplantation with a left ventricular assist device adversely affect posttransplantation survival? A comparative analysis of mechanical versus inotropic support (Morgan et al). 2003;126:1188-90 (Brief comm.)

Doppler microembolic load predicts risk of thromboembolic complications in Novacor patients (Nabavi et al). 2003; 126:160-7

Fifteen-month circulatory support for sustained ventricular fibrillation by left ventricular assist device (Nishimura et al). 2003;126:1190-2 (Brief comm.)

Implantation of a left ventricular assist device and the huband-spoke system in treating acute cardiogenic shock: who survives? (Kherani et al). 2003;126:1634-5 (Brief comm.)

Insertion of a left ventricular assist device in patients without thorough transplant evaluations: a worthwhile risk? (Williams et al). 2003;126:436-41

Mechanical support of the unrepaired postinfarction ventricular septal defect with the Abiomed BVS 5000 ventricular assist device (Samuels et al). 2003;126:2100-1 (Brief comm.)

Resistance to aspirin after external ventricular assist device implantation (Houël). 2003;126:1636-7 (Brief comm.)

Successful LVAS and RVAS-ECMO support in a patient with fulminant myocarditis who failed to recover from ventricular fibrillation with PCPS and IABP (Gojo et al). 2003;126:885-6 (Brief comm.)

Ventricular assist surprise: giant cell myocarditis or sarcoidosis? (Stoica et al). 2003;126:2072-4 (Brief comm.)

\section{Heart atrium}

Left atrial dissection after aortic valve replacement (Osawa et

\section{Heart block} al). 2003;126:604-5 (Brief comm.)

New lead for in utero pacing for fetal congenital heart block (Assad et al). 2003;126:300-2 (Brief comm.)
Heart catheterization; see Catheterization

Heart defects, congenital; see also specific defect

Antioxidant therapy with Salvia miltiorrhiza decreases plasma endothelin-1 and thromboxane B2 after cardiopulmonary bypass in patients with congenital heart disease (Xia et al). 2003;126:1404-10

Reoperations and survival after primary repair of congenital heart defects in children (Monro et al). 2003;126:511-20

Secretion of A-type and B-type natriuretic peptides into the bloodstream and pericardial space in children with congenital heart disease (Ootaki et al). 2003;126:1411-6

Spiral pattern: universe, normal heart, and complex congenital defects (Marino and Corno). 2003;126:1225-6 (Letter)

Surgically created double orifice repair of tricuspid regurgitation in infants with congenital heart disease (Fukuda et al). 2003;126:1220-1 (Brief comm.)

Heart failure, congestive; see also Cardiomyopathy, congestive

Global surgical experience with the Acorn cardiac support device (Oz et al). 2003;126:983-91

Left ventricular systolic performance in failing heart improved acutely by left ventricular reshaping (He et al). 2003;126:56-65

Passive ventricular constraint to improve left ventricular function and mechanics in an ovine model of heart failure secondary to acute myocardial infarction (Pilla et al). 2003; $126: 1467-76$

\section{Heart injuries}

Posttraumatic and iatrogenic foreign bodies in the heart: report of fourteen cases and review of the literature (Dato et al). 2003;126:408-14

Transcardiac gunshot wound recognized forty-eight years later (McClurken et al). 2003;126:293-5 (Brief comm.)

\section{Heart-lung machine}

A milestone in cardiovascular surgery (Cooley). 2003;126: 1243-4 (Hon. guest's address)

\section{Heart neoplasms}

Recurrence of a right ventricular hemangioma (Colli et al). 2003;126:881-3 (Brief comm.)

Right ventricular multiple myxomas obstructing right ventricular outflow tract (Paraskevaidis et al). 2003;126:913-4 (Brief comm.)

\section{Heart septal defects, atrial}

Free right atrial patches for septal defect closure (Kumar). 2003;126:303-4 (Letter)

Nickel allergy to the percutaneous patent foramen ovale occluder and subsequent systemic nickel allergy (Dasika and Kanter). 2003;126:2112 (Letter)

Totally endoscopic atrial septal repair in adults with computer-enhanced telemanipulation (Wimmer-Greinecker et al). 2003;126:465-8 (Evolving tech.)

\section{Heart septal defects, ventricular}

Mechanical support of the unrepaired postinfarction ventricular septal defect with the Abiomed BVS 5000 ventricular assist device (Samuels et al). 2003;126:2100-1 (Brief comm.)

Perventricular device closure of muscular ventricular septal defects on the beating heart: technique and results (Bacha et al). 2003;126:1718-23 
Staged repair of pulmonary atresia with ventricular septal defect and major aortopulmonary collateral arteries: experience with 104 patients (Gupta et al). 2003;126:1746-52

\section{Heart transplantation}

BVS 5000 support after cardiac transplantation (Petrofski et al). 2003;126:442-7

Cardiac transplantation in prisoners (Richenbacher) (Letter); (Sade) (McKneally) (Replies). 2003;126:1226-7

Does bridging to transplantation with a left ventricular assist device adversely affect posttransplantation survival? A comparative analysis of mechanical versus inotropic support (Morgan et al). 2003;126:1188-90 (Brief comm.)

L-Arginine polymers enhance coronary flow and reduce oxidative stress following cardiac transplantation in rats (Kown et al). 2003;126:1065-70

Long-term results of heart transplantation in patients older than 60 years (Demers et al). 2003;126:224-31

Prolonged donor ischemic time does not adversely affect long-term survival in adult patients undergoing cardiac transplantation (Morgan et al). 2003;126:1624-33

Regulated interleukin-10 expression prevents chronic rejection of transplanted hearts (Fischbein et al). 2003;126: 216-23

Results after transplantation using donor hearts with preexisting coronary artery disease (Marelli et al). 2003;126: $821-5$

Rigid sternal fixation in the cardiac transplant population (Song et al). 2003;126:896-7 (Brief comm.)

Should HIV-positive recipients undergo heart transplantation? (Bisleri et al). 2003;126:1639-40 (Brief comm.)

Ten-year follow-up in patients with combined heart and kidney transplantation (Trachiotis et al). 2003;126:2065-71

Heart valve prosthesis; see also Bioprosthesis

Assessment of mechanical aortic valve prosthesis by means of Doppler echocardiography: what to measure and why? (Vannan and Sarkar). 2003;126:317-20 (Editorial)

Early and late stroke after mitral valve replacement with a mechanical prosthesis: risk factor analysis of a 24-year experience (Bando et al). 2003;126:358-64

Obstruction of St Jude Medical valves in the aortic position: histology and immunohistochemistry of pannus (Teshima et al). 2003;126:401-7

Prosthesis-patient size: measurement and clinical implications (Gillinov et al). 2003;126:313-6 (Editorial)

Prosthesis size and long-term survival after aortic valve replacement (Blackstone et al). 2003;126:783-96

Serial Doppler echocardiographic evaluation of small-sized Sorin Bicarbon prostheses (De Carlo et al). 2003;126: 337-43

Twenty-year experience with the St Jude Medical mechanical valve prosthesis (Ikonomidis et al). 2003;126:2022-31

Use of flexibility tests in the manufacturing process of $60^{\circ}$ Björk-Shiley convexo-concave valves and the risk of outlet strut fracture (Omar et al). 2003;126:832-6

An in vitro assessment by means of laser Doppler velocimetry of the Medtronic Advantage bileaflet mechanical heart valve hinge flow (Saxena et al). 2003;126:90-8

\section{Heart valve prosthesis implantation}

A new aortoventriculoplasty for prosthetic aortic valve replacement (Hvass et al). 2003;126:818-20

Problems with complication rate analysis (Horstkotte) (Letter); (Wu and Grunkemeier) (Reply). 2003;126: 1668-70

Study design in valve surgery and outcome (Shuhaiber et al) (Letter); (Grunkemeier and $\mathrm{Wu}$ ) (Reply). 2003;126:1660-1

Heart valves; see also specific valve

Acellularized porcine heart valve scaffolds for heart valve tissue engineering and the risk of cross-species transmission of porcine endogenous retrovirus (Leyh et al). 2003; 126:1000-4

Gender-related differences in morbidity and mortality during combined valve and coronary surgery (Ibrahim et al). 2003;126:959-64

Risk factors for atherosclerosis and the degeneration of pericardial valves after aortic valve replacement (Nollert et al). 2003;126:965-8

\section{Heart ventricle}

Left ventricular external subannular plication: an indirect off-pump mitral annuloplasty method in a canine model (Kollár et al). 2003;126:977-82

Rapid progression of midventricular obstruction in adults with double-chambered right ventricle (Oliver et al). 2003; 126:711-7

Heat-shock proteins 70

Cell death induced by down-regulation of heat shock protein 70 in lung cancer cell lines is p53-independent and does not require DNA cleavage (Frese et al). 2003;126: 748-54

Helix-loop-helix motifs

The helix and the heart (Lunkenheimer) (Letter); (Buckberg) (Reply). 2003;126:920-2

Spiral pattern: universe, normal heart, and complex congenital defects (Marino and Corno). 2003;126:1225-6 (Letter)

\section{Hemangioma}

Recurrence of a right ventricular hemangioma (Colli et al). 2003;126:881-3 (Brief comm.)

\section{Hematoma, chronic expanding}

Successful treatment of huge chronic expanding hematoma after thoracoplasty (Takanami). 2003;126:1202-3 (Brief comm.)

Heme oxygenase (decyclizing)

Exhaled carbon monoxide and inducible heme oxygenase expression in a rat model of postperfusion acute lung injury (Zegdi et al). 2003;126:1867-74

\section{Hemodiafiltration}

Inflammatory response to cardiac bypass in ewe fetuses: effects of steroid administration or continuous hemodiafiltration (Carotti et al). 2003;126:1839-50

\section{Hemodilution}

The influence of hemodilution on outcome after hypothermic cardiopulmonary bypass: results of a randomized trial in infants (Jonas et al). 2003;126:1765-74 


\section{Hemodynamics}

Changes in left anterior descending coronary artery flow profiles after coronary artery bypass grafting examined by means of transthoracic Doppler echocardiography (Yoshitatsu et al). 2003;126:1531-6

Computational fluid dynamics in the evaluation of hemodynamic performance of cavopulmonary connections after the Norwood procedure for hypoplastic left heart syndrome (Bove et al). 2003;126:1040-7

Immediate flow reserve of $\mathrm{Y}$ thoracic artery grafts: an intraoperative flowmetric study (Gaudino et al). 2003;126: 1076-9

The influence of mechanical properties on wall stress and distensibility of the dilated ascending aorta (Okamoto et al). 2003;126:842-50

L-Arginine polymers enhance coronary flow and reduce oxidative stress following cardiac transplantation in rats (Kown et al). 2003;126:1065-70

Pulmonary blood pressure, not flow, is associated with net endothelin-1 production in the lungs of patients with congenital heart disease and normal pulmonary vascular resistance (Fratz et al). 2003;126:1724-9

Regional low-flow perfusion provides comparable blood flow and oxygenation to both cerebral hemispheres during neonatal aortic arch reconstruction (Andropoulos et al). 2003; 126:1712-7

Remote control of pulmonary blood flow: initial clinical experience (Corno et al). 2003;126:1775-80

Right ventricular to pulmonary artery conduit instead of modified Blalock-Taussig shunt improves postoperative hemodynamics in newborns after the Norwood operation (Mair et al). $2003 ; 126: 1378-84$

Sodium nitroprusside infusion after bidirectional superior cavopulmonary connection: preserved cerebral blood flow velocity and systemic oxygenation (Simsic et al). 2003; 126:186-90

An in vitro assessment by means of laser Doppler velocimetry of the Medtronic Advantage bileaflet mechanical heart valve hinge flow (Saxena et al). 2003;126:90-8

Hemorrhage; see Blood loss, surgical

Hemothorax

Intralobar sequestration: a rare cause of severe hemothorax (Wandschneider and Illiasch). 2003;126:872-3 (Brief comm.)

\section{Heparin}

Bivalirudin as alternative to both danaparoid and heparin in off-pump coronary artery bypass grafting (Baciewicz) (Letter); (Carrier) (Reply). 2003;126:2108-9

Coagulation, fibrinolysis, and cell activation in patients and in shed mediastinal blood during coronary artery bypass grafting with a new heparin-coated surface (Baufreton and de Brux). 2003;126:2116 (Letter)

Life-threatening anaphylactic shock caused by porcine heparin intravenous infusion during mitral valve repair (Bottio et al). 2003;126:1194-5 (Brief comm.)

Preoperative use of enoxaparin is not a risk factor for postoperative bleeding after coronary artery bypass surgery (Medalion et al). 2003;126:1875-9

\section{Hernia, diaphragmatic}

Bilateral lung transplantation for pulmonary hypoplasia caused by congenital diaphragmatic hernia (Lee et al). 2003;126:295-7 (Brief comm.)

\section{Herpesvirus 4, human}

Epstein-Barr virus-associated pulmonary leiomyosarcoma arising twenty-nine years after renal transplantation (Ferri et al). 2003;126:877-9 (Brief comm.)

\section{Histocompatibility antigens}

Human leukocyte antigen-DR and ABO mismatch are associated with accelerated homograft valve failure in children: implications for therapeutic interventions (Baskett et al). 2003;126:232-9

\section{History of medicine}

Priority issue: who is on first base? (Robicsek) (Editorial); (Wechsler) (Response). 2003;126:321-2

Sixty-year perspective on coronary artery bypass grafting in women (Hartz et al). 2003;126:620-2 (Editorial)

HIV

Should HIV-positive recipients undergo heart transplantation? (Bisleri et al). 2003;126:1639-40 (Brief comm.)

\section{Honored Guest's Address}

A milestone in cardiovascular surgery (Cooley). 2003;126: 1243-4

\section{Hospital costs}

Is discharge policy a balanced decision between clinical considerations and hospital ownership policy? The CABG example (Galai et al). 2003;126:1018-25

Hydatid disease; see Echinococcosis

\section{Hydropneumothorax}

Giant parenchymal bronchogenic cyst mimicking hydropneumothorax (Basoglu et al). 2003;126:1201-2 (Brief comm.)

\section{Hypercholesterolemia}

Hypercholesterolemia is a risk factor for bioprosthetic valve calcification and explanation (Farivar and Cohn). 2003; 126:969-76

\section{Hyperoxia}

Does hyperoxia affect glucose regulation and transport in the newborn? (Bandali et al). 2003;126:1730-5

\section{Hypersensitivity}

Nickel allergy to the percutaneous patent foramen ovale occluder and subsequent systemic nickel allergy (Dasika and Kanter). 2003;126:2112 (Letter)

\section{Hypertension, pulmonary}

Indications for pulmonary endarterectomy (Riedel) (Letter); (Thistlethwaite and Jamieson) (Reply). 2003;126:1227-9

Inhaled nitric oxide versus prostacyclin in chronic shuntinduced pulmonary hypertension (Wauthy et al). 2003; 126:1434-41

Intraoperative inhalation of the long-acting prostacyclin analog iloprost for pulmonary hypertension (Langer et al). 2003;126:874-5 (Brief comm.)

Pulmonary blood pressure, not flow, is associated with net endothelin-1 production in the lungs of patients with congenital heart disease and normal pulmonary vascular resistance (Fratz et al). 2003;126:1724-9 
Unilateral pulmonary thromboendarterectomy for iatrogenic pulmonary hypertension in a ten-year-old child (Zacharias et al). 2003;126:1210-1 (Brief comm.)

\section{Hypoplastic left heart syndrome}

Computational fluid dynamics in the evaluation of hemodynamic performance of cavopulmonary connections after the Norwood procedure for hypoplastic left heart syndrome (Bove et al). 2003;126:1040-7

Right ventricle-pulmonary artery shunt in first-stage palliation of hypoplastic left heart syndrome (Sano et al). 2003; 126:504-10

Right ventricular-pulmonary artery connection in stage 1 palliation of hypoplastic left heart syndrome (Pearl). 2003; 126:1268-70 (Editorial)

\section{Hypothermia, induced}

The effect of duration of deep hypothermic circulatory arrest in infant heart surgery on late neurodevelopment: the Boston Circulatory Arrest Trial (Wypij et al). 2003;126: 1397-403

The influence of hemodilution on outcome after hypothermic cardiopulmonary bypass: results of a randomized trial in infants (Jonas et al). 2003;126:1765-74

Poly-ADP-ribose polymerase inhibition protects against myocardial and endothelial reperfusion injury after hypothermic cardiac arrest (Szabó et al). 2003;126:651-8

\section{Hypoventilation}

Hypoventilation improves oxygenation after bidirectional superior cavopulmonary connection (Bradley et al). 2003; 126:1033-9

Hypoxemia; see Anoxemia

Hypoxia, brain

Postoperative hypoxia is a contributory factor to cognitive impairment after cardiac surgery (Browne et al). 2003; 126:1061-4

\section{I}

\section{Iatrogenic disease}

Fatal air embolism during computed tomography-guided pulmonary marking with a hook-type marker (Sakiyama et al). 2003;126:1207-9 (Brief comm.)

Posttraumatic and iatrogenic foreign bodies in the heart: report of fourteen cases and review of the literature (Dato et al). 2003;126:408-14

Unilateral pulmonary thromboendarterectomy for iatrogenic pulmonary hypertension in a ten-year-old child (Zacharias et al). 2003;126:1210-1 (Brief comm.)

\section{Iloprost}

Intraoperative inhalation of the long-acting prostacyclin analog iloprost for pulmonary hypertension (Langer et al). 2003;126:874-5 (Brief comm.)

\section{Immune tolerance}

Improving the allograft valve: does the immune response matter? (Hogan and O'Brien). 2003;126:1251-3 (Editorial)

Prolonged survival of fully allogeneic cardiac grafts in naive mice and those with sensitization induced by antigen delivery through the respiratory tract (Aramaki et al). 2003;126:853-4 (Brief comm.)

\section{Immunogenetics}

Immunogenicity of decellularized cryopreserved allografts in pediatric cardiac surgery: comparison with standard cryopreserved allografts (Hawkins et al). 2003;126:247-53

\section{Immunohistochemistry}

Obstruction of St Jude Medical valves in the aortic position: histology and immunohistochemistry of pannus (Teshima et al). 2003;126:401-7

\section{Immunologic factors}

The immunologic role of thymectomy in the treatment of myasthenia gravis: implication of thymus-associated Blymphocyte subset in reduction of the anti-acetylcholine receptor antibody titer (Okumura et al). 2003;126:1922-8

Immunotherapy, active

Cisplatin augments cytotoxic T-lymphocyte-mediated antitumor immunity in poorly immunogenic murine lung cancer (Merritt et al). 2003;126:1609-17

\section{Infant}

Apolipoprotein E genotype and neurodevelopmental sequelae of infant cardiac surgery (Gaynor et al). 2003;126:1736-45

The effect of duration of deep hypothermic circulatory arrest in infant heart surgery on late neurodevelopment: the Boston Circulatory Arrest Trial (Wypij et al). 2003;126: 1397-403

The influence of hemodilution on outcome after hypothermic cardiopulmonary bypass: results of a randomized trial in infants (Jonas et al). 2003;126:1765-74

Surgically created double orifice repair of tricuspid regurgitation in infants with congenital heart disease (Fukuda et al). 2003;126:1220-1 (Brief comm.)

Infant, newborn

Closed correction of systemic semilunar valve insufficiency in the neonate (Pigula et al). 2003;126:1650-2 (Brief comm.)

Does hyperoxia affect glucose regulation and transport in the newborn? (Bandali et al). 2003;126:1730-5

Postnatal increase in insulin-sensitive glucose transporter expression is associated with improved recovery of postischemic myocardial function (Friehs et al). 2003;126:263-71

Prevalence and predictors of neoaortic regurgitation after arterial switch operation for transposition of the great arteries (Formigari et al). 2003;126:1753-9

Regional low-flow perfusion provides comparable blood flow and oxygenation to both cerebral hemispheres during neonatal aortic arch reconstruction (Andropoulos et al). 2003; 126:1712-7

Right ventricular to pulmonary artery conduit instead of modified Blalock-Taussig shunt improves postoperative hemodynamics in newborns after the Norwood operation (Mair et al). 2003;126:1378-84

\section{Infant, premature}

Aortic arch repair with a working beating heart in premature infants (Ishino and Sano). 2003;126:1653-4 (Brief comm.)

Infection; see also Wound infection

Pyrexia after cardiac surgery: natural history and association with infection (Lim et al). 2003;126:1013-7 
Inflammatory response; see Sepsis syndrome

Insulin

Insulin-induced improvement of postischemic recovery is abolished by inhibition of protein kinase $\mathrm{C}$ in rat heart (Fischer-Rasokat and Doenst). 2003;126:1806-12

\section{Interleukins}

Genetic control of postoperative systemic inflammatory reaction and pulmonary and renal complications after coronary artery surgery (Gaudino et al). 2003;126:1107-12

Interleukin-10 gene transfection of donor lungs ameliorates posttransplant cell death by a switch from cellular necrosis to apoptosis (Fischer et al). 2003;126:1174-80

Plasma levels of interleukin-8 and expression of interleukin-8 receptors on circulating neutrophils and monocytes after cardiopulmonary bypass in children (Gessler et al). 2003; 126:718-25

Regulated interleukin-10 expression prevents chronic rejection of transplanted hearts (Fischbein et al). 2003;126: 216-23

\section{Intracranial embolism}

Rapid recognition and treatment of cerebral air embolism: the role of neuromonitoring (Yeh et al). 2003;126:589-91 (Brief comm.)

\section{Intraoperative care}

Intraoperative assessment of coronary artery bypass grafts (Wolf and Falk). 2003;126:634-7 (Editorial)

Ischemic preconditioning, myocardial

The aging human myocardium: tolerance to ischemia and responsiveness to ischemic preconditioning (Loubani et al). 2003;126:143-7

Integrated pharmacological preconditioning in combination with adenosine, a mitochondrial $\mathrm{K}_{\mathrm{ATP}}$ channel opener and a nitric oxide donor (Uchiyama et al). 2003;126:148-59

Protection of the human heart with ischemic preconditioning during cardiac surgery: role of cardiopulmonary bypass (Ghosh and Galiñanes). 2003;126:133-42

\section{Isoprostanes}

The relationship between plasma free $15-\mathrm{F}_{2 \mathrm{t}}$-isoprostane concentration and early postoperative cardiac depression following warm heart surgery (Ansley et al). 2003;126:1222-3 (Brief comm.)

\section{$J$}

\section{Jamplis, Robert W.}

Robert W. Jamplis (1920-2003) (Urschel). 2003;126:311-2 (In memoriam)

The Journal of Thoracic and Cardiovascular Surgery

The editorial board: 2003-2004 (Wechsler). 2003;126:1-4 (Editorial)

Guest and distinguished reviewers for 2003;126:2121-3

Peer review (Wechsler and Fried). 2003;126:1681-2 (Editorial)

\section{Jugular veins}

Use of bovine jugular vein to reconstruct the right ventricular outflow tract: early results (Boudjemline et al). 2003;126: 490-7
K

\section{Kidney transplantation}

Epstein-Barr virus-associated pulmonary leiomyosarcoma arising twenty-nine years after renal transplantation (Ferri et al). 2003;126:877-9 (Brief comm.)

Ten-year follow-up in patients with combined heart and kidney transplantation (Trachiotis et al). 2003;126:2065-71

\section{$\mathrm{L}$}

\section{Laser-Doppler flowmetry}

An in vitro assessment by means of laser Doppler velocimetry of the Medtronic Advantage bileaflet mechanical heart valve hinge flow (Saxena et al). 2003;126:90-8

Lasers, light-scattering

Platelet dysfunction in acute type A aortic dissection evaluated by the laser light-scattering method (Tanaka et al). 2003;126:837-41

Lavage fluid; see Bronchoalveolar lavage fluid

Leiomyosarcoma

Epstein-Barr virus-associated pulmonary leiomyosarcoma arising twenty-nine years after renal transplantation (Ferri et al). 2003;126:877-9 (Brief comm.)

Letters to the Editor

Activated prothrombin complex concentrates and recombinant factor VIIa in the bleeding patient: are they appropriate and safe? (Aledort). 2003;126:2112-3

Acute postoperative lobar torsion associated with pulmonary arterial rupture (Jones et al). 2003;126:303

Apical versus basal partial ventriculectomy (Lunkenheimer and Anderson) (Letter); (Koyama et al) (Reply). 2003; 126:2109-11

Asymptomatic mitral valve incompetence: is there evidence for surgery? (Shuhaiber) (Letter); (David et al) (Reply). 2003; 126:2117-9

Atrioesophageal fistula: Is it an unavoidable complication of radiofrequency ablation? (Sonmez et al) (Letter); (Doll et al) (Reply). 2003;126:1662-3

Authors should list confounding factors and alternative explanations for adverse events seen with new technologies (Anyanwu) (Letter); (Hornik) (Reply). 2003;126:1663-4

Bivalirudin as alternative to both danaparoid and heparin in off-pump coronary artery bypass grafting (Baciewicz) (Letter); (Carrier) (Reply). 2003;126:2108-9

Brachial artery cannulation (Kucuker and Tasdemir) (Letter); (Galajda et al) (Reply). 2003;126:2106-7

Cardiac transplantation in prisoners (Richenbacher) (Letter); (Sade) (McKneally) (Replies). 2003;126:1226-7

Caveat against the use of FEIBA in combination with recombinant factor VIIa (von Heymann et al). 2003;126:1667-8

Chronic and adjustable pulmonary artery banding: reflections on old knowledge (Sievers) (Letter); (Leeuwenburgh et al) (Reply). 2003;126:2104-6

Coagulation, fibrinolysis, and cell activation in patients and in shed mediastinal blood during coronary artery bypass grafting with a new heparin-coated surface (Baufreton and de Brux). 2003;126:2116 
Esophageal perforation during left atrial radiofrequency ablation: is the risk too high? (Gillinov et al) (Letter); (Doll et al) (Reply). 2003;126:1661-2

Esophageal perforation during left atrial radiofrequency ablation (Laczkovics et al) (Letter); (Doll et al) (Reply). 2003;126:2119-20

Exhaled nitric oxide and cardiac surgery with extracorporeal circulation (Marczin) (Letter); (Adatia et al) (Reply). 2003; $126: 1673-5$

A few critical aspects-and Achilles heels-of tissue engineering approaches to restore injured myocardium (Kofidis et al) (Letter); (Fazel et al) (Reply). 2003;126:2113-6

Foreign bodies expectorated through the pneumonectomy stump (Dieter). 2003;126:2104

Free right atrial patches for septal defect closure (Kumar). 2003; 126:303-4

Future technologic innovations for intraoperative visualization of native coronary artery and graft anastomoses (Suematsu and Takamoto) (Letter); (Borst et al) (Reply). 2003; 126:304-5

The helix and the heart (Lunkenheimer) (Letter); (Buckberg) (Reply). 2003;126:920-2

Indications for pulmonary endarterectomy (Riedel) (Letter); (Thistlethwaite and Jamieson) (Reply). 2003;126:1227-9

Influence of chromosome 22q11.2 microdeletion on surgical outcome after treatment of tetralogy of Fallot with pulmonary atresia (Carotti et al). 2003;126:1666-7

Is there an evidence in favor of off-pump coronary artery bypass? (El Oakley et al). 2003;126:1668

Lack of evidence for vitamin $\mathrm{C}$ as acute vasodilator (Madhavan and Goodfellow) (Letter); (Toumpoulis et al) (Reply). 2003;126:1671-2

The left anterior descending coronary artery is the best recipient (Zamvar and Sivaprakasam). 2003;126:923

Lobar transplantation (Haddy and Starnes) (Letter); (Kozower and Meyers) (Reply). 2003;126:2106

Malignant status at surgical margin of limited-resected nonsmall cell lung cancer: a crucial finding for predicting local relapse (Sawabata) (Letter); (Higashiyama et al) (Reply). 2003;126:610-1

Medical resources and capital punishment (Kumar) (Letter); (McKneally) (Reply). 2003;126:2107-8

Mitral valve in ischemic versus idiopathic dilated cardiomyopathy (Grossi et al). 2003;126:922

Myogenesis after myocardial stem cell transplantation (Taheri) (Letter); (Chiu) (Reply). 2003;126:2116-7

Negative aspects of preoperative delay in early stage nonsmall cell lung cancer (Sortini et al) (Letter); (Block) (Reply). 2003;126:609-10

Nickel allergy to the percutaneous patent foramen ovale occluder and subsequent systemic nickel allergy (Dasika and Kanter). 2003;126:2112

Pattern of lymphatic spread and prognosis of $\mathrm{pN} 1$ non-small cell lung cancer: what does it stand for? (Margaritora et al) (Letter); (Marra and Stamatis) (Reply). 2003;126:1664-5

Possible Tx N2 M0 atypical bronchial carcinoid associated with Cushing syndrome (Filosso) (Letter); (Sugawara et al) (Reply). 2003;126:1224-5
Preoperative localization techniques during thoracoscopic operations (Sortini et al) (Letter); (Saito et al) (Reply). 2003; 126:608-9

Problems with complication rate analysis (Horstkotte) (Letter); (Wu and Grunkemeier) (Reply). 2003;126:1668-70

Safety of bronchoplastic resection after induction therapy for lung cancer (Veronesi et al) (Letter); (Ohta et al) (Reply). 2003;126:1670-1

Short esophagi and long career (Herbella). 2003;126:1668

Spiral pattern: universe, normal heart, and complex congenital defects (Marino and Corno). 2003;126:1225-6

Study design in valve surgery and outcome (Shuhaiber et al) (Letter); (Grunkemeier and $\mathrm{Wu}$ ) (Reply). 2003;126:1660-1

Study of warm perfusion rather than cardioplegia (Savage) (Letter); (Mallidi and Fremes) (Reply). 2003;126:2111-2

Tuberculosis aneurysm of the aortic arch (Abad and Santamaria). 2003;126:1229

Leukocytes; see also Histocompatibility antigens

Conditioned blood reperfusion markedly enhances neurologic recovery after prolonged cerebral ischemia (Allen et al). 2003; $126: 1851-8$

High antithrombin III levels attenuate hemostatic activation and leukocyte activation during cardiopulmonary bypass (Koster et al). 2003;126:906-7 (Brief comm.)

Leukocyte-depleted terminal blood cardioplegia provides superior myocardial protective effects in association with myocardium-derived nitric oxide and peroxynitrite production for patients undergoing prolonged aortic crossclamping for more than 120 minutes (Hayashi et al). 2003;126:1813-21

Pentoxifylline is as effective as leukocyte depletion for modulating pulmonary reperfusion injury (Clark et al). 2003; 126:2052-7

Linkage (genetics)

Candidate locus analysis of familial ascending aortic aneurysms and dissections confirms the linkage to the chromosome 5q13-14 in Finnish families (Kakko et al). 2003;126: 106-13

\section{Lipoproteins}

Association of lipoprotein(a) excess with early vein graft occlusions in middle-aged men undergoing coronary artery bypass surgery (Pokrovsky et al). 2003;126:1071-5

\section{Liver diseases, parasitic}

Single-stage transthoracic approach for right lung and liver hydatid disease (Şahin et al). 2003;126:769-73

Lung diseases, interstitial

Impact of interstitial lung disease on surgical morbidity and mortality for lung cancer: analyses of short-term and longterm outcomes (Chiyo et al). 2003;126:1141-6

\section{Lung diseases, parasitic}

Single-stage transthoracic approach for right lung and liver hydatid disease (Şahin et al). 2003;126:769-73

Lung neoplasms; see also Carcinoma, non-small-cell lung

Cell death induced by down-regulation of heat shock protein 70 in lung cancer cell lines is p53-independent and does not require DNA cleavage (Frese et al). 2003;126:748-54 
Cisplatin augments cytotoxic T-lymphocyte-mediated antitumor immunity in poorly immunogenic murine lung cancer (Merritt et al). 2003;126:1609-17

Cyclooxygenase-2 inhibition decreases primary and metastatic tumor burden in a murine model of orthotopic lung adenocarcinoma (DiPerna et al). 2003;126:1129-33

Effect of radioisotope sentinel node mapping in patients with cT1 N0 M0 lung cancer (Sugi et al). 2003;126:568-73

Epstein-Barr virus-associated pulmonary leiomyosarcoma arising twenty-nine years after renal transplantation (Ferri et al). 2003;126:877-9 (Brief comm.)

Fluorodeoxyglucose positron emission tomography improves preoperative staging of resectable lung metastasis (Pastorino et al). 2003;126:1906-10

Histogram analysis of computed tomography numbers of clinical T1 N0 M0 lung adenocarcinoma, with special reference to lymph node metastasis and tumor invasiveness (Nomori et al). 2003;126:1584-9

Impact of interstitial lung disease on surgical morbidity and mortality for lung cancer: analyses of short-term and longterm outcomes (Chiyo et al). 2003;126:1141-6

Occult metastases: real harm or false alarm? (Cote). 2003; 126:332-3 (Editorial)

Optimal management when unsuspected N2 nodal disease is identified during thoracotomy for lung cancer: cost-effectiveness analysis (Ferguson). 2003;126:1935-42

Prognostic factors and survival after complete resection of pulmonary metastases from colorectal carcinoma: experiences in 167 patients (Pfannschmidt et al). 2003;126: 732-9

Safety of bronchoplastic resection after induction therapy for lung cancer (Veronesi et al) (Letter); (Ohta et al) (Reply). 2003;126:1670-1

Transthoracic needle biopsy in the diagnosis of solitary pulmonary nodules: a survey of Canadian physicians (Lacasse et al). 2003;126:761-8

\section{Lung transplantation}

Bilateral lung transplantation and pulmonary artery reconstruction in a patient with chronic obstructive pulmonary disease, and a giant pulmonary artery aneurysm (Force et al). 2003;126:864-6 (Brief comm.)

Bilateral lung transplantation for pulmonary hypoplasia caused by congenital diaphragmatic hernia (Lee et al). 2003;126:295-7 (Brief comm.)

Drowned donor lung for bilateral lung transplantation (McNamee et al). 2003;126:910-2 (Brief comm.)

Impaired endothelium-derived hyperpolarizing factor-mediated relaxation in porcine pulmonary microarteries after cold storage with Euro-Collins and University of Wisconsin solutions (Zou et al). 2003;126:208-15

Interleukin-10 gene transfection of donor lungs ameliorates posttransplant cell death by a switch from cellular necrosis to apoptosis (Fischer et al). 2003;126:1174-80

Living-donor lobar lung transplantation for various lung diseases (Date et al). 2003;126:476-81

Lobar transplantation (Haddy and Starnes) (Letter); (Kozower and Meyers) (Reply). 2003;126:2106
Modified reperfusion and ischemia-reperfusion injury in human lung transplantation (Ardehali et al). 2003;126:1929-34

Refractory chylothorax after lung transplantation for lymphangioleiomyomatosis successfully cured with instillation of povidone (Duariat et al). 2003;126:875-7 (Brief comm.)

Should lungs from donors with severe acute pulmonary embolism be accepted for transplantation? The Hanover experience (Fischer et al). 2003;126:1641-3 (Brief comm.)

Survival benefit of lung transplantation for patients with idiopathic pulmonary fibrosis (Thabut et al). 2003;126: 469-75

Lymph node mapping; see Neoplasm staging

Lymphangioleiomyomatosis

Refractory chylothorax after lung transplantation for lymphangioleiomyomatosis successfully cured with instillation of povidone (Duariat et al). 2003;126:875-7 (Brief comm.)

$\mathrm{M}$

\section{Macrophages, alveolar}

Early activation of the alveolar macrophage is critical to the development of lung ischemia-reperfusion injury (Naidu et al). 2003;126:200-7

\section{Magnetite}

A novel method for sentinel lymph node mapping using magnetite in patients with non-small cell lung cancer (Nakagawa et al). 2003;126:563-7

\section{Manubrium}

Decompressing manubriectomy under apneic oxygenation to release the median thoracic outlet compartment in Bechterew disease (Go et al). 2003;126:867-9 (Brief comm.)

Matrix, extracellular; see Extracellular matrix

Maze procedure; see also Cox maze procedure

The effect of the maze procedure on the secretion of argininevasopressin and aldosterone (Ad et al). 2003;126:1095100

A self-retaining retractor for the maze procedure (Gillinov). 2003;126:287-8 (Brief comm.)

Mediastinal cyst

A giant gastroenteric cyst associated with pectus excavatum and compression of the thoracic duct: a case report (Reisli et al). 2003;126:584-5 (Brief comm.)

\section{Mediastinal emphysema}

Spontaneous pneumomediastinum: a rare benign entity (Gerazounis et al). 2003;126:774-6

\section{Mediastinal irradiation}

Severe quadricuspid aortic valve stenosis after mediastinal irradiation (Mecozzi et al). 2003;126:1198-9 (Brief comm.)

\section{Mediastinal neoplasms}

Inflammatory myofibroblastic tumor of the mediastinum presenting as superior vena cava syndrome (Yamaguchi et al). 2003;126:870-2 (Brief comm.) 


\section{Mediastinitis}

Evaluation of vacuum-assisted closure in the treatment of poststernotomy mediastinitis (Domkowski et al). 2003; 126:386-90

Rigid sternal fixation in the cardiac transplant population (Song et al). 2003;126:896-7 (Brief comm.)

Mediastinoscopy

Chylous leak after cervical mediastinoscopy (Barthes et al). 2003;126:1199-200 (Brief comm.)

A comparative analysis of positron emission tomography and mediastinoscopy in staging non-small cell lung cancer (Gonzalez-Stawinski et al). 2003;126:1900-5

Management of major hemorrhage during mediastinoscopy (Park et al). 2003;126:726-31

Positron emission tomography with $2-\left[{ }^{18} \mathrm{~F}\right]$ fluoro-2-deoxy-Dglucose: can it be used to accurately stage the mediastinum in non-small cell lung cancer as an alternative to mediastinoscopy? (Kernstine). 2003;126:1700-3 (Editorial)

Medical errors; see also Iatrogenic disease

Our surgical culture of blame: a time for change (Dickey et al). 2003;126:1259-60 (Editorial)

\section{Melanoma}

Primary malignant melanoma of the bronchus intermedius (Filosso et al). 2003;126:1215-7 (Brief comm.)

Men

Association of lipoprotein(a) excess with early vein graft occlusions in middle-aged men undergoing coronary artery bypass surgery (Pokrovsky et al). 2003;126:1071-5

Long-term benefits of coronary bypass surgery: are the gains for women less than for men? (Vaccarino and Koch). 2003;126:1707-11 (Editorial)

\section{Mesothelioma}

Positron emission tomography defines metastatic disease but not locoregional disease in patients with malignant pleural mesothelioma (Flores et al). 2003;126:11-6

\section{Microelectrodes}

Microelectromechanical systems for endoscopic cardiac surgery (Bonanomi et al). 2003;126:851-2 (Evolving tech.)

Mitral valve

Early and late stroke after mitral valve replacement with a mechanical prosthesis: risk factor analysis of a 24 -year experience (Bando et al). 2003;126:358-64

Left ventricular external subannular plication: an indirect off-pump mitral annuloplasty method in a canine model (Kollár et al). 2003;126:977-82

Life-threatening anaphylactic shock caused by porcine heparin intravenous infusion during mitral valve repair (Bottio et al). 2003;126:1194-5 (Brief comm.)

Midterm results of edge-to-edge mitral valve repair without annuloplasty (Maisano et al). 2003;126:1987-97

Minimally invasive mitral valve repair suggests earlier operations for mitral valve disease (Greelish et al). 2003;126: 365-73

Mitral valve in ischemic versus idiopathic dilated cardiomyopathy (Grossi et al). 2003;126:922 (Letter)
Mitral valve replacement by a Gore-Tex reinforced pulmonary autograft in a child (Yamagishi et al). 2003;126: 1218-9 (Brief comm.)

Mitral valve surgery in patients with extensive calcification of the mitral annulus (Feindel et al). 2003;126:777-82

Origin of atrial fibrillation from the pulmonary veins in a mitral patient (Melo et al). 2003;126:914-6 (Brief comm.)

Systolic anterior motion after mitral valve repair: myectomy as an alternative solution (Rescigno et al). 2003;126:1196-7 (Brief comm.)

\section{Mitral valve insufficiency}

Asymptomatic mitral valve incompetence: is there evidence for surgery? (Shuhaiber) (Letter); (David et al) (Reply). 2003; $126: 2117-9$

"Cinching" the mitral valve (Robicsek). 2003;126:942-3 (Editorial)

Management of mitral paravalvular leak: therapy or misadventure? (Hussain et al). 2003;126:879-80 (Brief comm.)

Restrictive mitral annuloplasty in refractory cardiogenic shock with acute postinfarction mitral insufficiency and intact papillary muscle (Braun et al). 2003;126:284-6 (Brief comm.)

Monitoring, physiologic

Home surveillance program prevents interstage mortality after the Norwood procedure (Ghanayem et al). 2003;126: $1367-77$

The influence of mechanical properties on wall stress and distensibility of the dilated ascending aorta (Okamoto et al). 2003;126:842-50

Rapid recognition and treatment of cerebral air embolism: the role of neuromonitoring (Yeh et al). 2003;126:589-91 (Brief comm.)

\section{Monosaccharide transport proteins}

Does hyperoxia affect glucose regulation and transport in the newborn? (Bandali et al). 2003;126:1730-5

Postnatal increase in insulin-sensitive glucose transporter expression is associated with improved recovery of postischemic myocardial function (Friehs et al). 2003;126:263-71

\section{Morbidity/mortality}

Atrial fibrillation after esophagectomy is a marker for postoperative morbidity and mortality (Murthy et al). 2003; 126:1162-7

Decreasing significance of left ventricular dysfunction and reoperative surgery in predicting coronary artery bypass grafting-associated mortality: a twelve-year study (Davierwala et al). 2003;126:1335-44

Gender-related differences in morbidity and mortality during combined valve and coronary surgery (Ibrahim et al). 2003;126:959-64

Home surveillance program prevents interstage mortality after the Norwood procedure (Ghanayem et al). 2003;126: $1367-77$

Impact of interstitial lung disease on surgical morbidity and mortality for lung cancer: analyses of short-term and longterm outcomes (Chiyo et al). 2003;126:1141-6

Is it gender, methodology, or something else? (Koch et al). 2003;126:932-5 (Editorial) 
Is there an evidence in favor of off-pump coronary artery bypass? (El Oakley et al). 2003;126:1668 (Letter)

Pre-stage II mortality after the Norwood operation: addressing the next challenge (Forbess). 2003;126:1257-8 (Editorial)

Risk factors of mortality and permanent neurologic injury in patients undergoing ascending aortic and arch repair $(\mathrm{Cz}-$ erny et al). 2003;126:1296-301

Surgical revascularization in women: unique intraoperative factors and considerations (Lawton et al). 2003;126:936-8 (Editorial)

\section{Multicenter studies}

Clinical and six-month angiographic evaluation of coronary arterial graft interrupted anastomoses by use of a selfclosing clip device: a multicenter prospective clinical trial (Wolf et al). 2003;126:168-78

Magnetic vascular coupling for distal anastomosis in coronary artery bypass grafting: a multicenter trial (Klima et al). 2003;126:1568-74 (Evolving tech.)

Surgical radiofrequency ablation of both atria for atrial fibrillation: results of a multicenter trial (Raman et al). 2003; 126:1357-66

Muscle development

Myogenesis after myocardial stem cell transplantation (Taheri) (Letter); (Chiu) (Reply). 2003;126:2116-7

\section{Myasthenia gravis}

The immunologic role of thymectomy in the treatment of myasthenia gravis: implication of thymus-associated Blymphocyte subset in reduction of the anti-acetylcholine receptor antibody titer (Okumura et al). 2003;126:1922-8

\section{Myocardial infarction}

Does size matter? What is your infarct rate after coronary artery bypass grafting? (Mentzer). 2003;126:326-8 (Editorial)

Impact of sodium-hydrogen exchange inhibition by cariporide on death or myocardial infarction in high-risk CABG surgery patients: results of the CABG surgery cohort of the GUARDIAN study (Boyce et al). 2003;126:420-7

Mechanical support of the unrepaired postinfarction ventricular septal defect with the Abiomed BVS 5000 ventricular assist device (Samuels et al). 2003;126:2100-1 (Brief comm.)

Passive ventricular constraint to improve left ventricular function and mechanics in an ovine model of heart failure secondary to acute myocardial infarction (Pilla et al). 2003;126:1467-76

Pharmacologic inhibition of intracellular caspases after myocardial infarction attenuates left ventricular remodeling: a potentially novel pathway (Yarbrough et al). 2003;126: 1892-9

Prognostic significance of elevated creatine kinase MB after coronary bypass surgery and after an acute coronary syndrome: results from the GUARDIAN trial (Gavard et al). 2003; $126: 807-13$

Restrictive mitral annuloplasty in refractory cardiogenic shock with acute postinfarction mitral insufficiency and intact papillary muscle (Braun et al). 2003;126:284-6 (Brief comm.)
Transcoronary implantation of bone marrow stromal cells ameliorates cardiac function after myocardial infarction (Saito et al). 2003;126:114-23

\section{Myocardial ischemia}

Mitral valve in ischemic versus idiopathic dilated cardiomyopathy (Grossi et al). 2003;126:922 (Letter)

Postnatal increase in insulin-sensitive glucose transporter expression is associated with improved recovery of postischemic myocardial function (Friehs et al). 2003; 126:263-71

Survival after myocardial revascularization for ischemic cardiomyopathy: a prospective ten-year follow-up study (Shah et al). 2003;126:1320-7

Myocardial reperfusion injury; see Reperfusion injury

Myocardial revascularization; see also Coronary artery bypass

Radial versus right internal thoracic artery as a second arterial conduit for coronary surgery: early and midterm outcomes (Caputo et al). 2003;126:39-47

Radial versus right internal thoracic artery as a second arterial conduit for coronary surgery: early and midterm outcomes (Lytle). 2003;126:5-6 (Editorial)

Survival after myocardial revascularization for ischemic cardiomyopathy: a prospective ten-year follow-up study (Shah et al). 2003;126:1320-7

\section{Myocarditis}

Successful LVAS and RVAS-ECMO support in a patient with fulminant myocarditis who failed to recover from ventricular fibrillation with PCPS and IABP (Gojo et al). 2003;126:885-6 (Brief comm.)

Ventricular assist surprise: giant cell myocarditis or sarcoidosis? (Stoica et al). 2003;126:2072-4 (Brief comm.)

\section{Myocardium}

The aging human myocardium: tolerance to ischemia and responsiveness to ischemic preconditioning (Loubani et al). 2003;126:143-7

A few critical aspects-and Achilles heels-of tissue engineering approaches to restore injured myocardium (Kofidis et al) (Letter); (Fazel et al) (Reply). 2003;126:2113-6

Surgical reduction of ventricular radius by aspirated plication of the myocardial wall: an experimental study (Lunkenheimer et al). 2003;126:592-6 (Brief comm.)

Myocytes, cardiac

Cardiomyocyte-mediated contact programs human mesenchymal stem cells to express cardiogenic phenotype (Rangappa et al). 2003;126:124-32

Myxoma

Right ventricular multiple myxomas obstructing right ventricular outflow tract (Paraskevaidis et al). 2003;126:913-4 (Brief comm.)

\section{$\mathrm{N}$}

\section{Natriuretic peptide, brain}

Secretion of A-type and B-type natriuretic peptides into the bloodstream and pericardial space in children with congenital heart disease (Ootaki et al). 2003;126:1411-6 


\section{Neoplasm metastasis}

Cyclooxygenase-2 inhibition decreases primary and metastatic tumor burden in a murine model of orthotopic lung adenocarcinoma (DiPerna et al). 2003;126:1129-33

Fluorodeoxyglucose positron emission tomography improves preoperative staging of resectable lung metastasis (Pastorino et al). 2003;126:1906-10

Histogram analysis of computed tomography numbers of clinical T1 N0 M0 lung adenocarcinoma, with special reference to lymph node metastasis and tumor invasiveness (Nomori et al). 2003;126:1584-9

Malignant status at surgical margin of limited-resected nonsmall cell lung cancer: a crucial finding for predicting local relapse (Sawabata) (Letter); (Higashiyama et al) (Reply). 2003;126:610-1

Occult metastases: real harm or false alarm? (Cote). 2003; 126:332-3 (Editorial)

Optimal management when unsuspected N2 nodal disease is identified during thoracotomy for lung cancer: cost-effectiveness analysis (Ferguson). 2003;126:1935-42

Positron emission tomography defines metastatic disease but not locoregional disease in patients with malignant pleural mesothelioma (Flores et al). 2003;126:11-6

Possible Tx N2 M0 atypical bronchial carcinoid associated with Cushing syndrome (Filosso) (Letter); (Sugawara et al) (Reply). 2003;126:1224-5

Prognostic factors and survival after complete resection of pulmonary metastases from colorectal carcinoma: experiences in 167 patients (Pfannschmidt et al). 2003;126: $732-9$

The prognostic significance of intranodal isolated tumor cells and micrometastases in patients with non-small cell carcinoma of the lung (Marchevsky et al). 2003;126:551-7

\section{Neoplasm staging}

A comparative analysis of positron emission tomography and mediastinoscopy in staging non-small cell lung cancer (Gonzalez-Stawinski et al). 2003;126:1900-5

Effect of radioisotope sentinel node mapping in patients with cT1 N0 M0 lung cancer (Sugi et al). 2003;126:568-73

Extracapsular lymph node involvement is a negative prognostic factor in T3 adenocarcinoma of the distal esophagus and gastroesophageal junction (Lerut et al). 2003;126: 1121-8

Histogram analysis of computed tomography numbers of clinical T1 N0 M0 lung adenocarcinoma, with special reference to lymph node metastasis and tumor invasiveness (Nomori et al). 2003;126:1584-9

Lymph node involvement in esophageal adenocarcinoma: if you see one, have you seen them all? (DeMeester). 2003; 126:947-9 (Editorial)

A novel method for sentinel lymph node mapping using magnetite in patients with non-small cell lung cancer (Nakagawa et al). 2003;126:563-7

Pattern of lymphatic spread and prognosis of $\mathrm{pN} 1$ non-small cell lung cancer: what does it stand for? (Margaritora et al) (Letter); (Marra and Stamatis) (Reply). 2003;126:1664-5

Positron emission tomography with $2-\left[{ }^{18} \mathrm{~F}\right]$ fluoro-2-deoxy-Dglucose: can it be used to accurately stage the mediasti- num in non-small cell lung cancer as an alternative to mediastinoscopy? (Kernstine). 2003;126:1700-3 (Editorial)

Resection of multifocal non-small cell lung cancer when the bronchioloalveolar subtype is involved (Roberts et al). 2003; 126:1597-602

Results of the American College of Surgeons Oncology Group Z0050 Trial: the utility of positron emission tomography in staging potentially operable non-small cell lung cancer (Reed et al). 2003;126:1943-51

\section{Neurologic manifestations}

Apolipoprotein E genotype and neurodevelopmental sequelae of infant cardiac surgery (Gaynor et al). 2003;126:1736-45

Conditioned blood reperfusion markedly enhances neurologic recovery after prolonged cerebral ischemia (Allen et al). 2003;126:1851-8

The effect of duration of deep hypothermic circulatory arrest in infant heart surgery on late neurodevelopment: the Boston Circulatory Arrest Trial (Wypij et al). 2003;126: 1397-403

Neurodevelopmental status of eight years in children with dextro-transposition of the great arteries: the Boston Circulatory Arrest Trial (Bellinger et al). 2003;126:1385-96

Neuropsychometric outcome following aortic arch surgery: a prospective randomized trial of retrograde cerebral perfusion (Harrington et al). 2003;126:638-44

Postoperative hypoxia is a contributory factor to cognitive impairment after cardiac surgery (Browne et al). 2003; 126:1061-4

Preoperative and operative predictors of delayed neurologic deficit following repair of thoracoabdominal aortic aneurysm (Estrera et al). 2003;126:1288-95

Risk factors of mortality and permanent neurologic injury in patients undergoing ascending aortic and arch repair $(\mathrm{Cz}-$ erny et al). 2003;126:1296-301

\section{Neurons, afferent}

Surgery modifies cardiac sensory transduction (Waldmann et al). 2003;126:1792-7

Neuropsychology

Finding our way from the heart to the head (Petrucci). 2003; 126:944-6 (Editorial)

\section{Nickel}

Nickel allergy to the percutaneous patent foramen ovale occluder and subsequent systemic nickel allergy (Dasika and Kanter). 2003;126:2112 (Letter)

\section{Nitric oxide}

Exhaled nitric oxide and cardiac surgery with extracorporeal circulation (Marczin) (Letter); (Adatia et al) (Reply). 2003;126:1673-5

Inhaled nitric oxide versus prostacyclin in chronic shuntinduced pulmonary hypertension (Wauthy et al). 2003; 126:1434-41

Integrated pharmacological preconditioning in combination with adenosine, a mitochondrial $\mathrm{K}_{\mathrm{ATP}}$ channel opener and a nitric oxide donor (Uchiyama et al). 2003;126:148-59

Leukocyte-depleted terminal blood cardioplegia provides superior myocardial protective effects in association with myocardium-derived nitric oxide and peroxynitrite pro- 
duction for patients undergoing prolonged aortic crossclamping for more than 120 minutes (Hayashi et al). 2003;126:1813-21

\section{Nitric-oxide synthase}

MCI-186 prevents spinal cord damage and affects enzyme levels of nitric oxide synthase and $\mathrm{Cu} / \mathrm{Zn}$ superoxide dismutase after transient ischemia in rabbits (Takahashi et al). 2003;126:1461-6

\section{Nitroprusside}

Sodium nitroprusside infusion after bidirectional superior cavopulmonary connection: preserved cerebral blood flow velocity and systemic oxygenation (Simsic et al). 2003; 126:186-90

\section{Norwood procedure}

Computational fluid dynamics in the evaluation of hemodynamic performance of cavopulmonary connections after the Norwood procedure for hypoplastic left heart syndrome (Bove et al). 2003;126:1040-7

Home surveillance program prevents interstage mortality after the Norwood procedure (Ghanayem et al). 2003;126: 1367-77

Pre-stage II mortality after the Norwood operation: addressing the next challenge (Forbess). 2003;126:1257-8 (Editorial)

Right ventricle-pulmonary artery shunt in first-stage palliation of hypoplastic left heart syndrome (Sano et al). 2003; 126:504-10

Right ventricular to pulmonary artery conduit instead of modified Blalock-Taussig shunt improves postoperative hemodynamics in newborns after the Norwood operation (Mair et al). 2003;126:1378-84

Right ventricular-pulmonary artery connection in stage 1 palliation of hypoplastic left heart syndrome (Pearl). 2003; 126:1268-70 (Editorial)

\section{O}

\section{Obituary}

David Bernt Skinner (1935-2003): a thoracic surgeon and something more (Altorki). 2003;126:1245-6 (In memoriam)

Robert W. Jamplis (1920-2003) (Urschel). 2003;126:311-2 (In memoriam)

Organ preservation solutions

Impaired endothelium-derived hyperpolarizing factor-mediated relaxation in porcine pulmonary microarteries after cold storage with Euro-Collins and University of Wisconsin solutions (Zou et al). 2003;126:208-15

Outcome and process assessment (health care); see also Evaluation studies; Follow-up studies; Morbidity/mortality; Survival rate

Clinical outcomes and utility of cardiac catheterization prior to superior cavopulmonary anastomosis (Brown et al). 2003;126:272-81

The Cox maze III procedure for atrial fibrillation: long-term efficacy in patients undergoing lone versus concomitant procedures (Prasad et al). 2003;126:1822-8
Diabetes and evidence of atherosclerosis are major risk factors for adverse outcome after elective thoracic aortic surgery (Hagl et al). 2003;126:1005-12

Efficacy and safety of single-trocar technique for minimally invasive surgery of the chest in the treatment of noncomplex pleural disease (Migliore). 2003;126:1618-23

The female perspective: gender in cardiothoracic surgery (Nussmeier). 2003;126:618-9 (Editorial)

Gender and outcomes after coronary artery bypass grafting: a propensity-matched comparison (Koch et al). 2003;126: 2032-43

The gender initiative (Wechsler). 2003;126:617 (Editorial)

Impaired systemic ventricular relaxation affects postoperative short-term outcome in Fontan patients (Border et al). 2003;126:1760-4

Improved early outcome for end-stage dilated cardiomyopathy in children (McMahon et al). 2003;126:1781-7

Improving outcomes for women after coronary artery bypass grafting: a case for prevention (Oparil). 2003;126:1704-6 (Editorial)

Influence of chromosome 22q11.2 microdeletion on surgical outcome after treatment of tetralogy of Fallot with pulmonary atresia (Carotti et al). 2003;126:1666-7 (Letter)

The influence of hemodilution on outcome after hypothermic cardiopulmonary bypass: results of a randomized trial in infants (Jonas et al). 2003;126:1765-74

The influence of perioperative factors on outcomes in children aged less than 18 months after repair of tetralogy of Fallot (van Dongen et al). 2003;126:703-10

Is discharge policy a balanced decision between clinical considerations and hospital ownership policy? The CABG example (Galai et al). 2003;126:1018-25

Is what's good for the gander good for the goose? (Wenger). 2003;126:929-31 (Editorial)

Long-term benefits of coronary bypass surgery: are the gains for women less than for men? (Vaccarino and Koch). 2003;126:1707-11 (Editorial)

Long-term outcome after coronary artery bypass grafting in cardiogenic shock or cardiopulmonary resuscitation (Sergeant et al). 2003;126:1279-87

The long-term outcome of patients with coronary disease and atrial fibrillation undergoing the Cox maze procedure (Damiano et al). 2003;126:2016-21

Long-term results of heart transplantation in patients older than 60 years (Demers et al). 2003;126:224-31

Mitral valve surgery in patients with extensive calcification of the mitral annulus (Feindel et al). 2003;126:777-82

Outcome of symptomatic patients undergoing extracardiac Fontan conversion and cryoablation (Weinstein et al). 2003;126:529-36

Pneumonectomy in children for destroyed lung and the longterm consequences (Eren et al). 2003;126:574-81

Radial versus right internal thoracic artery as a second arterial conduit for coronary surgery: early and midterm outcomes (Caputo et al). 2003;126:39-47

Radial versus right internal thoracic artery as a second arterial conduit for coronary surgery: early and midterm outcomes (Lytle). 2003;126:5-6 (Editorial) 
In situ retrocaval skeletonized right internal thoracic artery anastomosed to the circumflex system via transverse sinus: technical aspects and postoperative outcome (Bonacchi et al). 2003;126:1302-13

Study design in valve surgery and outcome (Shuhaiber et al) (Letter); (Grunkemeier and Wu) (Reply). 2003; $126: 1660-1$

Use of bovine jugular vein to reconstruct the right ventricular outflow tract: early results (Boudjemline et al). 2003;126: 490-7

\section{Oxidative stress}

The antioxidant $\mathrm{N}$-acetylcysteine preserves myocardial function and diminishes oxidative stress after cardioplegic arrest (Fischer et al). 2003;126:1483-8

L-Arginine polymers enhance coronary flow and reduce oxidative stress following cardiac transplantation in rats (Kown et al). 2003;126:1065-70

Simultaneous progression of oxidative stress and angiogenesis in malignant transformation of Barrett esophagus ( $\mathrm{Si}$ hvo et al). 2003;126:1951-7

\section{Oxygenators, membrane}

Axillary artery cannulation for extracorporeal membrane oxygenator support in adults: an approach to minimize complications (Moazami et al). 2003;126:2097-8 (Brief comm.)

\section{$\mathrm{P}$}

\section{Pain, postoperative}

Extrapleural regional versus systemic analgesia for relieving postthoracotomy pain: a clinical study of bupivacaine compared with metamizol (Bilgin et al). 2003;126:1580-3

Improved pain control after cardiac surgery: results of a randomized, double-blind, clinical trial (Dowling et al). 2003; $126: 1271-8$

No pain, much gain? (Schwann and Chaney). 2003;126: 1261-4 (Editorial)

\section{Palliative care}

Right ventricular-pulmonary artery connection in stage 1 palliation of hypoplastic left heart syndrome (Pearl). 2003; 126:1268-70 (Editorial)

\section{Papaverine}

Detrimental effects of papaverine on the human internal thoracic artery (Gao et al). 2003;126:179-85

\section{Papilloma}

Solitary squamous papillomas of the bronchus: a rare case report and literature review (McNamee et al). 2003;126: 861-3 (Brief comm.)

\section{Parasympatholytics}

Comparative efficacies and durations of action of phenoxybenzamine, verapamil/nitroglycerin solution, and papaverine as topical antispasmodics for radial artery coronary bypass grafting (Mussa et al). 2003;126:1798-805

\section{Patient admission}

Emergency hospital admissions and three-year survival of adults with and without cardiovascular surgery for congenital cardiac disease (Kaemmerer et al). 2003;126:1048-52

\section{Patient discharge}

Is discharge policy a balanced decision between clinical considerations and hospital ownership policy? The CABG example (Galai et al). 2003;126:1018-25

Pectus excavatum; see Funnel chest

Peer review

The peer-review process in medical publishing: a reviewer's perspective (Sellke). 2003;126:1683-5 (Editorial)

Peer review (Wechsler and Fried). 2003;126:1681-2 (Editorial)

\section{Pentoxifylline}

Pentoxifylline is as effective as leukocyte depletion for modulating pulmonary reperfusion injury (Clark et al). 2003; 126:2052-7

\section{Perfusion}

Cardiac surgery during pregnancy: pulsatile or nonpulsatile perfusion? (Jahangiri et al) 2003;126:894-895 (Brief comm.) Correction 2003;126:1680

Neuropsychometric outcome following aortic arch surgery: a prospective randomized trial of retrograde cerebral perfusion (Harrington et al). 2003;126:638-44

Quantitative gated myocardial perfusion single photon emission computed tomography improves the prediction of regional functional recovery in akinetic areas after coronary bypass surgery: useful tool for evaluation of myocardial viability (Murashita et al). 2003;126:1328-34

Regional low-flow perfusion provides comparable blood flow and oxygenation to both cerebral hemispheres during neonatal aortic arch reconstruction (Andropoulos et al). 2003; 126:1712-7

Retrograde cerebral perfusion: more risk than benefit? (Murkin). 2003;126:631-3 (Editorial)

Study of warm perfusion rather than cardioplegia (Savage) (Letter); (Mallidi and Fremes) (Reply). 2003;126:2111-2

Surgical repair of acute type A aortic dissection: continuous pulmonary perfusion during retrograde cerebral perfusion prevents lung injury in a pilot study (De Santo et al). 2003; 126:826-31

Perioperative care

The influence of perioperative factors on outcomes in children aged less than 18 months after repair of tetralogy of Fallot (van Dongen et al). 2003;126:703-10

\section{Persistent fetal circulation syndrome}

Isolated persistent fifth aortic arch with systemic-to-pulmonary arterial connection (Hwang et al). 2003;126:1643-4 (Brief comm.)

\section{Phenoxybenzamine}

Phenoxybenzamine treatment is insufficient to prevent spasm in the radial artery: the effect of other vasodilators (Conant et al). 2003;126:448-54

Pretreatment with phenoxybenzamine attenuates the radial artery's vasoconstrictor response to $\alpha$-adrenergic stimuli (Corvera et al). 2003;126:1549-54

\section{Photochemotherapy}

A novel technique for light delivery through branched or bent anatomic structures (Friedberg et al). 2003;126:1963-7 (Evolving tech.) 


\section{Phrenic nerve}

Endoscopic, robotically assisted implantation of phrenic pacemakers (Morgan et al). 2003;126:582-3 (Brief comm.)

\section{Physicians}

Our surgical culture of blame: a time for change (Dickey et al). 2003;126:1259-60 (Editorial)

Pigment epithelium-derived factor

In vivo gene transfer of pigment epithelium-derived factor inhibits tumor growth in syngeneic murine models of thoracic malignancies (Mahtabifard et al). 2003;126:28-38

\section{Platelet aggregation inhibitors}

Clopidogrel before urgent coronary artery bypass graft (Genoni et al). 2003;126:288-9 (Brief comm.)

Platelet dysfunction in acute type A aortic dissection evaluated by the laser light-scattering method (Tanaka et al). 2003;126:837-41

Platelet-derived microparticles

Generation of platelet-derived microparticles in patients undergoing cardiac surgery is not affected by complement activation (van den Goor et al). 2003;126:1101-6

Platelet glycoprotein GPIIb-IIIa complex

Pharmacologic platelet anesthesia by glycoprotein IIb/IIIa complex antagonist and argatroban during in vitro extracorporeal circulation (Kanemitsu et al). 2003;126:428-35

\section{Pneumatocele}

Management of complicated pneumatocele (DiBardino et al). 2003;126:859-61 (Brief comm.)

Pneumomediastinum; see Mediastinal emphysema

\section{Pneumonectomy}

Acute postoperative lobar torsion associated with pulmonary arterial rupture (Jones et al). 2003;126:303 (Letter)

Foreign bodies expectorated through the pneumonectomy stump (Dieter). 2003;126:2104 (Letter)

Pneumonectomy in children for destroyed lung and the longterm consequences (Eren et al). 2003;126:574-81

Robot-assisted lobectomy (Ashton et al). 2003;126:292-3 (Brief comm.)

Total thoracoscopic pneumonectomy: indications and technical considerations (Conlan and Sandor). 2003;126:2083-5 (Brief comm.)

Use of autologous pleural flap buttress in thoracoscopic lung volume reduction surgery (Lee et al). 2003;126:298-9 (Brief comm.)

Poly(ADP-ribose) polymerases

Poly-ADP-ribose polymerase inhibition protects against myocardial and endothelial reperfusion injury after hypothermic cardiac arrest (Szabó et al). 2003;126:651-8

\section{Polymers}

L-Arginine polymers enhance coronary flow and reduce oxidative stress following cardiac transplantation in rats (Kown et al). 2003;126:1065-70

\section{Postoperative complications}

Acute postoperative lobar torsion associated with pulmonary arterial rupture (Jones et al). 2003;126:303 (Letter)

Aortopulmonary fistula in pseudoaneurysm after ascending aortic surgery (Kitamura et al). 2003;126:904-5 (Brief comm.)
Complication of benign tracheobronchial strictures by selfexpanding metal stents (Gaissert et al). 2003;126:744-7

Evaluation of vacuum-assisted closure in the treatment of poststernotomy mediastinitis (Domkowski et al). 2003; 126:386-90

Incisional atrial reentrant tachycardia: experimental study on the conduction property through the isthmus (Ishii et al). 2003;126:254-62

Inhaled nitric oxide versus prostacyclin in chronic shuntinduced pulmonary hypertension (Wauthy et al). 2003; 126:1434-41

Left atrial dissection after aortic valve replacement (Osawa et al). 2003;126:604-5 (Brief comm.)

Lobar transplantation (Haddy and Starnes) (Letter); (Kozower and Meyers) (Reply). 2003;126:2106

Postoperative hypoxia is a contributory factor to cognitive impairment after cardiac surgery (Browne et al). 2003; 126:1061-4

The relationship between plasma free $15-\mathrm{F}_{2 \mathrm{t}}$-isoprostane concentration and early postoperative cardiac depression following warm heart surgery (Ansley et al). 2003;126:1222-3 (Brief comm.)

Transcardiac gunshot wound recognized forty-eight years later (McClurken et al). 2003;126:293-5 (Brief comm.)

\section{Postoperative hemorrhage}

Preoperative use of enoxaparin is not a risk factor for postoperative bleeding after coronary artery bypass surgery (Medalion et al). 2003;126:1875-9

\section{Potassium channels}

Integrated pharmacological preconditioning in combination with adenosine, a mitochondrial $\mathrm{K}_{\mathrm{ATP}}$ channel opener and a nitric oxide donor (Uchiyama et al). 2003;126:148-59

Povidone

Refractory chylothorax after lung transplantation for lymphangioleiomyomatosis successfully cured with instillation of povidone (Duariat et al). 2003;126:875-7 (Brief comm.)

\section{Pregnancy}

Cardiac surgery during pregnancy: pulsatile or nonpulsatile perfusion? (Jahangiri et al) 2003;126:894-895 (Brief comm.) Correction 2003;126:1680

\section{Preoperative care}

Negative aspects of preoperative delay in early stage nonsmall cell lung cancer (Sortini et al) (Letter); (Block) (Reply). 2003;126:609-10

Preoperative localization techniques during thoracoscopic operations (Sortini et al) (Letter); (Saito et al) (Reply). 2003; 126:608-9

\section{Presidential Address}

Thoracic surgery education: responding to a changing environment (Crawford). 2003;126:1235-42

\section{Prisoners}

Cardiac transplantation in prisoners (Richenbacher) (Letter); (Sade) (McKneally) (Replies). 2003;126:1226-7

Medical resources and capital punishment (Kumar) (Letter); (McKneally) (Reply). 2003;126:2107-8

Product surveillance, postmarketing

Twenty-year experience with the St Jude Medical mechanical valve prosthesis (Ikonomidis et al). 2003;126:2022-31 


\section{Prosthesis failure}

Management of mitral paravalvular leak: therapy or misadventure? (Hussain et al). 2003;126:879-80 (Brief comm.)

Use of flexibility tests in the manufacturing process of $60^{\circ}$ Björk-Shiley convexo-concave valves and the risk of outlet strut fracture (Omar et al). 2003;126:832-6

\section{Prosthesis fitting}

Assessment of mechanical aortic valve prosthesis by means of Doppler echocardiography: what to measure and why? (Vannan and Sarkar). 2003;126:317-20 (Editorial)

Prosthesis-patient size: measurement and clinical implications (Gillinov et al). 2003;126:313-6 (Editorial)

Prosthesis size and long-term survival after aortic valve replacement (Blackstone et al). 2003;126:783-96

Serial Doppler echocardiographic evaluation of small-sized Sorin Bicarbon prostheses (De Carlo et al). 2003;126: $337-43$

\section{Protein kinases}

Activation of mitogen-activated protein kinases during preparation of vein grafts and modulation by a synthetic inhibitor (Bizekis et al) 2003;126:659-665. Correction 2003; 126:1680

Insulin-induced improvement of postischemic recovery is abolished by inhibition of protein kinase $\mathrm{C}$ in rat heart (Fischer-Rasokat and Doenst). 2003;126:1806-12

Subcellular distribution of protein kinase $\mathrm{C}$ isozymes during cardioplegic arrest (Jonjev et al). 2003;126:1880-5

\section{Publishing}

The peer-review process in medical publishing: a reviewer's perspective (Sellke). 2003;126:1683-5 (Editorial)

Peer review (Wechsler and Fried). 2003;126:1681-2 (Editorial)

Priority issue: who is on first base? (Robicsek) (Editorial); (Wechsler) (Response). 2003;126:321-2

\section{Pulmonary artery}

Acute postoperative lobar torsion associated with pulmonary arterial rupture (Jones et al). 2003;126:303 (Letter)

Anomalous origin of the left coronary artery from the main pulmonary artery associated with Berry syndrome (Senzaki et al). 2003;126:1645-7 (Brief comm.)

Bilateral lung transplantation and pulmonary artery reconstruction in a patient with chronic obstructive pulmonary disease, and a giant pulmonary artery aneurysm (Force et al). 2003;126:864-6 (Brief comm.)

Chronic and adjustable pulmonary artery banding: reflections on old knowledge (Sievers) (Letter); (Leeuwenburgh et al) (Reply). 2003;126:2104-6

Intraparenchymal replacement of the left pulmonary artery with implantation of segmental arteries in a 26-year-old patient (Cebi et al). 2003;126:2074-7 (Brief comm.)

Isolated persistent fifth aortic arch with systemic-to-pulmonary arterial connection (Hwang et al). 2003;126:1643-4 (Brief comm.)

Pulmonary artery remodeling in transposition of the great arteries: relevance for neoaortic root dilatation (Lalezari et al). 2003;126:1053-60

Remote control of pulmonary blood flow: initial clinical experience (Corno et al). 2003;126:1775-80
Right ventricle-pulmonary artery shunt in first-stage palliation of hypoplastic left heart syndrome (Sano et al). 2003; 126:504-10

\section{Pulmonary atresia}

Influence of chromosome 22q11.2 microdeletion on surgical outcome after treatment of tetralogy of Fallot with pulmonary atresia (Carotti et al). 2003;126:1666-7 (Letter)

Pulmonary atresia with intact ventricular septum: strategy based on right ventricular morphology (Yoshimura et al). 2003;126:1417-26

Staged repair of pulmonary atresia with ventricular septal defect and major aortopulmonary collateral arteries: experience with 104 patients (Gupta et al). 2003;126:1746-52

Staged repair of tetralogy of Fallot and diminutive pulmonary arteries with a fenestrated ventricular septal defect patch (Marshall et al). 2003;126:1427-33

Staged repair of tetralogy of Fallot with pulmonary atresia and major aortopulmonary collateral arteries (Duncan et al). 2003;126:694-702

Successful Fontan procedure for asplenia with pulmonary atresia and major aortopulmonary collateral arteries (Miyaji et al). 2003;126:1648-50 (Brief comm.)

Pulmonary blastoma

Clinical-pathologic conference in general thoracic surgery: pulmonary blastoma (Force and Patterson). 2003; $126: 1247-50$

Pulmonary disease, chronic obstructive

Bilateral lung transplantation and pulmonary artery reconstruction in a patient with chronic obstructive pulmonary disease, and a giant pulmonary artery aneurysm (Force et al). 2003;126:864-6 (Brief comm.)

\section{Pulmonary embolism}

Should lungs from donors with severe acute pulmonary embolism be accepted for transplantation? The Hanover experience (Fischer et al). 2003;126:1641-3 (Brief comm.)

\section{Pulmonary emphysema}

Development of a canine model of pulmonary emphysema and imaging of the emphysematous lung with infrared thoracoscopy (Gotoh et al). 2003;126:1916-21

\section{Pulmonary fibrosis}

Survival benefit of lung transplantation for patients with idiopathic pulmonary fibrosis (Thabut et al). 2003;126: 469-75

Pulmonary valve stenosis

Severe pulmonary stenosis and aortopulmonary fistula caused by a dissecting aneurysm in the ascending aorta (Imanaka et al). 2003;126:598-600 (Brief comm.)

\section{Pulmonary veins}

Origin of atrial fibrillation from the pulmonary veins in a mitral patient (Melo et al). 2003;126:914-6 (Brief comm.)

Pyrexia; see Fever

\section{R}

\section{Radial artery}

Atherosclerotic involvement of the radial artery in patients with coronary artery disease and its relation with midterm 
radial artery graft patency and endothelial function (Gaudino et al). 2003;126:1968-71

Comparative efficacies and durations of action of phenoxybenzamine, verapamil/nitroglycerin solution, and papaverine as topical antispasmodics for radial artery coronary bypass grafting (Mussa et al). 2003;126:1798-805

Phenoxybenzamine treatment is insufficient to prevent spasm in the radial artery: the effect of other vasodilators (Conant et al). 2003;126:448-54

Pretreatment with phenoxybenzamine attenuates the radial artery's vasoconstrictor response to $\alpha$-adrenergic stimuli (Corvera et al). 2003;126:1549-54

Radial versus right internal thoracic artery as a second arterial conduit for coronary surgery: early and midterm outcomes (Caputo et al). 2003;126:39-47

Radial versus right internal thoracic artery as a second arterial conduit for coronary surgery: early and midterm outcomes (Lytle). 2003;126:5-6 (Editorial)

\section{Radiation injuries}

Severe quadricuspid aortic valve stenosis after mediastinal irradiation (Mecozzi et al). 2003;126:1198-9 (Brief comm.)

Radiofrequency ablation; see Catheter ablation

\section{Radioisotope diagnostic techniques}

Effect of radioisotope sentinel node mapping in patients with cT1 N0 M0 lung cancer (Sugi et al). 2003;126:568-73

Randomized controlled trials; see also Clinical trials

Antifibrinolytic therapy during cardiopulmonary bypass reduces proinflammatory cytokine levels: a randomized, double-blind, placebo-controlled study of $\epsilon$-aminocaproic acid and aprotinin (Greilich et al). 2003;126:1498-503

Double crisscross sternal wiring and chest wound infections: a prospective randomized study (Bottio et al). 2003;126: $1352-6$

$\mathrm{N}$-acetylcysteine prevents reactive oxygen species-mediated myocardial stress in patients, undergoing cardiac surgery: results of a randomized, double-blind, placebo-controlled clinical trial (Tossios et al). 2003;126:1513-20

Neuropsychometric outcome following aortic arch surgery: a prospective randomized trial of retrograde cerebral perfusion (Harrington et al). 2003;126:638-44

Rapamycin; see Sirolimus

Reactive oxygen species

$\mathrm{N}$-acetylcysteine prevents reactive oxygen species-mediated myocardial stress in patients, undergoing cardiac surgery: results of a randomized, double-blind, placebo-controlled clinical trial (Tossios et al). 2003;126:1513-20

\section{Reoperation}

Automated proximal anastomosis for redo coronary artery bypass grafting through a lateral thoracotomy (Perreas et al). 2003;126:606-7 (Brief comm.)

Decreasing significance of left ventricular dysfunction and reoperative surgery in predicting coronary artery bypass grafting-associated mortality: a twelve-year study (Davierwala et al). 2003;126:1335-44

Management of mitral paravalvular leak: therapy or misadventure? (Hussain et al). 2003;126:879-80 (Brief comm.)
Reoperations and survival after primary repair of congenital heart defects in children (Monro et al). 2003;126:511-20

\section{Reperfusion injury, lung}

Early activation of the alveolar macrophage is critical to the development of lung ischemia-reperfusion injury (Naidu et al). 2003;126:200-7

Modified reperfusion and ischemia-reperfusion injury in human lung transplantation (Ardehali et al). 2003;126:1929-34

Pentoxifylline is as effective as leukocyte depletion for modulating pulmonary reperfusion injury (Clark et al). 2003; 126:2052-7

Simvastatin ameliorates injury in an experimental model of lung ischemia-reperfusion (Naidu et al). 2003;126:482-9

Tumor necrosis factor inhibitor gene transfer ameliorates lung graft ischemia-reperfusion injury (Tagawa et al). 2003; 126:1147-54

\section{Reperfusion injury, myocardial}

Attenuation of postcardioplegia injury with inhibitors of the sodium-hydrogen exchanger (Vinten-Johansen and Mentzer). 2003;126:1265-7 (Editorial)

Conditioned blood reperfusion markedly enhances neurologic recovery after prolonged cerebral ischemia (Allen et al). 2003;126:1851-8

Direct inhibition of the sodium/hydrogen exchanger after prolonged regional ischemia improves contractility on reperfusion independent of myocardial viability (Yarbrough et al). 2003;126:1489-97

Does antegrade blood cardioplegia alone provide adequate myocardial protection in patients with left main stem disease? (Onorati et al). 2003;126:1345-52

Fetal cardiac surgery: simplicity versus success in a new frontier (Allen). 2003;126:1254-6 (Editorial)

Insulin-induced improvement of postischemic recovery is abolished by inhibition of protein kinase $\mathrm{C}$ in rat heart (Fischer-Rasokat and Doenst). 2003;126:1806-12

Leukocyte-depleted terminal blood cardioplegia provides superior myocardial protective effects in association with myocardium-derived nitric oxide and peroxynitrite production for patients undergoing prolonged aortic crossclamping for more than 120 minutes (Hayashi et al). 2003;126:1813-21

A new role for cardioplegic buffering: should acidosis or calcium accumulation be counteracted to salvage jeopardized hearts? (Castellá et al). 2003;126:1442-8

Poly-ADP-ribose polymerase inhibition protects against myocardial and endothelial reperfusion injury after hypothermic cardiac arrest (Szabó et al). 2003;126:651-8

\section{Respiratory distress syndrome}

Exhaled carbon monoxide and inducible heme oxygenase expression in a rat model of postperfusion acute lung injury (Zegdi et al). 2003;126:1867-74

Surgical repair of acute type A aortic dissection: continuous pulmonary perfusion during retrograde cerebral perfusion prevents lung injury in a pilot study (De Santo et al). 2003;126:826-31

Respiratory system abnormalities

Benign intrapulmonary teratoma: report of a case (Eren et al). 2003;126:855-7 (Brief comm.) 
Video-assisted thoracoscopic resection for intralobar pulmonary sequestration: single modality treatment with videoassisted thoracic surgery (Klena et al). 2003;126:857-9 (Brief comm.)

\section{Respiratory tract neoplasms}

A novel technique for light delivery through branched or bent anatomic structures (Friedberg et al). 2003;126:1963-7 (Evolving tech.)

\section{Review, academic}

Guest reviewers for The Journal of Thoracic and Cardiovascular Surgery. 2003;126:2121-3

Priority issue: who is on first base? (Robicsek) (Editorial); (Wechsler) (Response). 2003;126:321-2

Review, multicase

Chondrosarcoma arising in the trachea: a case report and review of the literature (Maish and Vaporciyan). 2003; 126:2077-80 (Brief comm.)

Combined endovascular and video-assisted thoracoscopic procedure for treatment of a ruptured pulmonary arteriovenous fistula: case report and review of the literature (Litzler et al). 2003;126:1204-7 (Brief comm.)

Intralobar sequestration in the middle-aged and elderly adult: recognition and radiographic evaluation (Petersen et al). 2003;126:2086-9 (Brief comm.)

Posttraumatic and iatrogenic foreign bodies in the heart: report of fourteen cases and review of the literature (Dato et al). 2003;126:408-14

Solitary squamous papillomas of the bronchus: a rare case report and literature review (McNamee et al). 2003;126: 861-3 (Brief comm.)

\section{Rheology}

Immediate flow reserve of $\mathrm{Y}$ thoracic artery grafts: an intraoperative flowmetric study (Gaudino et al). 2003;126: 1076-9

\section{Rheumatic heart disease}

Long-term evaluation of Carpentier-Edwards porcine bioprosthesis for rheumatic heart disease (Yu et al). 2003; 126:80-9

\section{Risk factors}

Diabetes and evidence of atherosclerosis are major risk factors for adverse outcome after elective thoracic aortic surgery (Hagl et al). 2003;126:1005-12

Early and late stroke after mitral valve replacement with a mechanical prosthesis: risk factor analysis of a 24-year experience (Bando et al). 2003;126:358-64

Esophageal perforation during left atrial radiofrequency ablation: is the risk too high? (Gillinov et al) (Letter); (Doll et al) (Reply). 2003;126:1661-2

Esophageal perforation during left atrial radiofrequency ablation (Laczkovics et al) (Letter); (Doll et al) (Reply). 2003;126:2119-20

The gender initiative (Wechsler). 2003;126:617 (Editorial)

Hypercholesterolemia is a risk factor for bioprosthetic valve calcification and explanation (Farivar and Cohn). 2003; 126:969-76

Retrograde cerebral perfusion: more risk than benefit? (Murkin). 2003;126:631-3 (Editorial)
Risk factors for atherosclerosis and the degeneration of pericardial valves after aortic valve replacement (Nollert et al). 2003;126:965-8

Risk factors for leg harvest surgical site infections after coronary artery bypass graft surgery (Olsen et al). 2003; 126:992-9

Risk factors of mortality and permanent neurologic injury in patients undergoing ascending aortic and arch repair $(\mathrm{Cz}-$ erny et al). 2003;126:1296-301

\section{Robotics}

Endoscopic, robotically assisted implantation of phrenic pacemakers (Morgan et al). 2003;126:582-3 (Brief comm.)

The Janus syndrome: a perspective on a new era of computerenhanced robotic cardiac surgery (Boyd and Stahl). 2003; 126:625-30 (Editorial)

Robot-assisted lobectomy (Ashton et al). 2003;126:292-3 (Brief comm.)

Robotic cardiac surgery: Quo vadis? (Robicsek). 2003;126: 623-4 (Editorial)

\section{S}

\section{Samson Resident Prize Essay}

Annual meeting announcements. 2003;126:1233

Saphenous vein

Activation of mitogen-activated protein kinases during preparation of vein grafts and modulation by a synthetic inhibitor (Bizekis et al) 2003;126:659-665. Correction 2003; 126:1680

$\mathrm{C}$-reactive protein activates the nuclear factor- $\kappa \mathrm{B}$ signal transduction pathway in saphenous vein endothelial cells: implications for atherosclerosis and restenosis (Verma et al). 2003;126:1886-91

Carbon dioxide embolism during endoscopic saphenous vein harvesting in coronary artery bypass surgery (Lin et al). 2003;126:2011-5

Factors affecting saphenous vein graft patency: clinical and angiographic study in 1402 symptomatic patients operated on between 1977 and 1999 (Shah et al). 2003;126:1972-7

The left anterior descending coronary artery is the best recipient (Zamvar and Sivaprakasam). 2003;126:923 (Letter)

\section{Sarcoidosis}

Ventricular assist surprise: giant cell myocarditis or sarcoidosis? (Stoica et al). 2003;126:2072-4 (Brief comm.)

\section{Sepsis syndrome}

Genetic control of postoperative systemic inflammatory reaction and pulmonary and renal complications after coronary artery surgery (Gaudino et al). 2003;126:1107-12

Inflammatory response to cardiac bypass in ewe fetuses: effects of steroid administration or continuous hemodiafiltration (Carotti et al). 2003;126:1839-50

Plasma levels of interleukin-8 and expression of interleukin-8 receptors on circulating neutrophils and monocytes after cardiopulmonary bypass in children (Gessler et al). 2003; $126: 718-25$ 


\section{Shock, cardiogenic}

Implantation of a left ventricular assist device and the huband-spoke system in treating acute cardiogenic shock: who survives? (Kherani et al). 2003;126:1634-5 (Brief comm.)

Long-term outcome after coronary artery bypass grafting in cardiogenic shock or cardiopulmonary resuscitation (Sergeant et al). 2003;126:1279-87

Restrictive mitral annuloplasty in refractory cardiogenic shock with acute postinfarction mitral insufficiency and intact papillary muscle (Braun et al). 2003;126:284-6 (Brief comm.)

Ventricular aneurysms, shock, and late follow-up in patients with heart failure (McCarthy). 2003;126:323-5 (Editorial)

\section{Signal transduction}

C-reactive protein activates the nuclear factor- $\kappa \mathrm{B}$ signal transduction pathway in saphenous vein endothelial cells: implications for atherosclerosis and restenosis (Verma et al). 2003;126:1886-91

Surgery modifies cardiac sensory transduction (Waldmann et al). 2003;126:1792-7

\section{Simvastatin}

Simvastatin ameliorates injury in an experimental model of lung ischemia-reperfusion (Naidu et al). 2003;126:482-9

\section{Sinus syndromes}

Unroofed coronary sinus syndrome: Diagnosis, classification, and surgical treatment (Ootaki et al). 2003;126:1655-6 (Brief comm.)

\section{Sirolimus}

Rapamycin has no effect on fibrosis-associated gene expression or extracellular matrix accumulation when administered to animals with established or early allograft vasculopathy (Murphy and Nicholson). 2003;126:2058-64

\section{Skinner, David B.}

David Bernt Skinner (1935-2003): a thoracic surgeon and something more (Altorki). 2003;126:1245-6 (In memoriam)

\section{Sodium-hydrogen antiporter}

Attenuation of postcardioplegia injury with inhibitors of the sodium-hydrogen exchanger (Vinten-Johansen and Mentzer). 2003;126:1265-7 (Editorial)

Direct inhibition of the sodium/hydrogen exchanger after prolonged regional ischemia improves contractility on reperfusion independent of myocardial viability (Yarbrough et al). 2003;126:1489-97

Impact of sodium-hydrogen exchange inhibition by cariporide on death or myocardial infarction in high-risk CABG surgery patients: results of the CABG surgery cohort of the GUARDIAN study (Boyce et al). 2003;126:420-7

\section{Spinal cord ischemia}

MCI-186 prevents spinal cord damage and affects enzyme levels of nitric oxide synthase and $\mathrm{Cu} / \mathrm{Zn}$ superoxide dismutase after transient ischemia in rabbits (Takahashi et al). 2003;126:1461-6

\section{Spondylitis, ankylosing}

Decompressing manubriectomy under apneic oxygenation to release the median thoracic outlet compartment in Bechterew disease (Go et al). 2003;126:867-9 (Brief comm.)

\section{Statistics}

Problems with complication rate analysis (Horstkotte) (Letter); (Wu and Grunkemeier) (Reply). 2003;126:1668-70

Study design in valve surgery and outcome (Shuhaiber et al) (Letter); (Grunkemeier and Wu) (Reply). 2003;126:1660-1

Stem cell transplantation

Myogenesis after myocardial stem cell transplantation (TaStem cells heri) (Letter); (Chiu) (Reply). 2003;126:2116-7

Canine endothelial progenitor cell-lined hybrid vascular graft with nonthrombogenic potential (He et al). 2003;126: 455-64

Cardiomyocyte-mediated contact programs human mesenchymal stem cells to express cardiogenic phenotype (Rangappa et al). 2003;126:124-32

\section{Stents}

Combined repair of an aortic arch aneurysm by sequential transposition of the supra-aortic branches and endovascular stent-graft placement (Czerny et al). 2003;126:916-8 (Brief comm.)

Complication of benign tracheobronchial strictures by selfexpanding metal stents (Gaissert et al). 2003;126:744-7

Endovascular flexible stent grafting with arch vessel bypass for a case of aortic arch aneurysm (Nitta et al). 2003;126: 1186-8 (Brief comm.)

Off-pump management of aortic arch aneurysm by using an endovascular thoracic stent graft (Dietl et al). 2003;126: 1181-3 (Brief comm.)

Staged dilation and stenting for long segmental tracheobronchial stenosis caused by tuberculosis (Huang et al). 2003; 126:2090-2 (Brief comm.)

Stent graft treatment for abdominal pseudoaneurysm near the celiac artery (Takahashi et al). 2003;126:600-2 (Brief comm.)

\section{Sternum}

Cervical cannulation for resternotomy in pediatric patients (Delius et al). 2003;126:2095-6 (Brief comm.)

Double crisscross sternal wiring and chest wound infections: a prospective randomized study (Bottio et al). 2003;126: 1352-6

Laparoscopic omental flap for the treatment of major sternal wound infection after cardiac surgery (Puma et al). 2003; 126:1998-2002

New material for reconstruction of the anterior chest wall, including the sternum (Watanabe et al). 2003;126:1212-4 (Brief comm.)

\section{Stromal cells}

Transcoronary implantation of bone marrow stromal cells ameliorates cardiac function after myocardial infarction (Saito et al). 2003;126:114-23

\section{Superior vena cava syndrome}

Inflammatory myofibroblastic tumor of the mediastinum presenting as superior vena cava syndrome (Yamaguchi et al). 2003;126:870-2 (Brief comm.)

\section{Superoxide dismutase}

MCI-186 prevents spinal cord damage and affects enzyme levels of nitric oxide synthase and $\mathrm{Cu} / \mathrm{Zn}$ superoxide dis- 
mutase after transient ischemia in rabbits (Takahashi et al). 2003;126:1461-6

\section{Surgery, computer-assisted}

The Janus syndrome: a perspective on a new era of computerenhanced robotic cardiac surgery (Boyd and Stahl). 2003; 126:625-30 (Editorial)

Totally endoscopic atrial septal repair in adults with computer-enhanced telemanipulation (Wimmer-Greinecker et al). 2003;126:465-8 (Evolving tech.)

Surgery for Acquired Cardiovascular Disease

2003;126:39-113; 337-419; 777-850; 950-1025; 1271-366; 1968-2051

Surgery for Congenital Heart Disease

2003;126:232-81; 490-536; 694-725; 1026-60; 1367-441; 1712-87

\section{Surgical equipment}

Authors should list confounding factors and alternative explanations for adverse events seen with new technologies (Anyanwu) (Letter); (Hornik) (Reply). 2003;126:1663-4

Chronic and adjustable pulmonary artery banding: reflections on old knowledge (Sievers) (Letter); (Leeuwenburgh et al) (Reply). 2003;126:2104-6

Clinical and six-month angiographic evaluation of coronary arterial graft interrupted anastomoses by use of a selfclosing clip device: a multicenter prospective clinical trial (Wolf et al). 2003;126:168-78

Combined use of off-pump techniques and a sutureless proximal aortic anastomotic device reduces cerebral microemboli generation during coronary artery bypass grafting (Scarborough et al). 2003;126:1561-7 (Evolving tech.)

Coronary anastomotic devices: blood-exposed non-intimal surface and coronary wall stress (Scheltes et al). 2003; 126:191-9 (Evolving tech.)

Evaluation of a novel sutureless anastomotic connector: from endothelial function to mid-term clinical and angiographic follow-up (Verma et al). 2003;126:1555-60 (Evolving tech.)

Facilitated endoscopic beating heart coronary artery bypass grafting using a magnetic coupling device (Falk et al). 2003;126:1575-9 (Evolving tech.)

Gelatin sheet incorporating basic fibroblast growth factor enhances sternal healing after harvesting bilateral internal thoracic arteries (Iwakura et al). 2003;126:1113-20

Global surgical experience with the Acorn cardiac support device (Oz et al). 2003;126:983-91

Left ventricular systolic performance in failing heart improved acutely by left ventricular reshaping (He et al). 2003;126:56-65

Magnetic vascular coupling for distal anastomosis in coronary artery bypass grafting: a multicenter trial (Klima et al). 2003;126:1568-74 (Evolving tech.)

Mitral valve replacement by a Gore-Tex reinforced pulmonary autograft in a child (Yamagishi et al). 2003;126: 1218-9 (Brief comm.)

A new device for beating heart bipolar radiofrequency atrial ablation (Bonanomi et al). 2003;126:1859-66

New material for reconstruction of the anterior chest wall, including the sternum (Watanabe et al). 2003;126:1212-4 (Brief comm.)
Nickel allergy to the percutaneous patent foramen ovale occluder and subsequent systemic nickel allergy (Dasika and Kanter). 2003;126:2112 (Letter)

Perventricular device closure of muscular ventricular septal defects on the beating heart: technique and results (Bacha et al). 2003;126:1718-23

Vacuum-assisted venous return reduces blood usage (Banbury et al). 2003;126:680-7

Videothoracoscopic extrapleural insertion of Walter Lorenz Surgical bar for pectus excavatum (Hernández et al). 2003;126:2081-2 (Brief comm.)

\section{Surgical flaps}

Laparoscopic omental flap for the treatment of major sternal wound infection after cardiac surgery (Puma et al). 2003; 126:1998-2002

Use of autologous pleural flap buttress in thoracoscopic lung volume reduction surgery (Lee et al). 2003;126:298-9 (Brief comm.)

\section{Surgical instruments}

Combination of the HEARTSTRING proximal seal system with a blower mister: a possible source of gas emboli (Nollert et al). 2003;126:1192-4 (Brief comm.)

New lead for in utero pacing for fetal congenital heart block (Assad et al). 2003;126:300-2 (Brief comm.)

A self-retaining retractor for the maze procedure (Gillinov). 2003;126:287-8 (Brief comm.)

Surgical patch; see Cardiac surgical procedures; Thoracic surgical procedures

Surgical procedures, minimally invasive; see also Endoscopy;

Robotics

Efficacy and safety of single-trocar technique for minimally invasive surgery of the chest in the treatment of noncomplex pleural disease (Migliore). 2003;126:1618-23

Minimally invasive mitral valve repair suggests earlier operations for mitral valve disease (Greelish et al). 2003;126: 365-73

Survival rate; see also Follow-up studies

Emergency hospital admissions and three-year survival of adults with and without cardiovascular surgery for congenital cardiac disease (Kaemmerer et al). 2003; $126: 1048-52$

Factors affecting late survival rate after surgical remodeling of left ventricular aneurysms (Bolooki et al). 2003;126: 374-85

Implantation of a left ventricular assist device and the huband-spoke system in treating acute cardiogenic shock: who survives? (Kherani et al). 2003;126:1634-5 (Brief comm.)

The influence of blood transfusion on survival in operated non-small cell lung cancer patients (Rzyman et al). 2003; 126:755-60

Insertion of a left ventricular assist device in patients without thorough transplant evaluations: a worthwhile risk? (Williams et al). 2003;126:436-41

Long-term survival and prognostic factors of five-year survivors with complete resection of non-small cell carcinoma (Okada et al). 2003;126:558-62 
Prognostic factors and survival after complete resection of pulmonary metastases from colorectal carcinoma: experiences in 167 patients (Pfannschmidt et al). 2003;126: $732-9$

Prognostic significance of elevated creatine kinase MB after coronary bypass surgery and after an acute coronary syndrome: results from the GUARDIAN trial (Gavard et al). 2003; $126: 807-13$

Prosthesis size and long-term survival after aortic valve replacement (Blackstone et al). 2003;126:783-96

Reoperations and survival after primary repair of congenital heart defects in children (Monro et al). 2003;126:511-20

Survival benefit of lung transplantation for patients with idiopathic pulmonary fibrosis (Thabut et al). 2003;126: 469-75

Survival following intensive preoperative combined modality therapy with paclitaxel, cisplatin, 5-fluorouracil, and radiation in resectable esophageal carcinomas: a phase I report (Goldberg et al). 2003;126:1168-73

Syphilis, cardiovascular

Syphilitic aortic aneurysm: a rare case of tracheomalacia (Pacini et al). 2003;126:900-2 (Brief comm.)

\section{$\mathrm{T}$}

Tachycardia

Incisional atrial reentrant tachycardia: experimental study on the conduction property through the isthmus (Ishii et al). 2003;126:254-62

\section{Teratoma}

Benign intrapulmonary teratoma: report of a case (Eren et al). 2003;126:855-7 (Brief comm.)

\section{Tetralogy of Fallot}

Influence of chromosome 22q11.2 microdeletion on surgical outcome after treatment of tetralogy of Fallot with pulmonary atresia (Carotti et al). 2003;126:1666-7 (Letter)

The influence of perioperative factors on outcomes in children aged less than 18 months after repair of tetralogy of Fallot (van Dongen et al). 2003;126:703-10

Staged repair of tetralogy of Fallot and diminutive pulmonary arteries with a fenestrated ventricular septal defect patch (Marshall et al). 2003;126:1427-33

Staged repair of tetralogy of Fallot with pulmonary atresia and major aortopulmonary collateral arteries (Duncan et al). 2003;126:694-702

Therapies, investigational

Surgical reduction of ventricular radius by aspirated plication of the myocardial wall: an experimental study (Lunkenheimer et al). 2003;126:592-6 (Brief comm.)

\section{Thoracic arteries}

Detrimental effects of papaverine on the human internal thoracic artery (Gao et al). 2003;126:179-85

Gelatin sheet incorporating basic fibroblast growth factor enhances sternal healing after harvesting bilateral internal thoracic arteries (Iwakura et al). 2003;126:1113-20

Immediate flow reserve of $\mathrm{Y}$ thoracic artery grafts: an intraoperative flowmetric study (Gaudino et al). 2003;126: 1076-9
Noninvasive evaluation of internal thoracic artery and left anterior descending coronary artery anastomotic sites using transthoracic Doppler echocardiography: comparison with coronary arteriography (Hirata et al). 2003;126:1080-6

Radial versus right internal thoracic artery as a second arterial conduit for coronary surgery: early and midterm outcomes (Caputo et al). 2003;126:39-47

Radial versus right internal thoracic artery as a second arterial conduit for coronary surgery: early and midterm outcomes (Lytle). 2003;126:5-6 (Editorial)

In situ retrocaval skeletonized right internal thoracic artery anastomosed to the circumflex system via transverse sinus: technical aspects and postoperative outcome (Bonacchi et al). 2003;126:1302-13

Skeletonization of bilateral internal thoracic artery grafts lowers the risk of sternal infection in patients with diabetes (Peterson et al). 2003;126:1314-9

\section{Thoracic duct}

A giant gastroenteric cyst associated with pectus excavatum and compression of the thoracic duct: a case report (Reisli et al). 2003;126:584-5 (Brief comm.)

\section{Thoracic neoplasms}

In vivo gene transfer of pigment epithelium-derived factor inhibits tumor growth in syngeneic murine models of thoracic malignancies (Mahtabifard et al). 2003;126:28-38

\section{Thoracic surgery}

Apolipoprotein E genotype and neurodevelopmental sequelae of infant cardiac surgery (Gaynor et al). 2003;126:1736-45

Asymptomatic mitral valve incompetence: is there evidence for surgery? (Shuhaiber) (Letter); (David et al) (Reply). 2003; 126:2117-9

Can particulate extraction from the ascending aorta reduce neurologic injury in cardiac surgery? (Schmitz et al). 2003; $126: 1829-38$

Clinical-pathologic conference in general thoracic surgery: pulmonary blastoma (Force and Patterson). 2003; $126: 1247-50$

The female perspective: gender in cardiothoracic surgery (Nussmeier). 2003;126:618-9 (Editorial)

Finding our way from the heart to the head (Petrucci). 2003; 126:944-6 (Editorial)

Generation of platelet-derived microparticles in patients undergoing cardiac surgery is not affected by complement activation (van den Goor et al). 2003;126:1101-6

Improved pain control after cardiac surgery: results of a randomized, double-blind, clinical trial (Dowling et al). 2003;126:1271-8

The Janus syndrome: a perspective on a new era of computerenhanced robotic cardiac surgery (Boyd and Stahl). 2003; 126:625-30 (Editorial)

A milestone in cardiovascular surgery (Cooley). 2003;126: 1243-4 (Hon. guest's address)

No pain, much gain? (Schwann and Chaney). 2003;126: 1261-4 (Editorial)

Postoperative hypoxia is a contributory factor to cognitive impairment after cardiac surgery (Browne et al). 2003; 126:1061-4 
Pyrexia after cardiac surgery: natural history and association with infection (Lim et al). 2003;126:1013-7

Robotic cardiac surgery: Quo vadis? (Robicsek). 2003;126: 623-4 (Editorial)

Surgery modifies cardiac sensory transduction (Waldmann et al). 2003;126:1792-7

Thoracic surgery education: responding to a changing environment (Crawford). 2003;126:1235-42 (Pres. address)

Thoracic surgical procedures; see also Cardiac surgical procedures; specific procedure

The clamshell approach for the treatment of extensive thoracic aortic disease (Doss et al). 2003;126:814-7

Controlled exsanguination during sternal reentry (Aris). 2003;126:918-9 (Brief comm.)

Decompressing manubriectomy under apneic oxygenation to release the median thoracic outlet compartment in Bechterew disease (Go et al). 2003;126:867-9 (Brief comm.)

Efficacy and safety of single-trocar technique for minimally invasive surgery of the chest in the treatment of noncomplex pleural disease (Migliore). 2003;126:1618-23

Prognostic factors and survival after complete resection of pulmonary metastases from colorectal carcinoma: experiences in 167 patients (Pfannschmidt et al). 2003;126: 732-9

Reconstruction of the trachea with a tubed radial forearm free flap (Beldholm et al). 2003;126:545-50

Rigid sternal fixation in the cardiac transplant population (Song et al). 2003;126:896-7 (Brief comm.)

Safety of bronchoplastic resection after induction therapy for lung cancer (Veronesi et al) (Letter); (Ohta et al) (Reply). 2003;126:1670-1

Single-stage transthoracic approach for right lung and liver hydatid disease (Şahin et al). 2003;126:769-73

Tissue-engineered esophagus: experimental substitution by onlay patch or interposition (Grikscheit et al). 2003;126: $537-44$

\section{Thoracic wall}

New material for reconstruction of the anterior chest wall, including the sternum (Watanabe et al). 2003;126:1212-4 (Brief comm.)

\section{Thoracoplasty}

Successful treatment of huge chronic expanding hematoma after thoracoplasty (Takanami). 2003;126:1202-3 (Brief comm.)

\section{Thoracoscopy}

Combined endovascular and video-assisted thoracoscopic procedure for treatment of a ruptured pulmonary arteriovenous fistula: case report and review of the literature (Litzler et al). 2003;126:1204-7 (Brief comm.)

Development of a canine model of pulmonary emphysema and imaging of the emphysematous lung with infrared thoracoscopy (Gotoh et al). 2003;126:1916-21

Preoperative localization techniques during thoracoscopic operations (Sortini et al) (Letter); (Saito et al) (Reply). 2003; 126:608-9

Total thoracoscopic pneumonectomy: indications and technical considerations (Conlan and Sandor). 2003;126:2083-5 (Brief comm.)
Use of autologous pleural flap buttress in thoracoscopic lung volume reduction surgery (Lee et al). 2003;126:298-9 (Brief comm.)

Video-assisted thoracoscopic resection for intralobar pulmonary sequestration: single modality treatment with videoassisted thoracic surgery (Klena et al). 2003;126:857-9 (Brief comm.)

Videothoracoscopic extrapleural insertion of Walter Lorenz Surgical bar for pectus excavatum (Hernández et al). 2003;126:2081-2 (Brief comm.)

\section{Thoracotomy}

Automated proximal anastomosis for redo coronary artery bypass grafting through a lateral thoracotomy (Perreas et al). 2003;126:606-7 (Brief comm.)

Extrapleural regional versus systemic analgesia for relieving postthoracotomy pain: a clinical study of bupivacaine compared with metamizol (Bilgin et al). 2003;126:1580-3

Optimal management when unsuspected N2 nodal disease is identified during thoracotomy for lung cancer: cost-effectiveness analysis (Ferguson). 2003;126:1935-42

Pleural lavage cytology in non-small cell lung cancer: lessons from 1000 consecutive resections (Okada et al). 2003;126: 1911-5

Thromboembolism

Doppler microembolic load predicts risk of thromboembolic complications in Novacor patients (Nabavi et al). 2003; 126:160-7

\section{Thrombophilia}

Is there a hypercoagulable state after off-pump coronary artery bypass surgery? What do we know and what can we do? (Kurlansky). 2003;126:7-10 (Editorial)

\section{Thymectomy}

The immunologic role of thymectomy in the treatment of myasthenia gravis: implication of thymus-associated Blymphocyte subset in reduction of the anti-acetylcholine receptor antibody titer (Okumura et al). 2003;126:1922-8

\section{Thymoma}

Thymoma: a clinicopathologic study based on the new World Health Organization classification (Nakagawa et al). 2003; 126:1134-40

\section{Thymus gland}

Multilocular tuberculous cyst of thymus gland (Stephen et al). 2003;126:2093-4 (Brief comm.)

\section{Tissue donors}

Drowned donor lung for bilateral lung transplantation (McNamee et al). 2003;126:910-2 (Brief comm.)

Living-donor lobar lung transplantation for various lung diseases (Date et al). 2003;126:476-81

Medical resources and capital punishment (Kumar) (Letter); (McKneally) (Reply). 2003;126:2107-8

Prolonged donor ischemic time does not adversely affect long-term survival in adult patients undergoing cardiac transplantation (Morgan et al). 2003;126:1624-33

Should lungs from donors with severe acute pulmonary embolism be accepted for transplantation? The Hanover experience (Fischer et al). 2003;126:1641-3 (Brief comm.) 


\section{Tissue engineering}

A few critical aspects-and Achilles heels-of tissue engineering approaches to restore injured myocardium (Kofidis et al) (Letter); (Fazel et al) (Reply). 2003;126:2113-6

\section{Tissue therapy}

Canine endothelial progenitor cell-lined hybrid vascular graft with nonthrombogenic potential ( $\mathrm{He}$ et al). 2003; 126:455-64

Cardiomyocyte-mediated contact programs human mesenchymal stem cells to express cardiogenic phenotype (Rangappa et al). 2003;126:124-32

Implantation of an autologously endothelialized homograft (Gulbins et al). 2003;126:890-1 (Brief comm.)

Transcoronary implantation of bone marrow stromal cells ameliorates cardiac function after myocardial infarction (Saito et al). 2003;126:114-23

\section{Tissue transplantation}

Extracardiac total cavopulmonary connection using a tissueengineered graft (Isomatsu et al). 2003;126:1958-62 (Evolving tech.)

\section{Tomography, emission-computed}

A comparative analysis of positron emission tomography and mediastinoscopy in staging non-small cell lung cancer (Gonzalez-Stawinski et al). 2003;126:1900-5

Fluorodeoxyglucose positron emission tomography improves preoperative staging of resectable lung metastasis (Pastorino et al). 2003;126:1906-10

Positron emission tomography defines metastatic disease but not locoregional disease in patients with malignant pleural mesothelioma (Flores et al). 2003;126:11-6

Positron emission tomography with $2-\left[{ }^{18} \mathrm{~F}\right]$ fluoro-2-deoxy-Dglucose: can it be used to accurately stage the mediastinum in non-small cell lung cancer as an alternative to mediastinoscopy? (Kernstine). 2003;126:1700-3 (Editorial)

Quantitative gated myocardial perfusion single photon emission computed tomography improves the prediction of regional functional recovery in akinetic areas after coronary bypass surgery: useful tool for evaluation of myocardial viability (Murashita et al). 2003;126:1328-34

Results of the American College of Surgeons Oncology Group Z0050 Trial: the utility of positron emission tomography in staging potentially operable non-small cell lung cancer (Reed et al). 2003;126:1943-51

\section{Tomography, spiral computed}

Histogram analysis of computed tomography numbers of clinical T1 N0 M0 lung adenocarcinoma, with special reference to lymph node metastasis and tumor invasiveness (Nomori et al). 2003;126:1584-9

Tomography, x-ray computed

Fatal air embolism during computed tomography-guided pulmonary marking with a hook-type marker (Sakiyama et al). 2003;126:1207-9 (Brief comm.)

\section{Torsion}

Acute postoperative lobar torsion associated with pulmonary arterial rupture (Jones et al). 2003;126:303 (Letter)
Persistent abnormal left ventricular systolic torsion in dilated cardiomyopathy after partial left ventriculectomy (Setser et al). 2003;126:48-55

\section{Trachea}

Reconstruction of the trachea with a tubed radial forearm free flap (Beldholm et al). 2003;126:545-50

\section{Tracheal neoplasms}

Chondrosarcoma arising in the trachea: a case report and review of the literature (Maish and Vaporciyan). 2003; 126:2077-80 (Brief comm.)

Granular cell tumors of the tracheobronchial tree (van der Maten et al). 2003;126:740-3

\section{Tracheal stenosis}

Complication of benign tracheobronchial strictures by selfexpanding metal stents (Gaissert et al). 2003;126:744-7

Staged dilation and stenting for long segmental tracheobronchial stenosis caused by tuberculosis (Huang et al). 2003; 126:2090-2 (Brief comm.)

\section{Tracheomalacia}

Syphilitic aortic aneurysm: a rare case of tracheomalacia (Pacini et al). 2003;126:900-2 (Brief comm.)

Transforming growth factors

Cartilaginous metaplasia and calcification in aortic allograft is associated with transforming growth factor $\beta 1$ expression (Mathieu et al). 2003;126:1449-54

Transplantation, autologous

Comparison of autograft and allograft aortic valve replacement in children (Lupinetti et al). 2003;126:240-6

Mitral valve replacement by a Gore-Tex reinforced pulmonary autograft in a child (Yamagishi et al). 2003;126: 1218-9 (Brief comm.)

Reconstruction of the trachea with a tubed radial forearm free flap (Beldholm et al). 2003;126:545-50

Urgent inferior vena cava replacement with an autologous pericardium tube graft (Lam et al). 2003;126:2101-3 (Brief comm.)

Use of autologous pleural flap buttress in thoracoscopic lung volume reduction surgery (Lee et al). 2003;126:298-9 (Brief comm.)

\section{Transplantation, heterologous}

Acellularized porcine heart valve scaffolds for heart valve tissue engineering and the risk of cross-species transmission of porcine endogenous retrovirus (Leyh et al). 2003; 126:1000-4

Bovine valved xenograft conduits in the extracardiac Fontan procedure (Baslaim et al). 2003;126:586-8 (Brief comm.)

Hancock II bioprosthesis: a glance at the microscope in mid-long-term explants (Bottio et al). 2003;126:99-105

Long-term durability of the Hancock II porcine bioprosthesis (Rizzoli et al). 2003;126:66-74

Long-term evaluation of Carpentier-Edwards porcine bioprosthesis for rheumatic heart disease (Yu et al). 2003; 126:80-9

Use of bovine jugular vein to reconstruct the right ventricular outflow tract: early results (Boudjemline et al). 2003;126: 490-7 


\section{Transplantation, homologous}

Cartilaginous metaplasia and calcification in aortic allograft is associated with transforming growth factor $\beta 1$ expression (Mathieu et al). 2003;126:1449-54

Comparison of autograft and allograft aortic valve replacement in children (Lupinetti et al). 2003;126:240-6

Decellularization of rat aortic valve allografts reduces leaflet destruction and extracellular matrix remodeling (Grauss et al). 2003;126:2003-10

Depopulated vena caval homograft: a new venous conduit (Wells et al). 2003;126:498-503

Human leukocyte antigen-DR and ABO mismatch are associated with accelerated homograft valve failure in children: implications for therapeutic interventions (Baskett et al). 2003;126:232-9

Immunogenicity of decellularized cryopreserved allografts in pediatric cardiac surgery: comparison with standard cryopreserved allografts (Hawkins et al). 2003;126:247-53

Improving the allograft valve: does the immune response matter? (Hogan and O'Brien). 2003;126:1251-3 (Editorial)

Prolonged survival of fully allogeneic cardiac grafts in naive mice and those with sensitization induced by antigen delivery through the respiratory tract (Aramaki et al). 2003;126:853-4 (Brief comm.)

Rapamycin has no effect on fibrosis-associated gene expression or extracellular matrix accumulation when administered to animals with established or early allograft vasculopathy (Murphy and Nicholson). 2003;126:2058-64

Results after transplantation using donor hearts with preexisting coronary artery disease (Marelli et al). 2003;126: $821-5$

Valve-sparing aortic root reconstruction with a valveless aortic allograft (Schoof et al). 2003;126:282-3 (Brief comm.)

Transplants; see also specific vessel; Tissue donors

Extracardiac total cavopulmonary connection using a tissueengineered graft (Isomatsu et al). 2003;126:1958-62 (Evolving tech.)

Gender differences in quality of distal vessels: effect on results of coronary artery bypass grafting (Mickleborough et al). 2003;126:950-8

Interleukin-10 gene transfection of donor lungs ameliorates posttransplant cell death by a switch from cellular necrosis to apoptosis (Fischer et al). 2003;126:1174-80

Results after transplantation using donor hearts with preexisting coronary artery disease (Marelli et al). 2003;126: $821-5$

Risk factors for leg harvest surgical site infections after coronary artery bypass graft surgery (Olsen et al). 2003; 126:992-9

Tissue-engineered esophagus: experimental substitution by onlay patch or interposition (Grikscheit et al). 2003;126: 537-44

Urgent inferior vena cava replacement with an autologous pericardium tube graft (Lam et al). 2003;126:2101-3 (Brief comm.)
Transposition of great vessels

Neurodevelopmental status of eight years in children with dextro-transposition of the great arteries: the Boston Circulatory Arrest Trial (Bellinger et al). 2003;126:1385-96

Prevalence and predictors of neoaortic regurgitation after arterial switch operation for transposition of the great arteries (Formigari et al). 2003;126:1753-9

Pulmonary artery remodeling in transposition of the great arteries: relevance for neoaortic root dilatation (Lalezari et al). 2003;126:1053-60

\section{Tricuspid atresia}

Left ventricular remodeling in hearts with tricuspid atresia: morphologic observations and possible basis for ventricular dysfunction after surgery (Binotto et al). 2003;126: 1026-32

Tricuspid valve insufficiency

The "clover technique" as a novel approach for correction of post-traumatic tricuspid regurgitation (Alfieri et al). 2003; 126:75-9

Surgically created double orifice repair of tricuspid regurgitation in infants with congenital heart disease (Fukuda et al). 2003;126:1220-1 (Brief comm.)

\section{Tuberculosis}

Multilocular tuberculous cyst of thymus gland (Stephen et al). 2003;126:2093-4 (Brief comm.)

Staged dilation and stenting for long segmental tracheobronchial stenosis caused by tuberculosis (Huang et al). 2003; 126:2090-2 (Brief comm.)

Tuberculosis aneurysm of the aortic arch (Abad and Santamaria). 2003;126:1229 (Letter)

\section{Tumor necrosis factor}

Adenovirus encoding soluble tumor necrosis factor $\alpha$ receptor immunoglobulin prolongs gene expression of a cotransfected reporter gene in rat lung (Suda et al). 2003;126: 1155-61

Tumor necrosis factor inhibitor gene transfer ameliorates lung graft ischemia-reperfusion injury (Tagawa et al). 2003; 126:1147-54

\section{U}

\section{Ultrasonography}

Preoperative localization techniques during thoracoscopic operations (Sortini et al) (Letter); (Saito et al) (Reply). 2003; 126:608-9

Ultrasonography, Doppler, transcranial

Doppler microembolic load predicts risk of thromboembolic complications in Novacor patients (Nabavi et al). 2003; 126:160-7

Doppler microembolic signals during cardiac surgery: comparison between arterial line and middle cerebral artery (Georgiadis et al). 2003;126:1638-9 (Brief comm.)

\section{V}

Vascular surgical procedures; see also specific procedure

Bilateral lung transplantation and pulmonary artery reconstruction in a patient with chronic obstructive pulmonary 
disease, and a giant pulmonary artery aneurysm (Force et al). 2003;126:864-6 (Brief comm.)

Cannulation of the left common carotid artery for proximal aortic repair (Urbanski). 2003;126:887-8 (Brief comm.)

Combined repair of an aortic arch aneurysm by sequential transposition of the supra-aortic branches and endovascular stent-graft placement (Czerny et al). 2003;126:916-8 (Brief comm.)

Comparison of polytetrafluoroethylene patch aortoplasty and end-to-end anastomosis for coarctation of the aorta (Walhout et al). 2003;126:521-8

Endovascular flexible stent grafting with arch vessel bypass for a case of aortic arch aneurysm (Nitta et al). 2003;126: 1186-8 (Brief comm.)

The gut-first approach for repair of Crawford extent III thoracoabdominal aortic aneurysms (Karck et al). 2003;126: 602-4 (Brief comm.)

Intraparenchymal replacement of the left pulmonary artery with implantation of segmental arteries in a 26-year-old patient (Cebi et al). 2003;126:2074-7 (Brief comm.)

Off-pump management of aortic arch aneurysm by using an endovascular thoracic stent graft (Dietl et al). 2003;126: 1181-3 (Brief comm.)

Prevalence and predictors of neoaortic regurgitation after arterial switch operation for transposition of the great arteries (Formigari et al). 2003;126:1753-9

Pulmonary atresia with intact ventricular septum: strategy based on right ventricular morphology (Yoshimura et al). 2003;126:1417-26

Relocation of supra-aortic vessels to facilitate endovascular treatment of a ruptured aortic arch aneurysm (Drenth et al). 2003;126:1184-5 (Brief comm.)

Right ventricular to pulmonary artery conduit instead of modified Blalock-Taussig shunt improves postoperative hemodynamics in newborns after the Norwood operation (Mair et al). 2003;126:1378-84

A safe strategy for surgical repair of coarctation of the aorta in an adult (Yamada et al). 2003;126:597-8 (Brief comm.)

Staged repair of pulmonary atresia with ventricular septal defect and major aortopulmonary collateral arteries: experience with 104 patients (Gupta et al). 2003;126:1746-52

Staged repair of tetralogy of Fallot and diminutive pulmonary arteries with a fenestrated ventricular septal defect patch (Marshall et al). 2003;126:1427-33

Staged repair of tetralogy of Fallot with pulmonary atresia and major aortopulmonary collateral arteries (Duncan et al). 2003;126:694-702

\section{Vasodilator agents}

Lack of evidence for vitamin $\mathrm{C}$ as acute vasodilator (Madhavan and Goodfellow) (Letter); (Toumpoulis et al) (Reply). 2003; 126:1671-2

Phenoxybenzamine treatment is insufficient to prevent spasm in the radial artery: the effect of other vasodilators (Conant et al). 2003;126:448-54

Vasopressin; see Argipressin

Venae cavae

Depopulated vena caval homograft: a new venous conduit (Wells et al). 2003;126:498-503
Urgent inferior vena cava replacement with an autologous pericardium tube graft (Lam et al). 2003;126:2101-3 (Brief comm.)

\section{Ventricular fibrillation}

Fifteen-month circulatory support for sustained ventricular fibrillation by left ventricular assist device (Nishimura et al). 2003;126:1190-2 (Brief comm.)

Successful LVAS and RVAS-ECMO support in a patient with fulminant myocarditis who failed to recover from ventricular fibrillation with PCPS and IABP (Gojo et al). 2003;126:885-6 (Brief comm.)

\section{Ventricular function, left}

Apical versus basal partial ventriculectomy (Lunkenheimer and Anderson) (Letter); (Koyama et al) (Reply). 2003; 126:2109-11

Decreasing significance of left ventricular dysfunction and reoperative surgery in predicting coronary artery bypass grafting-associated mortality: a twelve-year study (Davierwala et al). 2003;126:1335-44

Impaired systemic ventricular relaxation affects postoperative short-term outcome in Fontan patients (Border et al). 2003;126:1760-4

Insertion of a left ventricular assist device in patients without thorough transplant evaluations: a worthwhile risk? (Williams et al). 2003;126:436-41

Passive ventricular constraint to improve left ventricular function and mechanics in an ovine model of heart failure secondary to acute myocardial infarction (Pilla et al). 2003;126:1467-76

Transplantation of cryopreserved muscle cells in dilated cardiomyopathy: effects on left ventricular geometry and function (Ohno et al). 2003;126:1537-48

Ventricular outflow obstruction

Right ventricular multiple myxomas obstructing right ventricular outflow tract (Paraskevaidis et al). 2003;126:913-4 (Brief comm.)

Systolic anterior motion after mitral valve repair: myectomy as an alternative solution (Rescigno et al). 2003;126:1196-7 (Brief comm.)

Use of bovine jugular vein to reconstruct the right ventricular outflow tract: early results (Boudjemline et al). 2003;126: 490-7

\section{Ventricular remodeling}

Left ventricular remodeling in hearts with tricuspid atresia: morphologic observations and possible basis for ventricular dysfunction after surgery (Binotto et al). 2003;126: 1026-32

Pharmacologic inhibition of intracellular caspases after myocardial infarction attenuates left ventricular remodeling: a potentially novel pathway (Yarbrough et al). 2003;126: 1892-9

Ventricular remodeling surgery

Apical versus basal partial ventriculectomy (Lunkenheimer and Anderson) (Letter); (Koyama et al) (Reply). 2003; 126:2109-11

Factors affecting late survival rate after surgical remodeling of left ventricular aneurysms (Bolooki et al). 2003;126: 374-85 
Global surgical experience with the Acorn cardiac support device (Oz et al). 2003;126:983-91

Left ventricular systolic performance in failing heart improved acutely by left ventricular reshaping ( $\mathrm{He}$ et al). 2003;126:56-65

Persistent abnormal left ventricular systolic torsion in dilated cardiomyopathy after partial left ventriculectomy (Setser et al). 2003;126:48-55

Surgical reduction of ventricular radius by aspirated plication of the myocardial wall: an experimental study (Lunkenheimer et al). 2003;126:592-6 (Brief comm.)

\section{Vertebral artery}

Successful treatment of a mycotic aortic arch aneurysm associated with an isolated left vertebral artery (Naito et al). 2003;126:883-5 (Brief comm.)

\section{Video-assisted surgery}

Combined endovascular and video-assisted thoracoscopic procedure for treatment of a ruptured pulmonary arteriovenous fistula: case report and review of the literature (Litzler et al). 2003;126:1204-7 (Brief comm.)

Efficacy and safety of single-trocar technique for minimally invasive surgery of the chest in the treatment of noncomplex pleural disease (Migliore). 2003;126:1618-23

Robot-assisted lobectomy (Ashton et al). 2003;126:292-3 (Brief comm.)

Video-assisted thoracoscopic resection for intralobar pulmonary sequestration: single modality treatment with videoassisted thoracic surgery (Klena et al). 2003;126:857-9 (Brief comm.)

\section{W}

\section{Western Thoracic Surgical Association}

Annual meeting announcements. 2003;126:309; 615; 927; $1233 ; 1679 ; 2127$

\section{Women's health}

The female perspective: gender in cardiothoracic surgery (Nussmeier). 2003;126:618-9 (Editorial)

Gender and outcomes after coronary artery bypass grafting: a propensity-matched comparison (Koch et al). 2003;126: 2032-43

Gender differences in quality of distal vessels: effect on results of coronary artery bypass grafting (Mickleborough et al). 2003;126:950-8

The gender initiative (Wechsler). 2003;126:617 (Editorial)
Gender profiling in coronary artery bypass grafting (Koch et al). 2003;126:2044-51

Gender-related differences in morbidity and mortality during combined valve and coronary surgery (Ibrahim et al). 2003;126:959-64

Improving outcomes for women after coronary artery bypass grafting: a case for prevention (Oparil). 2003;126:1704-6 (Editorial)

Is it gender, methodology, or something else? (Koch et al). 2003;126:932-5 (Editorial)

Is what's good for the gander good for the goose? (Wenger). 2003;126:929-31 (Editorial)

Long-term benefits of coronary bypass surgery: are the gains for women less than for men? (Vaccarino and Koch). 2003;126:1707-11 (Editorial)

Sixty-year perspective on coronary artery bypass grafting in women (Hartz et al). 2003;126:620-2 (Editorial)

Surgical revascularization in women: unique intraoperative factors and considerations (Lawton et al). 2003;126:936-8 (Editorial)

\section{World Health Organization}

Thymoma: a clinicopathologic study based on the new World Health Organization classification (Nakagawa et al). 2003; 126:1134-40

\section{Wound healing}

Gelatin sheet incorporating basic fibroblast growth factor enhances sternal healing after harvesting bilateral internal thoracic arteries (Iwakura et al). 2003;126:1113-20

\section{Wound infection}

Double crisscross sternal wiring and chest wound infections: a prospective randomized study (Bottio et al). 2003;126: 1352-6

Laparoscopic omental flap for the treatment of major sternal wound infection after cardiac surgery (Puma et al). 2003; 126:1998-2002

Risk factors for leg harvest surgical site infections after coronary artery bypass graft surgery (Olsen et al). 2003; 126:992-9

Skeletonization of bilateral internal thoracic artery grafts lowers the risk of sternal infection in patients with diabetes (Peterson et al). 2003;126:1314-9

\section{Wounds, gunshot}

Transcardiac gunshot wound recognized forty-eight years later (McClurken et al). 2003;126:293-5 (Brief comm.) 